\title{
2 «Wir wollten alle Amerikaner werden«: Der Gast und seine Arbeiter
}

\subsection{Der Gast und seine Arbeiter}

„Wo beginnt eigentlich die europäische Zivilisation? «" ${ }^{1}$, fragen sich Anfang der 1960er Jahre in gespannter und positiver Erwartung die zukünftigen Gastarbeiter Recep und Yüce (der Ich-Erzähler) ${ }^{2}$ zu Beginn des autobiografischen Romans Türkler Almanyada (»Türken in Deutschland«, 1966) auf ihrer Zugfahrt von Istanbul nach München. Es ist ihre erste Fahrt nach Deutschland und kurz nach der österreichischen Grenze sind sich beide einig: die europäische Zivilisation beginnt in Österreich. ${ }^{3}$ Dass man sich die Zivilisation dort anschauen müsste, »Medeniyeti görmek lazım«, sagt auch der Gastarbeiter Ibrahim in DöNüş (»Die Rückkehr«), einem der ersten türkischen Filme zur Arbeitsmigration nach Deutschland von 1972, zu seiner Frau Gülcan bei seiner ersten Rückkehr aus der Bundesrepublik. ${ }^{4}$ Ibrahim hat neben dem technischen Fortschritt besonders beeindruckt, wie Männer und Frauen in öffentlichen Lokalen gelassen zusammenkommen und aus "pokalgroßen Gläsern« Bier trinken. Nicht selten tragen Frauen dabei Miniröcke. Zudem beeindruckt ihn, wie die Wohnhäuser mit Wasser und Strom versorgt werden. Seine ersten Eindrücke von der deutschen Lebensweise sind durchweg positiv. Auch der türkische Schlepper Ahmet Tekin aus Tunc Okans international mehrfach ausgezeichnetem Film Отовüs von 1974 sagt den Dutzend türkischen Dörflern, die er illegal nach Schweden in einem kaum fahrtüchtigen Bus befördert, kurz vor Stockholm, dass sie nicht traurig dreinschauen sollten. Sie seien befreit und würden gleich in der Zivilisation ankommen (»Kurtuldunuz. Medeniyet işte, geldik«). ${ }^{5}$ Und im bekanntesten Text der deutsch-türkischen Literatur der ersten Phase, in Aras Örens Poem Was will Niyazi in der Naunynstraße von 1973, antwortet Niyazi auf die Frage, warum er und

1 YILDIZ, Bekir (1966): Türkler Almanyada, Istanbul: Selbstverlag, S. 20. Alle folgenden Übersetzungen aus dem Türkischen ins Deutsche in der vorliegenden Studie Narrative der Migration sind Übersetzungen des Autors.

2 Yüce steht im Türkischen eher selten für einen Eigennamen, sondern findet regelmäßig als Adjektiv für »hoch«, »erhaben« und »edel« Verwendung. Beispiele: yüce dağlar: hohe, erhabene Berge oder yüce insan: edler, erhabener Mensch.

3 Yildiz (1966): S. 21.

4 ŞoRAY, Türkan (1972): Dönüş, Spielfilm, Türkei, Akün Film. http://www.sinematurk.com/ film/1173-donus/ (04.07.2017).

5 OKan, Tunç (1974): Otobüs, Spielfilm, Türkei, Promete Film Yapımı. 
die anderen gekommen seien, weil Deutschland »ein kleines Amerika « sei. Und nur wenn man »wie ein Amerikaner lebt, kann der Mensch sagen, ich habe gelebt «. ${ }^{6}$

Im Unterschied zu Şorays und Okans Filmen und zu Örens Poem lässt der Protagonist und Ich-Erzähler in Bekir Yıldız' autobiografischem Roman Türkler Almanyada nach dreijähriger Arbeits- und Lebenszeit in der Bundesrepublik seine Frau und ihren gemeinsamen Sohn in die Bundesrepublik nachziehen. Auf die erste Frage seiner Frau, ob es in Deutschland schwierig sei, antwortet er: "Ja [...] es ist schwer [...], aber es gilt für alle. Das heißt, die Schwierigkeiten hier sind für alle Menschen gleich «. ${ }^{7}$ Yüce arbeitet hier bereits seit zwei Jahren als Drucker in einer Fabrik in der nordwestbadischen Stadt Leimen, südlich von Heidelberg, und hat bis zur Ankunft der Familie mit vielen anderen Gastarbeitern in einer Arbeiterbaracke gewohnt. ${ }^{8}$ Er geht nach Deutschland, weil er dort eine Druckermaschine erwerben will, was ihm am Ende des Romans auch gelingt. 1966 kehrt er schließlich mit Familie und Maschine in die Türkei zurück. ${ }^{9}$ Er erhofft sich, durch den Kauf eine gewisse Unabhängigkeit zu erlangen und seine Herkunftsgesellschaft auf diese Weise weiterentwickeln zu können. ${ }^{10}$ Tatsächlich wird der Autor damit 1966 in Istanbul seinen autobiografischen Roman Türkler Almanyada drucken - den ersten Text zum Leben der Gastarbeiter in Deutschland. ${ }^{11}$

Dass ihm die Migration und sein Leben als Gastarbeiter zur Publikation des eigenen Romans verhelfen und er zum Schriftsteller ${ }^{12}$ wird, ist sicher ein besonde-

6 ÖREN (1973): S. 25.

7 Ebd., S. 77.

8 Bekir Ylldız (1933-1998) war von 1962 bis 1966 als Gastarbeiter in einer Firma in Heidelberg tätig, wo er als Drucker arbeitete. Seine Erfahrungen, die er in dieser Zeit in Deutschland machte, hat er im autobiografischen Roman Türkler Almanyada festgehalten. Seine Darstellung der Familienzusammenführung in der Mitte seines Textes korreliert mit der 1964 vorgenommenen Änderung des Anwerbeabkommens von 1961 mit der Türkei. HunN, Karin (2005): »Nächstes Jahr kehren wir zurück ... «. Die Geschichte der türkischen »Gastarbeiter « in der Bundesrepublik, Göttingen: Wallstein, S. 185. Siehe ebenfalls: Yaban Silan olur (1998): S. 83. Siehe auch EsSER, Hartmut (1983): »Multikulturelle Gesellschaft als Alternative zu Isolation und Assimilation«. In: ders.: Die fremden Mitbürger. Möglichkeiten und Grenzen der Integration von Ausländern, Düsseldorf: Patmos, S. 25-38, hier S. 26.

9 Vgl. DoǦAN, Âbide (2003): »Almanya'daki türk işçilerini konu alan Romanlar Türkler Almanya'da, Sancl ... Sancı ..., A’nın gizli Yaşamı üzerine bir Değerlendirme«. In: Türkbilig 5, S. 56-68, hier S. 59.

10 Auch Ibrahim lobt die Bundesrepublik in Türkan Şorays Film DöNüş, die im Film selbst seine Frau Gülcan spielt.

11 Hunn (2005): 184. Der Arbeiteranwerbevertrag zwischen der Bundesrepublik und der Türkei wurde im Dezember 1961 unterzeichnet und kurz darauf die deutsche Verbindungsstelle in Istanbul eingerichtet.

12 Bekir Yıldız hat nach seinem ersten Roman bis Anfang der 1990er mehrere Romane, Erzählungen und Reportagen veröffentlicht. Ein äußerst geringer Teil seiner Publikationen ist 
rer biografisch-ästhetischer Clou in Türkler Almanyada. Und dennoch: Trotz vieler individueller Marker handelt es sich bei Bekir Yıldız' Text nicht um eine Autobiografie im klassischen Sinn. Weder wird die Entwicklung des Ich-Erzählers in den Vordergrund gerückt ${ }^{13}$ noch bietet der Text eine ästhetische Selbstreferenzialität. Der Roman beschreibt vielmehr das Leben der Gastarbeiter und repräsentiert diese auf eine bestimmte Art und Weise; ein alles andere als einfaches Unterfangen.

Zwar deutet bereits der Titel Türkler Almanyada darauf hin, dass es hier nicht nur um die Geschichte des Erzählers und seiner Familie geht, sondern dass die Erzählung mit der Geschichte einer ethnischen Gruppe verbunden ist. Auf der Zugfahrt nach Deutschland werden zu Beginn des Romans auch die Figuren Nihat, Ayşe und Sevim vorgestellt; die Gründe und Folgen auch ihrer Migration. ${ }^{14}$ Allerdings sei an dieser Stelle bereits angemerkt: Auch wenn diese Gruppe national einheitlich identifiziert ist und dem Roman einen vermeintlich spezifischen Rahmen gibt, stellt sie keine homogene Einheit dar, der eine prästabile Gemeinschaftsform vorausginge. Sie wird sich im Laufe des Romans auch nicht zu einer solidarischen Gruppe entwickeln. Anstelle einer einheitlichen türkischen Identität ist die Gruppe von Spannungen und Widersprüchen geprägt. Während Yüce als Arbeitsmigrant äußerst rational ${ }^{15}$ agiert und seine Ziele erreicht, verläuft und endet das deutsche Gastarbeiterleben der anderen Arbeitsmigrantinnen und -migranten völlig unterschiedlich.

Für Recep beispielsweise geht der Aufenthalt in Deutschland weitaus weniger erfolgreich zu Ende. Denn Recep, den der Erzähler anfänglich als imponierenden, grundehrlichen und rebellischen jungen Mann beschreibt, der sein türkisches Heimatdorf verlässt und nach Deutschland migriert, um mit eigenem Geld unabhängig vom tyrannischen Stiefvater zu werden und um die Familie ernähren zu können, entwickelt in der Fremde - aus Sicht des Erzählers - »falsche« Bedürfnisse. Nach den ersten Jahren des Gastarbeiterlebens in den Baracken von Leimen geht es ihm - wie vielen anderen Gastarbeitern auch - nicht mehr darum, Geld für eine bessere Existenz in der Türkei zu sparen oder unabhängig zu werden. Vielmehr wird jetzt der Kauf eines Autos, eines Ford, zum dring-

dabei auf Deutsch erschienen (siehe Literaturverzeichnis). Am bekanntesten sind dabei seine Reportagen zum türkischen Dorf in den 1980er Jahren. Siehe hierzu: YILdIZ, Bekir (1983): Südostverlies. Drei Reportagen über Anatolien, Berlin: Harran.

13 Siehe hierzu: LejEune, Philippe (1975): Der autobiografische Pakt, Frankfurt a. M.: Suhrkamp, S. 22.

14 Vgl. DoǦAn (2003): S. 59.

15 Siehe: ESSER, Hartmut (1978): „Wanderung, Integration und die Stabilisierung komplexer Sozialsysteme«. In: Soziale Welt 29:2, S. 180-200, hier S. 182. 
lichsten Wunsch der Arbeiter. ${ }^{16}$ Im türkischen Dorf werden alle seinen Ford als Zeichen des sozialen Aufstiegs und als ein Ankommen im Westen deuten, hält Recep fest. ${ }^{17}$ Zudem habe ihn eine »innere Unruhe« zum Autokauf getrieben, die sich erst danach wieder legte (»içim rahatladı«). ${ }^{18}$ Den stolzen Besitz kann er jedoch nicht wie geplant vorführen. Recep verliert bei einem Autounfall in Deutschland (gegen Ende des Romans) sein Leben. Für den Ich-Erzähler wird er zum Opfer des schnellen und konsumorientierten westlichen Lebens und der Bildungs- und der Ahnungslosigkeit seiner Herkunftsregion. ${ }^{19}$ Auch der Gastarbeiter Ibrahim in Türkan Şorays Film Dönüş stirbt am Ende des Films bei einem Autounfall, weil er zu schnell fährt. Und ebenso wie in Yıldız' Roman kommt es in diesem Film zu einer Unterbrechung und Umkehrung der Bedürfnisstruktur des Gastarbeiters. Ibrahim zieht nach Deutschland in die Fremde und lässt Frau und Kind zurück, um seine Schulden beim Verwalter des Großgrundbesitzers zu begleichen, der ihm ein kleines Grundstück zur Landwirtschaft verpachtet hat. Ähnlich wie bei Recep in Türkler Almanyada ist das Ziel der Familie, selbstständig im Dorf leben zu können. Doch bei seiner ersten Rückkehr ist Ibrahim schon ein anderer Mensch. Er begleicht seine Pachtschulden und könnte im Dorf bleiben. Doch ziehen ihn neue Wünsche wieder zurück in die Bundesrepublik. Er möchte nun ein Auto kaufen. Auch sein öffentlicher Auftritt hat sich verändert. Er ist im Dorf nun fast immer in seinem gelben Anzug und mit seinem voll aufgedrehten Transistorradio unterwegs. Beides hat er in Deutschland gekauft. Er hört damit aber nur türkisches Radio, türkische Volksmusik. Selbst in den wenigen intimen Momenten in seinem einstöckigen einfachen Haus im Dorf schwärmt er davon,

16 Die bekannte türkische Romanautorin Adalet Ağaoğlu hat diesen Wunsch der Gastarbeiter nach einem Auto in einem ihrer ersten Romane Fikrimin ince gülü von 1976 als eine Entfremdungsgeschichte eindrücklich erzählt. Siehe hierzu: AĞAOǦLU, Adalet (1976): Fikrimin Ince Gülü, Istanbul: Remzi Kitabevi. 2015 wurde ihr Roman neu aufgelegt: AĞAoĞLU, Adalet (2015): Fikrimin Ince Gülü, Istanbul: Everest Yayınları.

17 Der chinesisch-amerikanische Soziologe Paul C. P. Siu beschreibt in seinem Werk The Chinese Laundryman. A Study of Social Isolation von 1954, dass für den »Gastarbeiter « der Wandel seines Status in der Herkunfts- und nicht in der Ankunftsgesellschaft im Vordergrund stehe. Die chinesischen Arbeiter in der New Yorker Chinatown beschreiben und begreifen ihre (Gast-)Arbeit in den 1950er Jahren als einen Job und nicht als den Anfang einer Berufskarriere. Dieses Verhältnis resultiert für Siu aus einem engen Bezug zur Herkunft. Er sieht in diesem die Grundlage der sozialen Isolation der chinesischen Wäschereiarbeiter und Wäschereibesitzer in der amerikanischen Einwanderungsgesellschaft. Siehe hierzu: SiU, Paul C. P. (1987): »The Chinese Laundryman as a Sojourner«. In: ders.: The Chinese Laundryman. A Study of Social Isolation, New York: New York University Press, S. 294-303.

18 Yildiz (1966): S. 163. Siehe auch MARCuSE, Herbert (1967): Der eindimensionale Mensch. Studien zur Ideologie der fortgeschrittenen Industriegesellschaft, Neuwied: Luchterhand, S. 47. 19 YILDIZ (1966): S. 189. 
wie Männer und Frauen zusammen Alkohol trinken. Wasser und Licht sind über Leitungen frei verfügbar und wenn man Licht haben möchte, drückt man einfach einen Schalter. Bei seiner zweiten Rückkehr aus Deutschland, nun in einem Volkswagen, kommt Ibrahim wie Recep bei einem Autounfall ums Leben.

Die »innere Unruhe« des in die Fremde Gegangenen bei Yıldız und bei Şoray und ihre Folgen reduzieren sich als Kritik der Erzählerinnen und Erzähler keineswegs allein auf die Frage der Sozialstruktur und der Unterscheidung von Ost und West. Denn in beiden Erzählungen ist auch die Herkunft keineswegs von Integration geprägt. Receps und Ibrahims Migrationen gehen soziale Ungleichheiten in den Herkunftsorten bereits voraus. Die »innere Unruhe« ist auch deshalb besonders stark, weil man am Ort der Herkunft als ein sozialstrukturell Angekommener gelten will. ${ }^{20}$

Ein weiteres, immer wiederkehrendes Thema ist für die Gastarbeiter die Sexualität. In Yıldız' Roman reicht sie vom Sprechen darüber über den Kontakt mit deutschen Frauen, Fastnachtsbekanntschaften bis zum arrangierten Treffen in Hotelzimmern außerhalb der Arbeiterbaracken. Auch Ibrahim kehrt gegen Ende in Türkan Şorays Film mit einer neuen Frau und einem weiteren Kind zurück; bevor er nach Deutschland migrierte, hatten Ibrahim und Gülcan bereits ein Kind. Beim Unfall überlebt nur das jüngere Kind, dessen sich dann Gülcan annimmt. Ihr gemeinsames Kind stirbt, als Angestellte des Großgrundbesitzers sie am Fluss sexuell bedrängen. Ganz anders kehrt hingegen Nihat, der dritte Protagonist in Yıldız' Roman, zurück. Er wird aus der Bundesrepublik ausgewiesen, weil er eine deutsche Frau sexuell bedrängte. ${ }^{21}$ Ein Verhalten des >vermeintlichen Landsmannes, das bei Yüce, dem Erzähler von Türkler Almanyada, selbst große Scham auslöst. Bei den Gastarbeiterinnen des Romans sind die Motivationslagen und Folgen der Migration ganz andere. Ayşe sitzt im selben Zug wie Recep und Yüce, als diese sich als Gastarbeiter nach Deutschland aufmachen. Sie ist unterwegs nach Deutschland, weil sie es mit ihrem arbeitslosen Ehemann nicht mehr länger ausgehalten hat und ihr eigenes Geld verdienen will. In Deutschland beschließt sie, sich von ihrem Mann scheiden zu lassen, was diesen in seiner Ehre zutiefst verletzt: Er folgt ihr nach Deutschland und erschießt sie. Die unver-

20 Die »innere Unruhe« ist insbesondere auch eine körperliche, psychische und existenzielle Angelegenheit. Jean-Paul Sartre hält zu den Folgen der seriellen Industrialisierung in seiner Kritik der dialektischen Vernunft von 1960 fest, dass die serielle Produktion in das Gefüge des Sozialen und Psychischen ausgreife. Als Beispiel greift er den Einfluss der halbautomatischen Maschinen auf die sexuellen Träumereien der Arbeiter auf. »Umfragen haben gezeigt, dass kurz nachdem halbautomatische Maschinen eingeführt worden waren, die gelernten Arbeiterinnen sich bei der Arbeit Träumereien sexueller Art überfließen; sie erinnerten sich an das Schlafzimmer, das Bett, die Nacht, an alles, was nur die Person in der Einsamkeit des mit sich beschäftigten Paares angeht. Aber es war die Maschine in ihnen, die von Zärtlichkeiten träumte.« In: MARCuSE (1967): S. 47.

21 Ebd., S. 73. 
heiratete Sevim (als letzte der Gruppe aus dem Zug), bricht nach Deutschland auf, weil sie das freie Leben in Europa reizt. ${ }^{22}$

So unterschiedlich sich die Motivationen und Folgen der Arbeitsmigration für jeden der Akteure ausnehmen, so unterschiedlich sind in Yıldız' Roman auch die Einstellungen der Gastarbeiterinnen und Gastarbeiter zum Westen und zur eigenen Herkunft. An einer Stelle heißt es, man müsse die Rückschrittlichkeit der Türkei hinter sich lassen und Europäer werden, an anderer - welche die Position des Ich-Erzählers widerspiegelt - geht es darum, sich in Deutschland technisch weiterzubilden, um nach der Rückkehr die Herkunftsgesellschaft modernisieren zu können. ${ }^{23}$ Weitere wiederkehrende Themen des Romans sind das sittliche bzw. unsittliche Verhalten deutscher und türkischer Frauen, das unsolidarische Verhalten türkischer Beamter an der Grenze oder im Konsulat sowie die unmenschliche Kälte der Deutschen. ${ }^{24}$

Ebenso wie die Motivlagen der Gastarbeiterinnen und Gastarbeiter werden auch diese Themen in Türkler Almanyada auf mikro- und makrosozialer Ebene kontrovers entfaltet. Trotz der Kritik an der sexuellen Freizügigkeit der deutschen Frauen und ihrer scheinbaren Amoralität wollen fast alle Gastarbeiter eine deutsche Freundin haben. ${ }^{25}$ Um sich mit ihren deutschen Frauenbekanntschaften ungestört treffen zu können, ziehen jene Gastarbeiter, die es sich leisten können, aus den Baracken in eine Pension. ${ }^{26}$ Und trotz der Kritik am diskriminierenden Verhalten der türkischen Behörden identifizieren sich die Gastarbeiter mit ihnen. Später ist es hingegen ein deutscher Arbeitskollege, mit dem sich der Ich-Erzähler am besten versteht, wenn sie über die deutsche und türkische Gesellschaft urteilen. Für beide haben die zentralen Aspekte des Spätkapitalismus, die Urbanisierung und Industrialisierung in beiden Gesellschaften, negative Auswirkungen auf das soziale Leben. ${ }^{27}$ Diesem Deutschen stehen wiederum andere Deutsche entge-

22 YILDIZ (1966): S. 16. In Okans Film ОтовÜs wird hingegen ein türkischer Gastarbeiter von einem homosexuellen Schweden sexuell bedrängt.

23 Tatsächlich war die Argumentation, dass die Migration türkischer Staatsbürger als Arbeiter nach Deutschland für die Türkei bei ihrer Re-Migration wichtige Impulse im Prozess ihrer wirtschaftlichen und gesellschaftlichen Entwicklung bringen würde, politisch sehr verbreitet. Die türkische Regierung hatte wie die deutsche ein Interesse daran, weniger bis kaum qualifizierte Arbeiter in die Bundesrepublik zu entsenden, damit sie dort berufliche Qualifikationen erwerben konnten. Siehe hierzu: HunN (2005): S. 60.

24 Vgl. YiLDIZ (1966): S. 60.

25 Siehe ebd., S. 36.

26 Ebd., S. 44.

27 Milton Gordon hält ebenfalls in Assimilation in American Life fest, dass die eigentliche Herausforderung für eine gelingende Integration die Verhandlung von Entfremdungserfahrungen sei, die die Prozesse der Urbanisierung und Industrialisierung in modernen Gesellschaften be- 
gen, die empathieloser und rationaler nicht hätten dargestellt werden können. Widersprüche sind ein zentraler Bestandteil dieser und anderer Erzählungen, die in diesem Kapitel noch diskutiert werden. Das Resultat ist eine Verkettung kontroverser Positionen, die am Ende von Türkler Almanyada so weit reicht, dass sich die Antwort auf die Ausgangsfrage im Roman, wo die europäische Zivilisation beginnt, verschiebt: von Österreich über Deutschland und schließlich nach Frankreich. Während eines zweitägigen Urlaubsaufenthaltes erkennt der Ich-Erzähler, dass das moderne Leben in Frankreich angenehmer gestaltet wird als in Deutschland. In Deutschland werde gelebt um zu arbeiten, in Frankreich gearbeitet um zu leben. ${ }^{28}$ Das Verhältnis von Identität und Identifikation, von Akteuren zwischen Herkunfts- und Ankunftsgesellschaften ist in diesem ersten Text zur türkischen Arbeitsmigration unerwartet prekär. Es ist oft im Wandel begriffen und verschiebt nicht zuletzt sogar den Ausgangspunkt europäischer Zivilisation. Ein Grund für diese Verschiebungen: Die Migration schafft mit der Zeit neue Bedürfnisse. ${ }^{29}$

In Türkler Almanyada sind diese Verhältnisse aber auch prekär, weil die Begegnung von Akteuren, ihre Interaktionen, an funktionalen Orten und Transiträumen stattfinden: in Zugabteilen, internationalen Grenzbereichen, Arbeiterbaracken, Arbeitsplätzen und Hotelzimmern. ${ }^{30}$ In Şorays DöNüş spielt der ganze Film zwar im Unterschied dazu nur in einem namentlich nicht genannten Dorf, doch entwickelt sich dieser vermeintliche Ursprungsort der Protagonisten für sie durch den Einfluss der Zivilisation (»Medeniyet«) und durch die Bedürfnisse

stimmten. Siehe hierzu: GoRdon, Milton (1964): Assimilation in American Life. The Role of Race, Religion, and National Origins, New York: Oxford University Press, S. 18. Die genannten Entfremdungsaspekte spielen auch in den äußerst wirkmächtigen Arbeiten Der eindimensionale Mensch von Herbert Marcuse (1967) und in Critique de la raison dialectique von Jean-Paul Sartre (Paris, 1960) eine herausragende Rolle. Marcuses Buch erschien zuerst in einer englischen Fassung. Siehe: MARCuSE, Herbert (1964): One-Dimensional Man, Boston: Beacon Press.

28 Die 1960er Jahre sind in der Kulturgeschichte der Bundesrepublik das Jahrzehnt, in dem die Deutschen das Ausland, wie Frankreich, Italien und Jugoslawien, verstärkt als touristische Ziele wiederentdeckten. So kommt es, dass 1968 erstmals seit dem Ende des Zweiten Weltkrieges in der Bundesrepublik die Zahl der deutschen Auslandstouristen höher ist als die der deutschen Inlandstouristen. Siehe hierzu: SchiLDT, Axel (2009): Deutsche Kulturgeschichte. Die Bundesrepublikvon 1945 bis zur Gegenwart, München: Hanser, S. 194. Diesen Befund hält auch Bekir Yıldız fest, wenn er beschreibt, dass an Feiertagen viele Deutsche, wie die Gastarbeiter, für Tagesausflüge nach Frankreich fahren. Siehe hierzu: YILDIZ (1966): S. 123.

29 Dieser Vorrang der Bedürfnisse und Bedürftigkeiten steht auch im Vordergrund der Filme DöNüş und ОтовÜs. Und wie wir sehen werden, stehen sie auch im Zentrum der zur selben Zeit verfassten Literatur.

30 Âbide Doğan erwähnt diese Lokalitäten nur beiläufig, ohne ihre spezifische narrative Funktion einzubeziehen. Siehe hierzu: DoĞAN, Abide (2003): »Almanya'daki türk işcilerini konu alan romanlar üzerine bir değerlendirme«. In: Türkbilig, 2003/6, S. 56-68. 
des Großgrundbesitzers zu einem unsicheren Ort. Weil Gülcan sich dem Großgrundbesitzer auch während der migrationsbedingten Abwesenheit Ibrahims sehr selbstbewusst widersetzt, wird ihr und Ibrahims Haus zerstört, ihr Acker in Brand gesteckt. Der türkische Großgrundbesitzer hat sich in Gülcans Schönheit, in ihre rebellische Art und in ihre Wut verliebt. Und er ist von einem Überschuss an Bedürfnissen getrieben, die den öffentlichen Raum im Dorf für Gülcan immer unsicherer machen. Mehrmals entgegnet er ihr, als sie sich ihm widersetzt, dass man am Ende schon sehen werde, wem die Welt gehöre, ihr oder ihm. ${ }^{31}$ In Okans Отовӥs ist der öffentliche Raum außerhalb des Busses ebenfalls ein gefährlicher Ort für die Gruppe von Türken, weil ihnen Pässe und Bescheinigungen fehlen. Öffentliche Räume, Orte und Akteurinnen und Akteure stehen in keinem zugehörenden oder besitzenden Verhältnis zueinander. Dieses Nicht-Verhältnis entwickelt sich in DöNÜş migrationssoziologisch spiegelverkehrt, so dass man sich am Ende fragen muss, wohin eigentlich Ibrahim zurückkehrt, wenn es kein Land, kein Haus und keine soziale Ordnung am Ort der Herkunft mehr gibt. Auch Yıldız' autobiografischer Roman konterkariert seinen Titel. Erstens steht die äußerst heterogene Gruppe der Migranten in Ylldız' Roman quer zum ersten Teil des Titels des Romans »Türkler «, der Homogenität verspricht. Und zum zweiten wird auch der zweite Teil des Titels, seine Topologie, konterkariert: »Almanyada«. Der Lokativ $d a$ weist im Türkischen funktional auf einen realen, stabilen Ort, einen Platz, den es in Ylldız' Text nicht gibt.

Mit den beiden bekannten Geografen der 1970er Jahre, dem Kanadier Edward Relph und dem chinesisch-amerikanischen Yi-Fu Tuan gesprochen, existiert hier kein wechselseitiges Verhältnis zwischen Raum, Platz und Ort (space \& place); ${ }^{32}$ ein Verhältnis, das der französische Soziologe Henri Lefebvre auch in den 1970ern

31 Auch in dem bekannten türkischen Film Kibar FeYzo von 1978 beweist der Großgrundbesitzer Maho Ağa immer wieder durch Ausweisungen eines Dorfbewohners, dass ihm das Land gehört. Nur kehrt der ausgewiesene Feyzo aus der türkischen Stadt zurück und bringt mit seinen Ideen von dort das Dorfleben immer wieder durcheinander. Beispielsweise demonstrieren irgendwann im Film die Frauen gegen das Brautgeld, das im Dorf von jeher Tradition ist. Der politische Wandel im Dorf führt so weit, dass am Ende der Großgrundbesitzer selbst aus dem Dorf ausgewiesen wird. Siehe hierzu: Yilmaz, Atif (1978): Kibar Feyzo, Spielfilm, Türkei, Arzu Film.

32 Der kanadische Geograf Edward Relph hält in seiner bekannten Arbeit Place and Placesness von 1976 als Grundlage für einen stabilen Ort "as concept of place« fest, dass diesem ein Wissen und ein Gefühl eines Raums (space) vorausgehen muss. Das Verhältnis von place und space ist dabei in der Abfolge ein wechselseitiges: »In general it seems that space provides the context for places but derives its meaning from particular places«. RELPH, Edward (1976): Place and Placelessness, London: Pion Ltd., S. 8. In diesem Zusammenhang unterscheidet der chinesisch-amerikanische Geograf Yi-Fu Tuan, dass place für Sicherheit und Stabilität stehe und space für Offenheit, Freiheit und zugleich auch für Gefahr. Siehe hierzu: TuAN, Yi-Fu (1977): 
als Grundlage für die Aneignung des öffentlichen Raums beschreibt. ${ }^{33} \mathrm{Ihm}$ ist es ein besonderes Anliegen, den öffentlichen Raum im Zentrum der Städte, das in den 1970er Jahren von Kaufhäusern geprägt ist, lebensweltlich zu gestalten. Die Frage nach der Gruppe und die Frage nach Ort und Platz gehören auf unterschiedlichsten Ebenen zu den zentralen Themen der Verhandlung von Integration in Literatur, Film, öffentlicher Debatte und Theorie der 1960er und 1970er Jahre. Äußerst eindrücklich zeigt sich dies in Tunç Okans Film ОтовÜs. Kaum hat der türkische Schlepper die türkischen Arbeiter nach Stockholm gebracht, parkt er auf der Flucht vor der schwedischen Polizei den Bus mitten auf einem öffentlichen Platz. Er verlangt von den Türken im Bus, ihm die Pässe und ihr letztes Geld zu geben. Er würde sie ihnen gleich wieder mit den Arbeitsbescheinigungen zurückbringen. Bis dahin sollten sie auf keinen Fall den Bus verlassen, weil sie dann ohne Papiere ausgewiesen würden. Der Schlepper kehrt nicht mehr zurück und in ihren abendlichen Touren streifen die Türken, als sie die öffentlichen Toiletten aufsuchen müssen, durch ein Stockholm, das nur aus Geschäften besteht. Äußerst irritierend wird die Erfahrung für den Türken Mehmet, der vom Regisseur selbst gespielt wird, als ihn ein schwedischer Homosexueller von der öffentlichen Toilette mit auf eine öffentliche Veranstaltung nimmt, bei der Schwedinnen und Schweden in edler Abendkleidung essen, trinken und gemeinsam einen Pornofilm anschauen. Außerdem wählt der Moderator der Veranstaltung aus dem Publikum ein Paar aus, das vor allen anderen auf der Bühne Geschlechtsverkehr haben soll. Als dann der homosexuelle Schwede den zu Stein erstarrten Türken dabei auch noch sexuell bedrängt, hält es dieser keine Sekunde mehr aus und verlässt mit einem Schrei die Bar. Am Ende des Films wird der Bus von der Polizei mit den Insassen abtransportiert und jeder der Türken wird einzeln aus dem Bus in Polizeigewahrsam gebracht.

Was die Rezeption von türkischen Filmen und türkischer Literatur zu Migration der 1960er und 1970er Jahre betrifft, haben sie bislang in der Forschung wenig Beachtung gefunden. Eine wichtige Ausnahme stellt hier die kürzliche erschiene Arbeit Die visuelle Kultur der Migration von Ömer Alkın dar. ${ }^{34}$ Ein Grund

Space and Place: The Perspective of Experience, Minneapolis: University of Minnesota, S. 6. Für beide Humangeografen gilt, dass space und place sich wechselseitig bedingen.

33 Lefebvre, Henri (2006): »Die Produktion des Raums«. In: Stephan Günzel: Raumtheorie. Grundlagentexte aus Philosophie und Kulturwissenschaften, Frankfurt a. M.: Suhrkamp, S. $337 \mathrm{f}$.

34 AlKIN (2019). Siehe hierzu auch den Aufsatz von Tuncay Kulaoglu und Martina Priessner "Stationen der Migration« von 2017, in dem die Autoren mehrere Seiten den Filmen der 1970er Jahre widmen. Siehe hierzu: KulaoĞLU, Tuncay/PrIESSNER, Martina (2017): »Stationen der Migration. Aufbruch, Unterwegssein, Ankunft und Rückkehr im türkischen Yeşilçamkino bis zum subversiven Migrationskino der Jahrtausendwende«. In: Deutsch-Türkische Filmkultur im Migrationskontext, Wiesbaden: Springer VS, S. 25-44 u. S. 26-32. 
für die ausgebliebene Rezeption ist sicherlich die fehlende Übersetzung ins Deutsche oder Englische und das nicht vorhandene Interesse von Filmverleihen, die Filme als DVDs herauszubringen. ${ }^{35}$ Dabei stehen Türkler Almanyada, DöNÜş und ОтовÜs - beim letztgenannten zeigen es in jedem Fall die mehrfachen internationalen Prämierungen ${ }^{36}$ - in einem äußerst weitreichenden Zusammenhang repräsentativ für die 1960er und 1970er Jahre: politisch in internationaler Rahmung, typologisch mit ihren Fokussen auf eine fragile soziale Gruppe, auf ein fragiles Verhältnis zwischen place und space, zwischen Privatheit und Öffentlichkeit, mit ihren Themen Arbeit, Fortschritt, Konsum, Sexualität, Sittlichkeit und die Beherrschung all dessen durch Zivilität. Dieser Zusammenhang ist zur gleichen Zeit auch in den ästhetisch anspruchsvolleren und linkspolitisch motivierten Bearbeitungen des Migrationsthemas durch Rainer Werner Fassbinder, Aras Ören, Helma Sanders-Brahms, Güney Dal und abschließend mit Şerif Görens Film Almanya, ACI Vatan (»Deutschland, bitteres Vaterland«) von 1979 konstitutiv. ${ }^{37}$ Dabei vollzieht der zuletzt genannte Film ziemlich genau in seiner Mitte einen narrativen Wandel auf mehreren Ebenen. Während in der ersten Hälfte Aufnahmen von öffentlichen Räumen, von Straßen, von Schwellenbegegnungen, das bewegungs- und beschäftigungsreiche Leben in mehrparteilichen Wohnungen im türkischen Dorf und in Berlin-Kreuzberg den Film bestimmen, führt die zweite Hälfte Immobilitäten ein, die den zweiten Leitsatz der vorliegenden Kulturgeschichte neben und mit anderen Werken einleitet. Aber auch diesen Werken wird in der Forschung mitunter vorgehalten, ihre Akteure zu schematisch und zu schablonenartig dargestellt zu haben. ${ }^{38}$

Diese deutlich zu psychologische und zu sehr auf das Subjekt verengte Perspektive verkennt das Thema und den eigentlichen Fokus. In diesen Produktionen stehen - wie ich zeigen werde - nicht die Ausgestaltung einer komplexen psychisch-inneren Disposition oder die besondere Handlungsfähigkeit eines Individuums im Vordergrund, sondern die Kartierung eines Feldes mit Bedürfnisstrukturen, die eine Veränderung von Personen und Gruppen einleiten, die das soziale Gefüge der Erzählungen unerwartet verschieben. Als Orientierung steht im Zentrum die Frage nach den Bedingungen, Möglichkeiten und Unmöglichkeiten

35 Dank türkischer Internetportale ist es jedoch möglich, sich diese Filme im Internet anzusehen. 36 Wenn Otobüs international sehr positiv aufgenommen wurde, ist er jedoch in der Türkei für lange Zeit verboten worden, weil er die türkischen Dörfler besonders abwertend, naiv, dumm und als stumme Personen darstellt. Siehe hierzu: ALKIN (2019): S. 161.

37 Siehe zu Aci Vatan: Alkin (2019): S. 582f.

38 Chin, Rita (2007): The Guest Worker Question in Postwar Germany, New York: Cambridge University Press; GöKтÜRK, Deniz (2000b): »Migration und Kino. Subnationale Mitleidskultur oder transnationale Rollenspiele?«. In: Interkulturelle Literatur in Deutschland. Ein Handbuch, hg. v. Carmine Chiellino, Stuttgart, Weimar: Metzler, S. 329-347. 
von sozialstrukturellem Wandel. Dieses lässt sich sehr gut in der vielschichtigen, ausführlichen und bewegungsreichen Antwort Niyazis greifen, warum er den überhaupt nach Deutschland gekommen sei.

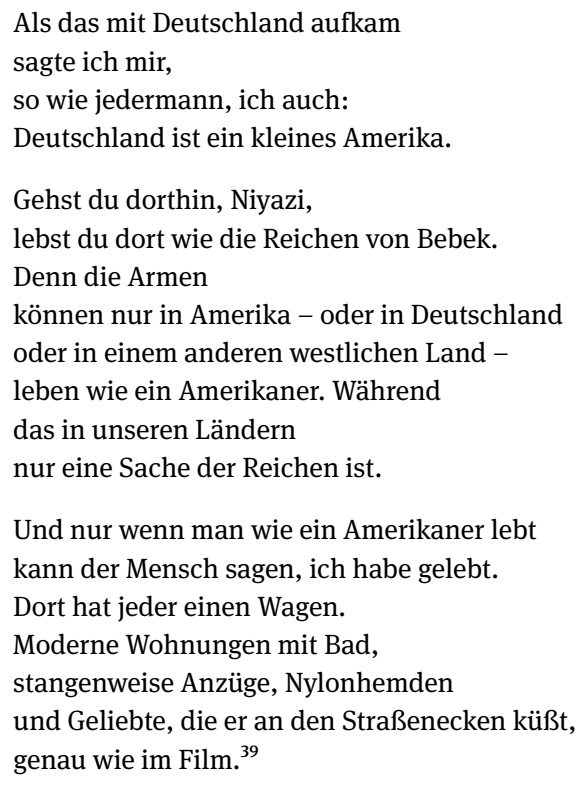

Doch diese Wünsche werden weder in Yıldız' autobiografischem Roman, in Şorays und Okans Filmen noch in Örens Poem wahr. Vielmehr entwickeln sich die Wünsche und die Bedürfnisse zu Grundlagen von Kritik. Da Reflexionen zu Integration von der Kritik an Ist-Zuständen ausgehen, durchziehen die genannten Themen die Sozialtypologie von Orten, Plätzen und Räumen, von Sexualität und Sittlichkeit, die kulturell-nationale Orientierung, Wirtschaft, Konsumkritik bis hin zur Frage der Zivilität. Wie ich weiter aufzeigen werde, bestimmen sie ebenso sehr die Integrationsdebatten und -theorien der 1960er und 1970er Jahre in unterschiedlichen Graden. Es sind Themen, die den innerdeutschen Diskurs ästhetisch wie

39 ÖREN (1973): S. 25. Dass ein sozialstruktureller Aufstieg zugleich für einen Identitätswandel steht, für eine Integration in eine Mehrheitsgesellschaft, ist nicht nur im Kern Bestandteil der Integrationstheorien von den 1920ern bis Ende der 1980er Jahre, also von Robert Ezra Park bis Hartmut Esser. Auch türkische kemalistische Parteifunktionäre vertraten und propagierten zwischen den 1950ern und 1970ern, »dass sich gut ausgebildete, im westlichen Sinn erzogene Menschen« ein aufgeklärtes Verhältnis gegenüber Traditionen und Religionen aneignen würden. Siehe hierzu: Kreiser, Klaus/Neumann, Christoph (2009): Kleine Geschichte der Türkei, Stuttgart: Reclam, S. 416. 
politisch bestimmen, die Produktionen des Neuen Deutschen Films ebenso wie die Debatten zur inneren Demokratisierung Deutschlands. ${ }^{40}$ In beiden thematischen Feldern - der Migration und dem demokratischen Zustand der Bundesrepublik steht dabei ein zentraler Befund, dass es für die innere Demokratisierung der Bundesrepublik nämlich unentbehrlich ist, einen Zusammenhang zwischen privatem und öffentlichem Leben, zwischen privatem und öffentlichem Raum zu entwickeln; ${ }^{41}$ ein Konnex, der für die deutsch-türkische Literatur- und Filmproduktion, wie an einigen Beispielen mit Zaimoğlu, Özdamar und Şenocak im Einleitungskapitel bereits festgehalten wurde, ebenfalls konstitutiv ist.

Der Fokus auf Einstellungen, Verhaltensweisen und Gruppenkonstellationen ist jedoch nicht nur der Literatur und dem Film inhärent. Systematisch finden wir ihn auch in der bereits genannten Integrationstheorie Milton Gordons, der Assimilation in American Life. Im Gegensatz zu Robert Ezra Parks anvisierter kultureller Fusion von Herkunft und Ankunft durch den marginal man sieht Gordon das Gelingen von Integration in der Generierung neuer sozialer Bindungen durch »participational identifications«. Deren Träger können nicht einzelne Individuen, sondern nur Gruppen sein, die sozialstrukturell und kulturell eine Überschneidungsdichte und Kontakte mit anderen Gruppen entwickeln. ${ }^{42}$ Der erste Schritt zu neuen sozialen und kulturellen Bindungen ist für Gordon der Abbau rassistischer, religiöser und nationaler Diskriminierungen und die Entstehung angemessener Verhaltensweisen, die neue integrative Gruppenbindungen auslösen und $\mathrm{zu}$ einer »civic assimilation « führen können. ${ }^{43}$ Diesen Prozess, den Gordon anhand von sieben Etappen in seinem Buch beschreibt, bezeichnet er nicht als eine Kultur- oder Zivilisationstheorie sondern als »a >theory of group life «. ${ }^{44}$ Gelingen kann dieses Konzept jedoch nur, wenn die small group in Kommunikation und engem Austausch mit einer larger society steht, die sie als ihr zugehörig rahmt. Er bezeichnet diese core society als »America«, was für Zivilgesellschaft steht. Dabei darf »America« in

40 Siehe hierzu: DAHRENDORF, Ralf (1966): Gesellschaft und Demokratie in Deutschland, München: Piper, S. 464-482.

41 Das zentrale Thema des Neuen deutschen Films, der Mitte der 1960er Jahre mit den Filmen ABSCHIED VON GESTERN (Alexander Kluge, 1966) und DER ZöGLING TöRLESS (Volker Schlöndorff, 1966) einsetzt und bis Ende der 1970er Jahre den deutschen Film definiert, ist ebenfalls das Verhältnis von privatem und öffentlichem Leben. Siehe hierzu: HAKE, Sabine (2004): Film in Deutschland. Geschichte und Geschichten ab 1895, Reinbek: Rowohlt, S. 255.

42 GORDON (1964): S. 53.

43 Ebd., S. 71.

44 Ebd., S. 18. Dieser Fokus auf die Gruppe resultiert aus Milton Gordons Ergebnis, dass kulturelle Identifikationen von small groups eine soziale Tatsache darstellen, die sich für ihn besonders in den Bürgerbewegungen der 1960er herauskristallisiert hat. 
Gordons Theorie nicht ein Territorium sein, das nur einer bestimmten Gruppe gehört, wie beispielsweise den weißen Protestanten. »Indeed, the white Protestant is rarely conscious of the fact that he inhabits a group at all. He inhabits America. The others live in groups. ${ }^{45}$ Solche ungleichen Wohnverhältnisse sind für Gordon die Grundlagen gesellschaftlicher Diskriminierung. ${ }^{46}$ "America« sollte eine stabile »wohnliche« Referenz für alle Gruppenmitglieder als eine large society sein. ${ }^{47}$ In den bereits kurz skizzierten Filmen und Texten zur türkischen Migration nach Deutschland entsteht weder am Ort der Herkunft noch an dem der Ankunft eine stabile »wohnliche« Referenz.

Wenn in Gordons theoretischen Ausführungen das real bewohnte Territorium der Gruppen von den katholischen Farbigen über Chinesen bis hin zu weißen Protestanten mit der vorgestellten large society als »America in einen identifizierenden Zusammenhang gebracht werden kann, findet sich diese Form der Korrelation von Territorium, Bewegung von »drinnen« nach »draußen « und narrativer Identifikation in der Bundesrepublik Deutschland in den 1960er und 1970er Jahren nicht - oder höchstens für den Europäer und den Amerikaner, aber nicht für den Gastarbeiter. Das Pendant für die larger society in der Bundesrepublik ist in dieser Zeit in wirtschaftlicher Hinsicht Europa und in kultureller Hinsicht Amerika. ${ }^{48}$ Ähnlich wie die Akteurinnen und Akteure in den bereits erwähnten und beschriebenen Produktionen ihre Erfahrungen in Deutschland etwas unbestimmt als Erfahrungen mit der europäischen Zivilisation bezeichnen, beschreiben deutsche Politiker und Journalisten Sinn und Zweck der ausländi-

45 GORDON (1964): S. 5, Hervorhebung im Original.

46 Ebd., S. 3.

47 "In the last analysis, what is gravely required is a society in which one may with equal pride and without internal disquietude at the juxtaposition: $>$ I am a Jew, or a Catholic, or a Protestant, or a Negro, or an Indian, or an Oriental, or a Puerto Rican; ‘ >I am an American; ‘ and \I am a man`.« GORDON (1964): S. 265. Weniger auf ein reales und zugleich imaginäres Territorium mit »America« setzt Anfang der 1970er Jahre der Soziologe Mark Granovetter auf ein Netzwerk zwischen unterschiedlichen Gruppen, das aus weak ties, schwachen Verbindungen, entsteht. Für ihn sind es nicht die umstehenden Verwandten und Freunde, die die Integration in eine moderne Gesellschaft ermöglichen, sondern Bekanntschaften aus anderen Gruppen, die soziale Mobilität ermöglichen können. »Weak ties are actually vital for an individual's integration into modern society.« GranovetTER, Mark S. (1973): »The Strength of Weak Ties«. In: American Journal of Sociology, Volume 78, Issue 6, S. 1360-1380, hier S. 1366.

48 Wenn die 1950er Jahre als erste Phase der Amerikanisierung »an einer Wand traditionsreicher Ressentiments « in der Bundesrepublik zerschellten, erfolgte in den 1960er Jahren die eigentliche Amerikanisierung. Die 1960er sind für viele Zeithistoriker das »entscheidende Jahrzehnt« der Amerikanisierung. Siehe hierzu: SCHILDT (2009): S. 188. Siehe auch: DoERING-MANTEUFFEL, Anselm (2011): »Amerikanisierung und Westernisierung «. Version: 1.0, In: Docupedia-Zeitgeschichte, 18.01.2011, http://docupedia.de/zg/Amerikanisierung_und_Westernisierung (20.05.2016). 
schen Arbeitsmigration - besonders in der Anwerbephase zwischen 1955 und 1973 - auch als ein europäisches Integrationsprojekt. ${ }^{49}$

Im ersten deutschen Zeitungsartikel zu Gastarbeitern wird beispielsweise bei der Anwerbung der italienischen Arbeitskräfte im Dezember 1955 die europäische Solidarität beschworen. ${ }^{50}$ Und knapp fünfzehn Jahre danach ist es noch Tenor unter vielen deutschen vorsitzenden Gewerkschaftern, dass »der ausländische Arbeiter von heute [...] der europäische Bürger von morgen [ist] «. ${ }^{51}$ Auch für die Schweiz hält der Zürcher Soziologe Hans-Joachim Hoffmann-Nowotny in seiner Soziologie des Fremdarbeiterproblems von 1973 fest, dass die Integration der Fremdarbeiter in der Schweiz nur gelingen könne, wenn sie als eine europäische und darüber hinaus sogar als eine weltgesellschaftliche begriffen werde. ${ }^{52}$ Auf die kognitive Assimilation folgt die sozialstrukturelle, auf diese die soziale und am Ende ergibt sich die identifikative Assimilation wie von selbst. Im Zentrum seiner Integrationstheorie stehen die Expansion und die Öffnung der Beschäftigungsstruktur für Fremdarbeiter wie für die Autochthonen. ${ }^{53}$ Was aber diesen neuen europäischen Bürger jenseits seiner Bestimmung als Arbeiter oder Konsument auszeichnen soll, wird - wie auch in Bekir Ylldız autobiografischem Roman an keiner Stelle der genannten Texte, ob journalistisch oder wissenschaftlich, explizit. Es dominiert die Vorstellung, dass Zeit, Wirtschaft und sozialstruktureller Aufstieg die sozial bestehenden Spannungen der Migration werden auflösen können. ${ }^{54}$ Diese mangelnde Äquivalenz zwischen Wirtschaft und politischem

49 »Eingliederung" und "Anpassung" sind die zwei am häufigsten verwendeten Begriffe in dieser Zeit, wenn es um die Frage der Integration der Arbeitsmigranten geht. Siehe hierzu: SCHÖNWÄLDER, Karen (2001): Einwanderung und ethnische Pluralität, Berlin: Klartext, S. 165. Siehe auch: RAUER, Valentin (2013): »Integrationsdebatten in der deutschen Öffentlichkeit (1947-2012)«. In: Die Integrationsdebatte zwischen Assimilation und Diversität. Grenzziehungen in Theorie, Kunst und Gesellschaft, hg. v. Özkan Ezli, Andreas Langenohl, Valentin Rauer, Claudia Voigtmann, Bielefeld: transcript, S. 51-86, hier S. 77.

50 FAZ (1955): »Hunderttausend italienische Gastarbeiter kommen«, 21.12.1955.

51 StEPhAN, Günter (1969): „Einstellung und Politik der Gewerkschaften“. In: Strukturfragen der Ausländerbeschäftigung, hg. v. Prof. Dr. Johannes Chr. Papalekas, Herford: Maximilian, S. 34-46, hier S. 40.

52 Siehe hierzu: Hoffmann-Nowotny, Hans-Joachim (1973): Soziologie des Fremdarbeiterproblems. Eine theoretische und empirische Analyse am Beispiel der Schweiz, Stuttgart: Enke, S. 317-321. 53 Ebd., S. 23.

54 Da dies aber in der Praxis weder die Politik der Bundesregierung noch die anderer europäischer Länder ist, steht neben diesem insgesamt sehr unbestimmt gehaltenen Narrativ einer europäischen Integration eine äußerst konkret und bestimmt geführte Kosten-Nutzen-Kalkulation der Arbeitsmigration nach Deutschland, wie sie Ulrich Herbert und Karin Hunn in ihren Publikationen aufgezeigt haben. Durch die Neufassung des Anwerbeabkommens zwischen der Bundesrepublik und der Türkei 1964 - nach 1961 - war es den türkischen Gastarbeitern nach zwei 
Entwurf, um welchen europäischen Bürger es beim Arbeitsmigranten in Zukunft gehen soll, impliziert eine gespaltene Repräsentation, die Literatur und Film der 1970er Jahre zentral bestimmt. Diese Spannung und Spaltung hat paradoxerweise auch ihr Gutes gehabt, denn sie war die Grundlage der beginnenden informellen Einwanderungsgeschichte in der Bundesrepublik. Man war zwar kein Einwanderungsland, doch wurden aufgrund des bundesrepublikanischen wirtschaftlichen Bedarfs und des politischen Projekts wieder Teil der zivilen westlichen Welt $\mathrm{zu}$ werden, Familienzusammenführungen erlaubt, die logischerweise Einwanderungsprozesse einläuteten. »Sowohl für die konservativ als auch die sozialdemokratisch geführten Regierungen der mittleren 1950er bis mittleren 1970er Jahre war die Arbeitsmigration aus dem Ausland verknüpft mit zentralen Zielen ihrer Politik. ${ }^{55}$ Aktiver Teil dieser Politik sollten die ausländischen Arbeitskräfte aber nicht werden, wie es auch das Ausländergesetz von 1965 dokumentiert.

Es ist mitunter diese uneinheitliche Adressierung der Gastarbeiter als ein uneinheitliches Objekt, die die erste große öffentliche Debatte über Gastarbeiter weder von nationalen noch kulturellen Merkmalen bestimmen ließ. ${ }^{56} \mathrm{Im}$ Gegenteil bündelt das Thema, das die Bildzeitung im Frühjahr 1966 aufwarf, Disziplin, Körperlichkeit und Fleiß. ${ }^{57}$ Sie titelte im Zusammenhang einer Tagung des Bundes Deutscher Arbeitgeber (BDA) zum »Gastarbeiter«, ob »Gastarbeiter fleißiger als deutsche Arbeiter« seien. Tags darauf legten mehr als 5000

Jahren Aufenthalt in Deutschland möglich, ihre Frauen und Kinder nach Deutschland nachziehen zu lassen. Siehe hierzu: HERBERT, Ulrich (2001): Geschichte der Ausländerpolitik in Deutschland. Saisonarbeiter, Zwangsarbeiter, Flüchtlinge, Gastarbeiter, München: Beck, S. 227-229. Dies führte dazu, dass der Anteil nicht arbeitender Gastarbeiter ab Mitte der 1960er zunahm und dadurch erhöhte Kosten auf kommunaler Ebene entstanden. Letzteres war am Ende die eigentliche Grundlage für den Anwerbestopp im November 1973 durch die Regierung von Willy Brandt und weniger die Erdölkrise. Siehe hierzu: HunN (2005): S. 341. Hinzu kommt - neben dem Gastarbeiter als Europäer und der Kosten-Nutzen-Kalkulation - ein weiteres immer wieder auftretendes Narrativ, dass die Sprechweisen der Integration in den 1960er und 1970er Jahren ebenfalls mitbestimmt. Oft wird die Gastarbeiteranwerbung als eine Art Entwicklungshilfe beschrieben, bei der die Gastarbeiter viel für ihre Herkunftsländer und Herkunftsgesellschaften auf industrieller und zivilisatorischer Ebene lernen würden. Auf diesen Aspekt werde ich in Kapitel 2.7 »Zivilisation als unbestimmte Soziokultur« noch näher eingehen.

55 ScHöNwÄLDER, Karen (1999): » Ist nur Liberalisierung Fortschritt?^ Zur Entstehung des ersten Ausländergesetzes der Bundesrepublik«. In: 50 Jahre Bundesrepublik. 50 Jahre Einwanderung. Nachkriegsgeschichte als Migrationsgeschichte, Frankfurt a. M.: Campus, S. 127-144, hier S. 141.

56 Auf diesen Aspekt, dass Kultur in den Anfängen der Arbeitsmigration, selbst bei den türkischen Gastarbeitern, keine besondere Rolle gespielt hat, macht auch die Historikerin Karin Hunn explizit aufmerksam. Siehe hierzu: HunN (2005): S. 139.

57 Auch im türkischen Film DöNüşs sehen wir fast in jeder Sequenz arbeitende Menschen. Entweder auf dem Feld, beim Wasserholen oder den Dorflehrer beim Unterrichten. 
deutsche Arbeiter der metallverarbeitenden Betriebe in Baden-Württemberg protestierend ihre Arbeit für mehrere Tage nieder; sie fühlten sich »beleidigt«, in ihrer »Ehre« gekränkt. ${ }^{58}$ Erst achtzehn Monate zuvor, am 10. September 1964, wurde dem einmillionsten Gastarbeiter, dem Portugiesen Armando Rodrigues, am Bahnhof von Köln-Deutz ein zweisitziges Moped zusammen mit einem Nelkenstrauß geschenkt. ${ }^{59}$ Einen weiteren Nachweis dafür, dass explizit keine nationalen oder religiösen Kategorien in den 1960er und 1970ern als trennende bestimmend waren, zeigt auch eindrücklich, dass beispielsweise 1965 das Ende des Ramadans im Kölner Dom gefeiert wurde. Dabei wurde diese Feier nicht als ein interreligiöses Fest begriffen, sondern vielmehr als eine Möglichkeit für alle Muslime in Köln an einem großen und angemessenen Ort das Ende der Fastenzeit feiern zu können. ${ }^{60}$

Trotz dieser Zeichen bleibt die Gastarbeitermigration in die Bundesrepublik ein wirtschaftliches Projekt. Der Weltmarkt der 1960er Jahre setzt sich aus dem angloamerikanischen und westeuropäischen Markt zusammen und das nach Westen wachsende Europa dieser Zeit ist in erster Linie eine Wirtschaftsgemeinschaft (EWG). Länder wie Italien, Portugal, Jugoslawien oder Griechenland gehören nicht dazu, die daraufhin, ebenso wie die Türkei, die meisten Gastarbeiter auf Basis von Anwerbeverträgen nach Deutschland entsenden. Die Zahl der Gastarbeiter in der Bundesrepublik bleibt zwischen den Jahren 1964 und 1968, sprich bis zur

58 Allein bei der Daimler-Benz AG waren es im Werk bei Untertürkheim und im Zweigbetrieb Stuttgart-Hedelfingen über 3000 streikende Metallarbeiter. Vgl. hierzu: CoHN-BENDIT, Daniel/ Schmid, Thomas (1993): Heimat Babylon. Das Wagnis der multikulturellen Demokratie, Hamburg: Hoffmann und Campe, S. 121. Über $35 \%$ der Gastarbeiter waren in der Eisen- und Metallerzeugung und -verarbeitung beschäftigt. Siehe auch: HERBERT (2001): S. 225.

59 FAZ (1964): „Großer Bahnhof für Armando Sa Rodrigues«, 11.09.1964. Im Zusammenhang dieses Empfangs schrieb der damalige Bundesarbeitsminister Theodor Blank im Bulletin des Presse- und Informationsamtes der Bundesregierung, dass der deutsche ökonomische Fortschritt ohne die Gastarbeiter nicht denkbar wäre. »Diese Million Menschen auf deutschen Arbeitsplätzen trägt mit dazu bei, daß unsere Produktion weiter wächst, unsere Preise stabil und unsere Geltung auf dem Weltmarkt erhalten bleibt. Die Rolle der Gastarbeiter auf dem Arbeitsmarkt wird in den kommenden Jahren sicher noch gewichtiger werden.« BLANK, Theodor: "Eine Million Gastarbeiter«. In: Bulletin des Presse- und Informationsamtes der Bundesregierung, 30.10.1964, Nr. 160, S. 1480.

60 Siehe hierzu: HunN, Karin (2011): »Türken sind auch nur Menschen. Und zwar Menschen mit einer anderen Kultur.« Ursachen von Fremd- und Selbstethnisierung türkischer Migranten in der Bundesrepublik«. Vortrag im Rahmen der Tagung Ist das Konzept der Integration überholt? Theoretische Fassungen einer aktuellen Debatte (14.-15.07.2011), Universität Konstanz, 14.07.2014, https://streaming.uni-konstanz.de/talks-events/integrationstagung-ist-das-konzept-der-integration/tuerken-sind-auch-nur-menschen-und-zwar-menschen-mit-einer-anderen-kultur/ (05.07.2017). 
ersten kurzen wirtschaftlichen Rezession 1967, konstant bei knapp einer Million. Aufgrund erneuter wirtschaftlicher Konjunktur verdoppelt sie sich zwischen den Jahren 1968 und 1973 auf 2,595 Millionen. ${ }^{61}$ Seit Januar 1972 bilden die Türken bis heute die größte nationale Gastarbeiter-Gruppe in der Bundesrepublik Deutschland. Zu Beginn der 1970er Jahre nimmt die Kritik an der Anwerbung von Arbeitsmigranten öffentlich zu, besonders was die Fragen der öffentlichen Ordnung und ihrer Sicherheit betrifft. Zugleich wächst die Kritik an den Unterbringungen und Wohnverhältnissen der Gastarbeiter in Baracken und Wohnheimen. ${ }^{62}$

Diese gesellschaftspolitische Gemengelage zwischen Gastarbeiter in einem europäisch-westlichen Auftrag als Gäste zu empfangen und sie dennoch ausschließlich am wirtschaftlichen Profit zu messen, kennzeichnet die widersprüchlichen Entstehungsbedingungen und Grundlagen der Migration in den 1960er und 1970er Jahren. Meine Fragen, die sich daraus ergeben: Zeigt sich diese diametrale Spannungslage zwischen politischem und wirtschaftlichem System, die sich auch in der Begriffsgeschichte »Gastarbeiter « ablesen lässt, als eine zusammengehörige, paradoxe epistemische Einheit in Literatur, Film und politischer Reflexion? Und wenn ja, in welche narrativen Formen haben die Diskurse diese Spannungen übersetzt? Was sind das für Geschichten, die sie erzählen? Mit welchen Plots, narrativen Abfolgen wurden sie gerahmt? Wie ist das komplexe Verhältnis der Repräsentation zwischen Darstellen und Vertreten in diesen Anfängen der deutsch-türkischen Literatur und des deutsch-türkischen Films gelöst worden? Ist es überhaupt gelöst worden? Haben Literatur und Film Antworten auf diese Spannungslagen geben können?

Da die hier im Zentrum stehenden Filme und Texte von Helma SandersBrahms, Türkan Şoray, Aras Ören, Tunç Okan, Güney Dal, Rainer Werner Fassbinder und Şerif Gören in den 1970ern im Unterschied zu Bekir Yıldız' Roman sehr erfolgreich waren, stellt sich die Frage, welches größere gesellschaftspolitische Narrativ ihre Geschichten aktualisierten und modifizierten, um als gelungene Erzählungen klassen- und schichtübergreifend rezipiert werden zu können. Was hat man letztlich in den 1960er und 1970er Jahren unter »Integration « verstanden? Wie weit reichte die Semantik des Begriffs? Galt er vielleicht über die Südländer, Gastarbeiter und Ausländer hinaus auch für die vermeintlich alteingesessenen Deutschen selbst? Denn die Frage, wo die europäische Zivilisation beginnt, hätte in den 1960er und 1970er Jahren auch in einem deutschen autobiografischen Roman gestellt werden können.

61 Siehe hierzu: Herbert (2001): S. 224.

62 Siehe hierzu: ebd., S. 235. 


\subsection{Einfache Geschichten: Überraschend viele Lesarten}

Es war die Nachricht über die Ermordung einer blonden Türkin in einem Kölner Boulevard-Blatt 1971, die die Regisseurin Helma Sanders-Brahms auf die Idee ihres sehr erfolgreichen und zugleich umstrittenen Spielfilms SHIRINS HocHZEIT (1976) brachte. Dem Zeitungsbericht zufolge wurde der Türkin, vermutlich eine Prostituierte, in der Nähe eines Kölner Arbeiterwohnheims in den Rücken geschossen. ${ }^{63}$ Wochen vor dieser Tat arbeitet Sanders-Brahms an ihrem Dokumentarfilm DIE INDUSTRIELLE RESERVE-ARMEE, einem 36-minütigen Kurzfilm in Farbe, der die Funktion und Situation der Arbeitsmigranten in der Bundesrepublik Deutschland zum Thema hat. ${ }^{64}$

Bei ihren Recherchen zu diesem Film ist ihr das besondere Anliegen des Leiters eines Kölner Arbeiterwohnheims der Fordwerke aufgefallen. Der Mann will »bei Ford den Bau eines Bordells in Heimnähe anregen, um damit das sexuelle Problem der Arbeiter zu lösen, die ein Jahr von ihren Frauen getrennt in einem fremden Land ohne soziale Kontakte leben müssen $« .^{65}$ Mit seinem Vorschlag möchte er auch gegen die »Tricks« der Kölner Zuhälter angehen, denen es immer wieder gelingt, »trotz Pfortenschlusses um 22:00 [hauptsächlich durch die Kellerfenster] Mädchen in die Heime zu bringen «. ${ }^{66} \mathrm{Im}$ Zusammenhang all dieser Recherchen kommt Helma Sanders-Brahms eine Kette von Situationen in den Sinn, die ihr Filmprojekt plastisch werden lassen. Sie denkt »an die Kellerfenster, an die Zimmer mit vier bis sechs Männern darin, an das Mädchen, das in diese Zimmer gehen [muss], ein Bett nach dem anderen, während die übrigen Zimmerinsassen « zuhören, warten. Und sie denkt »an die Situation dieser Männer, an die Situation des Mädchens « ${ }^{67}$ Diese aus Nachrichten, Recherchen und Interviews imaginierten Szenen dienen später auch als Vorlagen für die letzten 20 Minuten des zweistündigen Spielfilms SHIRINS HochzeIT. Zugleich evozieren diese Situationen auch Sanders-Brahms' narrative Folge des Films von Anfang, Mitte und

63 Siehe: SANDERs-BrahMS, Helma (1980): Shirins Hochzeit, Freiburg: Panta Rhei Filmverlag, S. 107. 64 Siehe: http://www.filmportal.de/film/die-industrielle-reserve-armee_e0445ac032354c129bfd4d 5695e63aaa (17.08.2016). Vor diesem Dokumentarfilm zu den Gastarbeitern in Deutschland hatte Helma Sanders-Brahms in ihren ersten Film ANGELIKA URBAN, VERKÄUfERIN, VERLOBT (1970) den Alltag einer Verkäuferin in der Modeschmuckabteilung eines Kaufhauses dokumentiert. SANDERS-BRAHMS, Helma (1970): Angelika Urban, Verkäuferin, verlobt, Dokumentation, BRD, Zentral Film Verleih.

65 SANDERS-BRAHMS (1980): S. 107.

$66 \mathrm{Ebd}$.

67 Ebd. 
Ende, ihre »causes« und »effects « $^{68}$ : Wie ist es zur Tötung der türkischen Prostituierten gekommen und wie ist sie in diese Umstände hineingeraten? Vermutlich kommt sie aus einem türkischen Dorf, räsoniert sie weiter, aber warum ist sie von dort weggegangen? Und warum nach Deutschland, und wie sieht ihr Leben hier aus? An der Abfolge dieses Schicksals und vorerst Einzelfalls gibt es für Helma Sander-Brahms kaum Zweifel. »Heim, Fabrik, Arbeitslosigkeit, danach Verlust des Heimplatzes, aber die Verpflichtung, Geld nach Hause zu schicken. Also der Strich. Shirin war in meinem Kopf geboren, nach ihrem Tod. « ${ }^{69}$

Ausgehend von diesen Assoziationen und Kausalitäten entsteht SHIRINS HochzeIT. Er ist der erste deutsche Spielfilm, der die türkische Migration nach Deutschland zum Thema hat und wird am 20. Januar 1976 im Ersten Deutschen Fernsehen zum ersten Mal ausgestrahlt. Der Film erzählt die Geschichte einer jungen türkischen Frau, die, als sie von den Brüdern ihres Vaters an einen reichen Brautwerber verkauft werden soll, aus einem türkischen Dorf zunächst nach Istanbul und dann nach Deutschland flieht. Der Aufbruch ist aber mehr als nur eine Flucht, denn sie geht nach Köln, zu dem Mann - einem türkischen Gastarbeiter -, den sie liebt und der ihr ursprünglich versprochen war. Sie wird ihm, am Ende des Films, als Prostituierte in einem Kölner Arbeiterwohnheim begegnen. Aber er wird sie nicht erkennen, weil sie gezwungen wurde, sich dem »westlichen Leben« anzupassen.

Trotz dieser einfachen und schematisch sehr simplen Story hätte die Rezeption dieser unglücklichen Liebesgeschichte sowohl unmittelbar nach der Ausstrahlung als auch später in der Forschung kaum unterschiedlicher und widersprüchlicher ausfallen können. Auf Vorschlag der Jury der Funkkorrespondenz der Katholischen Kirche wird der Film von ARD und ZDF zum Fernsehspiel des Monats gekürt. ${ }^{70}$ Seine Einschaltquote (damals: „Sehbeteiligung «) lag bei der Erstausstrahlung bei $37 \%{ }^{71}$ Die Zeitungskritik (vom Stern über die Zeit bis zum Spiegel) wertet den Film als eine empfindsam-realistische Geschichte, der es eindrucksvoll gelinge, sich in die »Psyche einzufühlen und zugleich in dieser Deutlichkeit den gesellschaftlichen und politischen Kausalitäten auf die Spur« zu kommen. ${ }^{72}$ An anderer Stelle wird er in einem Atemzug genannt mit Fellinis

68 Vgl. Bordwell, David/Thompson, Kristin (2012): Film Art. An Introduction, 10. Aufl., New York: McGraw-Hill, S. 77-79.

69 Ebd., S. 108.

70 Siehe hierzu: Medien aktuell, 02.02.1976. Aus: SANDERS-BRAHMS (1980): S. 140.

71 Zum Vergleich: Die höchste Einschaltquote des aktuell erfolgreichsten Tatortermittlerpaars seit den 1990er Jahren - Tatort: Münster - beträgt 13,2 \%. Siehe hierzu: http://de.statista.com/ statistik/daten/studie/169503/umfrage/durchschnittliche-einschaltquote-der-tatort-ermittler/ (17.08.2016).

72 BRÖDER, F. J. (1976): Das Märchen vom eisernen Berg. In: Nürnberger Nachrichten, 22.01.1976. 
Klassiker LA STRADA (1954) und mit Volker Schlöndorffs prämiertem Film DIE VERLORENE EHRE DER KATHARINA BLUM (1975). Auf dieser Interpretationsebene ist die »türkische« Figur Shirin mit der »deutschen« Figur Katharina Blum identisch.

Der allgemein-verbindlichen existenziell kulturübergreifenden Lesart steht eine andere gegenüber; eine spezifische national-kulturelle, die Shirin mit Katharina nicht länger gleichsetzt. Der Film zeige eindrücklich die Mentalität eines »türkischen Mädchens « und die »Eigenart des Miteinanderumgehens der türkischen Landsleute « untereinander. ${ }^{73}$ Diesen beiden sich widersprechenden Lesarten fügt sich wenige Tage nach der Erstausstrahlung eine dritte Deutungsebene seitens der rechtskonservativen türkischen Boulevardzeitung Tercüman (»Dolmetscher«) hinzu, die die anderen Interpretationen für null und nichtig erklärt. ${ }^{74}$ Entsprechend der Artikel, die Tercüman zwischen dem 23. und dem 25. Januar 1976 veröffentlicht, zeigt dieser Film weder allgemeine gesellschaftliche Zwänge und Kausalitäten auf, noch stellt er in irgendeiner Form die türkische Kultur dar. Im Gegenteil: Eine Türkin würde sich niemals so verhalten, wie dies die türkische Protagonistin im Film tut. Sie stehe - nach Ansicht des Redakteurs - nicht für das türkische Mädchen, weil »die sozialen Gegebenheiten des türkischen Volkes [im Film] bewusst so wirklichkeitsfremd dargestellt« werden und die wirklichen Verhältnisse überhaupt nicht zum Vorschein kommen. ${ }^{75}$ Vielmehr würden durch den Film die »Ehre der türkischen Mädchen mit den Füßen getreten « und die »Mentalität, [die] Sitten und die Gebräuche der Türken lächerlich gemacht «. ${ }^{76}$

73 SANDERS-BRAHMS (1980): S. 140.

74 Der Tercüman war die erste türkische Zeitung, die ab 1971 in Deutschland, in Frankfurt am Main eine eigene Druckerei unterhielt. In den 1960er und 1970er Jahren gehörte sie neben den Zeitungen Hürriyet und Cumhuriyet zu den wirkmächtigsten Zeitungen in der Türkei. In Deutschland folgten auf den Tercüman 1972 die international bekannte Zeitung Hürriyet und die Milliyet. Siehe hierzu: KARACABEY, Makfi (1996): Türkische Tageszeitungen in der BRD. Rolle, Einfluß, Funktionen, Dissertation Universität Frankfurt a. M., S. 11. Siehe hierzu auch: CALAǦAN, Nesrin Z. (2010): Türkische Presse in Deutschland. Der deutsch-türkische Medienmarkt und seine Produzenten, Bielefeld: transcript, S. 81.

75 Ebd., S. 83. Die äußerst disparate und mitunter »konfliktträchtige« Rezeption des Films SHIRINS HochzeIT steht auch im Zentrum des Aufsatzes Das gefallene Märchen. Zur filmischen Narration und Semiotik transkultureller Missverständnisse von Klaus Schenk. Siehe hierzu: Schenk, Klaus (2020): „Das gefallene Märchen. Zur filmischen Narration und Semiotik transkultureller Missverständnisse«. In: Der deutsch-türkische Film. Neue kulturwissenschaftliche Perspektiven, hg. v. Deniz Bayrak u. a., Bielefeld: transcript, S. 39-64, S. 41.

76 Die Artikel im Tercüman und die von der WDR geplante Wiederausstrahlung des Films ein paar Wochen später führten Anfang Februar zu einer Demonstration von knapp 200 türkischen Gastarbeitern vor dem WDR-Funkhaus in Köln. In Interviews hielten die Regisseurin Helma Sanders-Brahms und die türkische Schauspielerin fest, dass sie von nationalistischen Türken beschimpft worden seien und Morddrohungen erhalten hätten, worauf ihnen Polizeischutz 
Mit historischem und sozialpolitischem Abstand liest die Forschung ab den 1990er Jahren SHIRINS HochzEIT nochmals ganz anders. Annette Brauerhoch sieht Mitte der 1990er nicht mehr das existenzialistisch isolierte Innenleben einer Frau oder die Dar- bzw. Bloßstellung einer anderen Kultur. Sie interpretiert den Film, indem sie vom kommentierenden und strukturierenden Off-Dialog zwischen der Regisseurin Sanders-Brahms und der Hauptdarstellerin Ayten Eren ausgeht, als einen kolonialistischen, der zwar dem Westen eine Geschichte erzähle, aber keineswegs den Akteurinnen und Akteuren der Dritten Welt. ${ }^{77}$ Welche Geschichte hier dem Westen, oder genauer der Bundesrepublik, gegeben wird, ist aber aus dem Film allein zu erschließen. Fünfzehn Jahre nach Brauerhochs Interpretation sieht Jochen Neubauer in Sanders-Brahms' Film eine moderne bundesrepublikanische Gesellschaft, der eine vom Islam geprägte Gesellschaft diametral gegenübergestellt würde. ${ }^{78}$ Entgegen dieser Interpretation sehen wir in diesem Film keine einzige Person, die einer spezifisch muslimischen Verpflichtung wie Beten (salāt), Fasten (saum) oder der muslimischen Pilgerfahrt (Hadsch) nach Mekka nachgeht. Einzig das Kopftuch, das Shirin trägt, verleitet zu einer derartigen Interpretation. Doch dass das nicht ausreicht, wird die Analyse zeigen. Und Klaus Schenk richtet in seiner kürzlich erschienen Analyse zu SHIRINS HocHzEIT sein Augenmerk auf die transkulturellen »Polarisierungen und gegenläufgen Deutbarkeiten « des Films, wie ich sie hier auch kurz angerissen habe. ${ }^{79}$ Die Breite

gewährt wurde. Zitiert aus: Hunn (2005): S. 430. In ihren Notizen hält Sanders-Brahms fest, dass über SHIRINS HochzEIT mehr als eine Stunde im türkischen Parlament debattiert wurde. SANDERS-BRAHMS (1980): S. 102. Siehe hierzu auch: ScHENK (2020): S. 46f. Ali Osman Öztürk und Derya Canbolat analysieren in ihrem Aufsatz Rezeption des Spielfilms ,Shirins Hochzeit (1976) aus der Perspektive der türkischen Musikproduktion in Deutschland drei türkische Deutschlandlieder, die von den türkischen Liedermachern Metin Türköz und Adnan Varveren in Deutschland als Reaktion auf Helma Sanders-Brahms Film geschrieben wurden. Die Liedermacher fühlten sich, wie Öztürk und Canbolat festhalten, vom Film in ihrer türkischen Ehre verletzt und beleidigt, weil keine echte türkische Frau sich so verhalten würde wie Shirin in Sanders-Brahms Film. Die schweren sozialen und ökonomischen Bedingungen, denen die Protagonisten im Film ausgesetzt ist, spielen in den Liedertexten keine Rolle. Siehe hierzu: ÖzTürk, Ali Osman/CANBoLAT, Derya (2020): »Rezeption des Spielfilms ,Shirins Hochzeit‘ (1976) aus der Perspektive der türkischen Musikproduktion in Deutschland«. In: Der deutsch-türkische Film. Neue kulturwissenschaftliche Perspektiven, hg. v. Deniz Bayrak u. a., Bielefeld: transcript, S. 65-80.

77 Vgl. Brauerhoch, Annette (1995): "Die Heimat des Geschlechts - oder mit der fremden Geschichte die eigene erzählen. Zu Shirins Hochzeit von Helma Sanders-Brahms«. In: »Getürkte Bilder «. Zur Inszenierung von Fremden im Film, hg. v. Ernst Karpf, Doron Kiesel, Karsten Vilarius, S. 108-115, hier S. 115.

78 Neubauer, Jochen (2011): Türkische Deutsche, Kanakster und Deutschländer. Identität und Fremdwahrnehmung in Film und Literatur, Würzburg: Königshausen \& Neumann, S. 76.

79 SCHENK (2020): S. 57. 
und Diversität dieser Film-Rezeption (von einer existenzialistischen Isoliertheit über die Frage kultureller Repräsentation, den Kolonialismus bis hin zur Unterscheidung zwischen Religion und Moderne), hat jedoch nicht nur mit den jeweils spezifisch historischen Konstellationen und Positionen ihrer Interpretinnen und Interpreten zu tun.

Die Vielfalt der unterschiedlichen Deutungen von SHIRINS HocHzEIT, die wir auch bei Aras Örens Was will Niyazi in der Naunynstraße (1973) und bei Rainer Werner Fassbinders ANGST ESSEN SEELE AUF (1973) werden feststellen können, liegt, wie ich aufzeigen möchte, besonders an der Konstellation, was als Kritik an einem Ist-Zustand, was als Problem und was als seine Lösung begriffen wurde. Dieser jeweils unterschiedliche Zugang bestimmt mitunter die narrative Abfolge, die Plotstruktur und die Situationen zwischen den Akteurinnen und Akteuren in Literatur und Film; eine Konstellation, die sich aus losen Anfängen und losem Ende konstituiert. In ihrem Zentrum stehen die körperlichen Bedürfnisse der Akteurinnen und Akteure, wechselseitig konstitutive Verhältnisse zwischen Individuen und Gruppen, Arbeits- und Solidaritätsverhältnisse, Entfremdungen und nicht zuletzt angemessene und unangemessene Verhaltensweisen. Nationale, kulturelle und religiöse Marker sind zwar im Einsatz, bestimmen aber nicht den Kern des Gelingens oder Scheiterns sozialer Integration, wie sie es dann ab den 1980ern der Fall ist. Die abstrakten kulturellen Marker sind in den 1960er und 1970er Jahren durch soziale Umstände gerahmt und kontextualisiert. Um diese These differenzierter und überzeugender ausbuchstabieren zu können und um aufzuzeigen, aus welchen Bausteinen die Äquivalenzkette des Narrativs der Integration in den 1960er und 1970er Jahre besteht, folgen mit den nächsten beiden Unterkapiteln Analysen der Texte und Filme von Helma Sanders-Brahms und Aras Ören. Ich werde aufzeigen, wie in diesen Werken Migration und Integration als Konzepte der Bewegung und der Identifikation verhandelt werden. Im Zentrum der folgenden Analyse stehen SHIRINS HocHzeIT und Was will Niyazi in der Naunynstraße.

\subsection{ShIRINS HochzeIt: Eine Geschichte ohne Herkunft und Ankunft}

In den ersten Einstellungen des Schwarzweißfilms SHIRINS HocHzEIT hören wir die sanften melancholischen Klänge einer türkischen Langhalslaute, das Bild ist schwarz und aus dem Off spricht eine Frau mit ausländischem Akzent: »Jetzt bin ich tot. Tot wie der eiserne Berg, der zwischen Shirin und Ferhat ist«. Das Bild wird heller und wir sehen einen Berg. Die Stimme spricht weiter: »Ferhat muss mit bloßen Händen einen Weg durch eisernen Berg zu Shirin graben. Und gräbt 
und gräbt, kommt an. Eine Geschichte sagt: zu spät. Eine andere Geschichte sagt: noch gerade zur rechten Zeit. ${ }^{80}$ Der Titel des Films, die ersten Einstellungen und die ersten Sätze spielen auf die Liebesgeschichte zwischen Chosrou und Shirin des persischen Dichters Nizami an. ${ }^{81}$

Die nächsten Bilder zeigen eine traditionell das Kopftuch tragende Frau in Nahaufnahme; der Berg verblasst und löst sich in ihr auf. Die Sprecherin stellt sich als Shirin vor. Sie ist aus Anatolien, von klein auf Mahmud versprochen, der nun als Gastarbeiter in Deutschland lebt. Es folgt eine halbtotale Einstellung eines steinernen Feldes und die Sprecherin kommentiert, dies sei ihr Land. Darauf folgt eine Nahaufnahme, in der wir Shirin Steine sammeln sehen. Eine andere Stimme ohne

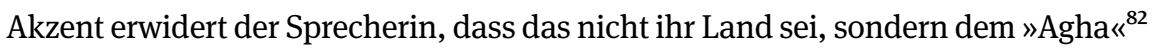
gehöre und sie nur hier sei, weil der »Agha« sie und ihre Familie auf dem Land arbeiten lasse. Selbst die Steine auf dem Boden gehören dem »Ağa «. ${ }^{83}$

Die Kamera entfernt sich von der Steine sammelnden Shirin, nimmt ihre ebenfalls Steine sammelnden Geschwister ins Objektiv und in einer weiteren Bewegung weg von Shirin ihren Steine sammelnden Vater. Auf eine in die Tiefe gesetzte totale Einstellung, die ein trockenes Feld mit arbeitenden Dorfbewohnern zeigt, ${ }^{84}$ folgt die Sequenz mit derselben Einstellung, in der Shirins Vater von der Gendarmarie verhaftet wird, weil er den Grundbesitzer ( $A \breve{g} a)$ mit einem Stein am Kopf verletzte. ${ }^{85}$ Dies passiert alles im Sommer 1971. Shirins Vater habe dies getan, weil seine Frau an Unterernährung gestorben sei, informiert die akzentfreie

80 SANDER-BRAhMs, Helma (1976): Shirins Hochzeit, Spielfilm, BRD, DVD Zweitausendeins Edition. 81 Vgl. NizAmi (2009): Chosrou und Shirin, Zürich: Menasse.

82 Mit Agha (türkische Schreibweise Ağa) ist hier der »Großgrundbesitzer« gemeint. Helma Sanders-Brahms spricht das Wort aus dem Off phonetisch nicht korrekt aus. Sie spricht statt eines weichen $\mathrm{g}$ ein normales $\mathrm{g}$.

83 Ağa stammt ursprünglich aus dem Mongolischen und ist in den Turksprachen ein verbreiteter Titel, der im Bedeutungsgebrauch von »Vater«, »Onkel« über besondere Würdenträger im Osmanischen Reich bis zum »Großgrundbesitzer« in der modernen türkischen Republik reicht. Der Großgrundbesitzer ist in der türkischen Literatur und im türkischen Film der 1970er und 1980er Jahre eine oft auftretende Figur, wenn es um die Thematisierung sozialer Ungerechtigkeit und Ungleichheit geht. Siehe hierzu paradigmatisch die sozialkritische Komödie KIBAR FeYzo (»Der vornehme Feyzo«) von Atif Yilmaz aus dem Jahr 1978. In der Wortkontraktion Ağabey (kurz: $A b i)$ wird der Titel heute für den älteren Bruder verwendet, während er in der Bedeutung »Großgrundbesitzer« heute nicht mehr gebräuchlich ist.

84 Ebenfalls mit arbeitenden Frauen auf dem Feld beginnt auch Türkan Şorays Film DöNüş.

85 In einem gänzlich anderen Kontext werden wir diesem Bild vom türkischen Dorf in Hark Bohms Film YASEMIN aus dem Jahre 1988 begegnen. Dort werden wir auch arbeitende Menschen sehen, jedoch ohne den Großgrundbesitzer, der der eigentliche Verwalter des Territoriums in Sanders-Brahms' Film ist. 
deutsche Stimme den Zuschauer aus dem Off. ${ }^{86}$ Shirin verflucht in der nächsten Einstellungsabfolge von Nahaufnahmen den Verwalter, spuckt ihm ins Gesicht. Die Gendarmerie fährt mit dem Vater und dem Verwalter fort, zurück bleibt Shirin mit ihren Geschwistern auf dem Feld, die Kamera entfernt sich vom Geschehen, bis sie eine supertotale Position einnimmt. Shirin und ihre Geschwister sehen wir nur noch als weiße Punkte auf dem Feld, das nun als ein dürrer Ackerboden mit einem Streifen grauem Himmel darüber erscheint. In diese Einstellung wird der Titel des Films SHIRINS HochzeIT eingeblendet.

Dieser Vorspann des Films zeigt eine besitzlose Protagonistin, deren Familie zerbricht. Diese Trennung zu Beginn des Films steht quer zum eingeblendeten Titel des Films und sie wird noch weiter getrieben. Die Brüder ihres Vaters, die Shirin aufnehmen, geben dem Wunsch des Großgrundbesitzers nach und versprechen, nach dem Erhalt des vereinbarten Brautgeldes, Shirin zu verehelichen. Diese ist aber - nach eigener Aussage - dem Gastarbeiter Mahmud versprochen, der, wie gesagt, seit ein paar Jahren sein Geld in Köln verdient. In die Zeit der Hochzeitsvorbereitung fällt der sommerliche Urlaubsaufenthalt Mahmuds im Dorf. Seine An- und Abfahrt wird gezeigt und vor allem die Verteilung der mitgebrachten Geschenke für die eigene Mutter und für Honoratioren im Dorf. ${ }^{87} \mathrm{Zu}$ diesen gehört interessanterweise nicht der Imam, der seinen Wunsch nach einem deutschen Staubsauger äußert. Mahmud verspricht ihm, im nächsten Jahr für die Moschee einen Staubsauger mitzubringen. Bis dahin werde es auch sicherlich überall im Dorf Elektrizität geben, beendet er das kurze Gespräch in der Gruppe mit dem Imam. ${ }^{88}$ Danach packt er eine Miniatur des Kölner Doms aus, und die Dorfbewohner äußern halb erstaunt und halb amüsiert, dass diese Kirche ja viel größer sei als ihre Moschee. ${ }^{89}$ Für Shirin hat Mahmud nichts mitgebracht, aber es bleibt am

86 Bei dieser zweiten Stimme handelt es sich um die von Helma Sanders-Brahms persönlich. Sie stellt sich allerdings selbst im Film aus dem Off nicht vor, wie Ayten Erten alias Shirin Özgül es tut.

87 In Türkler Almanyada von 1966 spielt das Mitbringen von Waren und Geschenken aus Deutschland in die Türkei ebenfalls eine wichtige Rolle. Ylldız stellt es im Unterschied zu Sanders-Brahms aber aus einer konsumkritischen Perspektive dar. Sanders-Brahms will in dieser Sequenz das Dorf als Gruppe darstellen. Zur Episode bei Yıldız siehe: YILDIZ (1966): S. 94.

88 Es gibt hier einige Parallelen zum Film DöNÜş. Neben den auf dem Feld arbeitenden Frauen, will auch hier der Großgrundbesitzer die rebellierende Frau zu seiner Frau machen. Obwohl Gülcan und Ibrahim heiraten, helfen die anderen Dorfbewohner aus eigener Not dem Großgrundbesitzer, Ibrahim zur Arbeitsmigration zu zwingen, so dass Gülcan allein mit ihrem Kind im Dorf bleibt. Doch im Unterschied zu Shirin beugt sich Gülcan dem Willen des Großgrundbesitzers nicht und stellt sich auch gegen das Dorf.

89 Als Pendant zu dieser Kirchenminiatur gibt es im letzten Drittel des Films in gleicher Größe einen Moscheewecker im Arbeiterfrauenwohnheim in Köln. Dass die Religion keine sinnstiftende Funktion ausübt, sondern ein Teil von vielen anderen Teilen der Alltagswelt darstellt, ist auch ein gängiges Motiv in Ylldız Roman, in Örens Poem Was will Niyazi in der Naunynstraße (1973) 
Ende eine kleine Plastikwanne übrig, die er ihr schließlich schenkt. Shirin freut sich halb kindlich und halb beschämt. Die deutsche Stimme aus dem Off kommentiert: Mahmud habe in diesem Land nicht an sie gedacht. Dieses Geschenkeverteilen wurde mit wenigen Einstellungen gedreht. Insgesamt dominiert hier eine halbtotale Einstellung, die alle Akteure tableauartig, nicht in den Raum und in die Tiefe fotografiert, sondern als Gruppe im Bauernhaus rahmt. Paradigmatisch für solche Gruppenaufnahmen ist auch eine Szene in Okans Film Отовüs. Während der Rast kurz vor Stockholm macht der türkische Schlepper Ahmet mit einer amerikanischen Sofortbildkamera ein Gruppenfoto der türkischen Arbeiter. Dieses Bild wird am Ende des Films aufgelöst, indem jeder türkische Arbeiter einzeln von der schwedischen Polizei in Gewahrsam genommen wird.

Bei seiner Abfahrt reicht Mahmud in Sanders-Brahms' Film Shirin am Dorfausgang aus dem Auto heraus die Hand, und sie erfährt, dass er nun zurück nach Köln gehe. Doch trotz Mahmuds emotionaler Teilnahmslosigkeit wird Shirin vor dem Großgrundbesitzer fliehen und nach Köln gehen, um mit Mahmud, ihrem Ferhat, zusammen zu kommen. Shirins Hochzeit ist aufgeschoben. »Denken muss Shirin mit bloßen Händen durch eisernen Berg. Wenn nicht sein kann Ferhat, muss sein Shirin. Aber einer muss«, erwidert Shirin während der Fluchtsequenz aus dem Off ihrer deutschen Dialogpartnerin, die fragt, ob sie denn keine Angst habe, alleine nach Deutschland zu fliehen. ${ }^{90}$ Auf diese erste Filmeinheit folgt Shirins Odyssee nach Deutschland; eine Dokumentation der Etappen der Arbeitsmigration kurz vor dem Anwerbestopp 1973. Die Flucht beginnt mit Shirins Binnenmigration in die Peripherie Istanbuls, die mittels Fotomontage (Sanders-Brahms' Team durfte in der Türkei nicht drehen) in den Film integriert wird. ${ }^{91}$ Darauf folgt die Anmeldung Shirins an der Deutschen Verbindungsstelle des deutschen Arbeitsministeriums in Istanbul. ${ }^{92}$ Auf ihrer Flucht nach Istanbul lernt sie eine Frau kennen, die

und auch im ersten international bekannten türkei-türkischen Film zur Migration der Türken nach Europa, in Tunc Okans Film ОтовÜs von 1974.

90 Im Unterschied zur Geschichte Nizamis ist es nicht der Mann, sondern die Frau, die sich durch den Berg zu ihrem Geliebten begeben wird. Vgl. NizAMI (2009).

91 In der vorherigen Dorfsequenz wird auch eine Fotostrecke eingesetzt, um Shirins Leben von der Kindheit bis ins Erwachsenenalter zur Jetztzeit des Filmes Revue passieren zu lassen. Später wird auch das deutsche Arbeitervermittlungsbüro in Istanbul mittels einer Fotostrecke gezeigt. Grund hierfür ist, dass nach mehreren Anläufen von Helma Sanders-Brahms vom türkischen Ministerium, die Drehgenehmigung für den Film zu erhalten, abgelehnt wurde. Die Location für das türkische Dorf in SHIRINS HochzEIT ist die Eifel.

92 Siehe hierzu auch die Dokumentation zur Ausstellung von 1998 in Essen: ERYILMAZ, Aytaç (1998): »Wie geht man als Arbeiter nach Deutschland? Işçi Olarak Almanya'ya Nasıl Gidilir?«. In: Fremde Heimat. Yaban, Silan Olur. Eine Geschichte der Einwanderung aus der Türkei, hg. v. Mathilde Jamin, Aytaç Eryılmaz, Essen: Klartext, S. 93-123. 
ihr in Istanbul Unterschlupf gewährt, während ihr Arbeitsantrag bei der Deutschen Verbindungsstelle bearbeitet wird. Der Film stellt hier vor allem die Gesundheitsprüfung der Arbeitsanwärterinnen und Arbeitsanwärter der deutschen Gastarbeiterverbindungsstelle in den Mittelpunkt. ${ }^{93}$ Dabei wecken die »leere[n] Kellerräume mit Lautsprechern in den Ecken, [durch] lange Reihen von Holzbänken « Assoziationen an Konzentrationslager. ${ }^{94}$ Darüber hinaus gleichen die Aufnahmeeinstellungen der Istanbuler Verbindungsstelle in Sanders-Brahms' Film den Aufnahmen des Fotografen Jean Mohr, der die entsprechenden Anmeldestellen in Verona und in Istanbul von 1973 fotografisch dokumentierte. ${ }^{95}$

Den Arbeitsvertrag, den Shirin schließlich erhält, zeigt eine Nahaufnahme, während zeitgleich eine türkische Beamtenstimme aus dem Off erläutert, wo Shirin in Deutschland arbeiten und was sie in der Stunde verdienen wird. ${ }^{96}$ Dabei erfahren wir zum ersten und einzigen Mal den Nachnamen der Protagonistin, die neben dem deutschen Behördenstempel ihre Unterschrift setzt: Shirin

93 Die Aufnahmen, die für die Arbeiterverbindungsstellen stehen, haben als Bilder für den bürokratischen Vorgang nichts kulturell Spezifisches an sich. Siehe hierzu auch: VON DER GRÜN, Max (1975): Leben im gelobten Land, München: dtv, S. 7. Die Verbindungsstelle in Istanbul war von 1961 bis 1973 in Betrieb. In dieser Zeit wurden knapp ein Drittel der Anträge, die dort eingingen und die körperliche Konstitution der Antragsteller prüften, positiv bewilligt. Die Wartezeit auf die Bewilligung oder Genehmigung eines Antrags konnte zwischen 3 Monaten und zwei Jahren liegen. Siehe hierzu: JAMIN, Mathilde (1998): »Die deutsch-türkische Anwerbevereinbarung von 1961 und 1964«. In: Fremde Heimat. Yaban Silan olur, S. 69-82, hier S. 45. Die Ablehnung eines Arbeitsantrags aufgrund ungesunder Zähne ist Thema im Melodram BABA des türkischen Regisseurs Yilmaz Güney von 1971. GüNEY, Yllmaz (1971): Baba, Istanbul: Akün Film.

94 Brauerhoch (1995): S. 113f. Siehe auch: NeUbauer (2011): S. 176.

95 Die erste Dokumentation zur Anwerbung und Durchführung der Gesundheitskontrollen von Gastarbeitern aus dem Süden Europas in den Westen legten der englische Romancier und Künstler John Berger gemeinsam mit dem Schweizer Dokumentarfotografen Jean Mohr mit ihrem Bild- und Textband A Seventh Man im Jahre 1975 vor. Die Aufnahmen sind aus dem Jahre 1972/73. Aufgrund der neuen Arbeitsmigration aus dem Süden Europas - bedingt durch die weltweite Finanzkrise von 2008 - aus Spanien und Griechenland in den Westen und Norden Europas, wurde das Buch 2010 wieder aufgelegt. Es hat 2010 und 2011 eine weitaus stärkere Rezeption erfahren als in der Erstauflage 1975, die kaum Beachtung fand. Siehe: BERGER, John/MoHR, Jean (2010): A Seventh Man, London, New York: Verso. Zur Gesundheitskontrolle der möglichen Gastarbeiter in der Verbindungsstelle Istanbul siehe ebd., S. 50-62. Die erste ausführliche Dokumentation der deutschen Gastarbeiteranwerbung in Bild, Text und Exponaten erfolgte in Deutschland hingegen erst 1998 mit der zuvor erwähnten Ausstellung Fremde Heimat. Yaban, Silan olur im Ruhr Museum Essen und mit dem Katalog zur Ausstellung, die in Kooperation mit DOMiD (Dokumentationszentrum und Museum über die Migration in Deutschland) entstanden ist. Siehe: ERYILMAZ/JAMIN (1998): Fremde Heimat. Yaban Silan olur.

96 Auch in Şorays Film rechnet der Verwalter des Großgrundbesitzers Ibrahim genau vor, wie viel Geld er am Tag in Deutschland verdienen wird und dass er für die Übernachtung wird nichts zahlen müssen, da man dort in Arbeiterwohnheimen lebe. Siehe hierzu: DöNÜş (1972). 
Özgül. Die nächste Station ist der Flughafen. Dort wartet Shirin auf ihren um sechs Stunden verspäteten Sonderflug für die Gastarbeiter nach Deutschland. Anschließend folgen die Pass- und Gepäckkontrolle am Düsseldorfer Flughafen, die Einfahrt am Kölner Bahnhof mit dem Zug und die Ankunft in einem Kölner Arbeiterwohnheim. Die gesamte Dokumentation zeigt Shirin als eine von vielen. Als Kameraeinstellungen wechseln sich in diesen Sequenzen halbtotale und halbnahe shots ab. Diese Einstellungen sind ideal für Gruppenaufnahmen: die Halbtotale für körperbetonte Aktionen und die Halbnahe für die Darstellung von Zweier- und Dreierbeziehungen. ${ }^{97}$ Durch diese Kameraführung sehen wir Shirin stets im Umfeld mit vielen anderen Frauen: in der Verbindungsstelle werden viele Frauen zeitgleich getestet. Wir sehen, wie viele Männer und Frauen am Flughafen warten, kontrolliert werden und im Zug von Düsseldorf nach Köln reisen. Shirin ist dabei eine der wenigen Frauen, die ein Kopftuch trägt.

Im Arbeiterwohnheim angekommen, ist ihr erster Kontakt die Leiterin des Wohnheims, die während des gesamten Films fast ausschließlich energisch, unerbittlich und kommandierend auftritt. ${ }^{98}$ Sie unterweist die Ankömmlinge, macht sie mit der Hausordnung vertraut und erläutert, wie man sich hier zu verhalten habe. Die übrigen Gastarbeiterinnen hingegen umarmen Shirin und nehmen sie wie eine verlorene Schwester auf. Die Zärtlichkeit im Unterschied zur Zudringlichkeit der Heimleiterin nimmt eine Differenz auf, die bereits im türkischen Dorf gezeigt wurde. ${ }^{99}$ Die türkischen Frauen umarmen Shirin zum Abschied, als diese - zu Beginn des Films - zur Hochzeit in das Dorf des Großgrundbesitzers ziehen soll.

97 Siehe hierzu: BoRdwELL (2010): S. 172.

98 Der Auftritt der deutschen Heimleiterin in SHIRINS HochzeIT folgt der Beschreibung der Verhaltensweisen einer Heimleiterin im Handelsblatt vom 16. Februar 1967. Der Artikel »Fremd- statt Gastarbeiter?« geht dabei auf eine Razzia der Polizei in einem Wohnheim zurück. Identisch mit dem Film von Sanders-Brahms ist das Verhältnis von Ordnung und Verhalten, dass sich bei der Heimleiterin im Artikel zeigt: »Mit betonter Freundlichkeit bittet die Vermieterin die beiden Beamten ins Haus. Sie sei sehr dafür, daß sich die Polizei hin und wieder davon überzeuge, daß in ihrem Haus alles in Ordnung ist, meint sie, auf das erste Zimmer losgehend. Ohne anzuklopfen tritt sie ein, schaltet Licht an. Sechs Marokkaner schlafen in dem Raum. Einem nach dem anderen reißt sie die fast bis über den Kopf gezogene Decke vom Gesicht. Für den bescheidenen Einwand der Kripo-Leute, soviel Aufwand sei gar nicht nötig, hat die Frau nur ein Lächeln übrig: >Ach, das haben die gerne. Über sich selbst spricht sie nur als der >Mamar." Siehe hierzu auch: HERBERT (2001): S. 216. Siehe ebenfalls: SCHEFFER, Paul (2013): Land of Promise, Dokumentation, USA, NTR Channel.

99 Im ein Jahr zuvor erschienenen Film Die VERLOREne EHRE DER KATHARINA BLUM (1975) von Volker Schlöndorff spielt die Unterscheidung zwischen zärtlichem und zudringlichem Verhalten ebenfalls eine entscheidende Rolle. Beispielsweise unterschreibt die Protagonistin im Film ein polizeiliches Protokoll nur, wenn darin vermerkt wird, dass der Bankräuber, Ludwig Götten, der auf seiner Flucht vor der Polizei bei Blum übernachtete, nicht zudringlich gewesen sei, wie es 
Die Solidarität der Frauen untereinander ist ein zentrales Element der Versammlung der Akteure in Sanders-Brahms' Film. ${ }^{100}$ Sie steht im Dorf gegen die Herrschaft des Mannes. Shirin teilt ihr Zimmer im Arbeiterwohnheim mit drei weiteren türkischen Frauen. Auf der Etage leben insgesamt 24 Frauen. ${ }^{101}$

Bei einem Küchengespräch im Gemeinschaftsraum mit anderen Gastarbeiterinnen erfahren wir dann zum ersten Mal, dass Shirin aus der Provinz Kırşehir stammt, die südlich von Ankara liegt. Shirin erfährt wiederum, dass eine ihrer neuen Freundinnen den von ihr beschriebenen Mahmud kennt und sie gerne zu ihm bringen kann. Doch bevor die einseitige Liebesgeschichte wieder aufgenommen wird, steht das Leben der Gastarbeiterinnen, ihr Dasein zwischen Arbeitsplatz und Wohnheim, im Vordergrund.

$\mathrm{Zu}$ Shirins Aufgabe in der Fabrik gehört das Entgraden von Gewinden, eine Tätigkeit, die ihr der deutsche Schichtführer in rheinländischem Akzent erläutert. $\mathrm{Zu}$ ihrer besten Freundin in der Fabrik wird eine griechische Gastarbeiterin, die an ihrer Seite arbeitet. Es folgen mehrere Sequenzen in Fabrik und Wohnheim, bis schließlich Shirins blonde, türkische Freundin sie - in der Mitte des Films - zu Mahmud mitnimmt. Zuvor berät sie Shirin in Sachen Outfit und schlägt vor, keine Hose unter ihrem Rock zu tragen und ihr Kopftuch abzulegen. Shirin lässt sich zwar darauf ein, ihre Beine zu zeigen, das Kopftuch aber legt sie wieder an mit der Begründung, in ihrem Dorf sei es eine Sünde, sich ohne Tuch in der Öffentlichkeit $\mathrm{zu}$ zeigen. Im Wohnheim selbst und unter anderen Frauen, trägt Shirin selbstredend kein Kopftuch. In derselben Film-Sequenz bringt ihr die Freundin das Tanzen bei (zum damaligen Hit von Udo Jürgens »Siebzehn Jahr, blondes Haar«) und schminkt sie. Am Ende steht Shirin vor einem großen Spiegel, in dem sie sich komplett betrachten kann und ihr gefällt, was sie sieht. ${ }^{102}$

der Kommissar immer behauptet, sondern im Gegenteil zärtlich. ScHLÖNDoRfF, Volker (1975): Die verlorene Ehre der Katharina Blum, Spielfilm, Deutschland, Arthaus.

100 In der Rezeption wurde der Film auch explizit als Frauenfilm wahrgenommen.

101 Sanders-Brahms folgt in der Darstellung der Größe der Räumlichkeiten, der Trennung von Gastarbeiterinnen und Gastarbeitern und der Anzahl der Betten pro Raum im Film, den Richtlinien für die Unterkünfte ausländischer Arbeitnehmer in der Bundesrepublik Deutschland, die am 1. April 1971 in Kraft trat. Diese sollte vor allem den räumlichen Zuständen in Baracken- und Sammelunterkünften entgegenwirken. Die Richtlinie sah vor, dass »auf jede Person mindestens $8 \mathrm{qm}$ Gesamtwohnfläche entfällt« und dass nicht mehr als 4 Betten in einem Raum aufgestellt werden dürfen. Der Filmemacher Yüksel Yavuz hält in seiner Dokumentation von 1995 MEIN VATER, DER GASTARBEITER fest, dass er und sein Vater zusammen in einer Baracke einer Hamburger Werft 12 qm hatten. Siehe hierzu: GöKTÜRK, Deniz/KaEs, Anton/GramLIng, David/LANGENoHL, Andreas (Hg.) (2011): Transit Deutschland. Debatten zu Nation und Migration, Konstanz: Konstanz University Press, S. 499.

102 Brauerhoch identifiziert Shirins Freundin als eine "verdeutschte« Türkin, weil sie enge Hosen trägt, kein Kopftuch und ihre Haare blond gefärbt sind. Siehe hierzu: BRAUERHOCH 
Gemeinsam verlassen die beiden Frauen das Wohnheim und nach 40 Minuten Spielzeit sehen wir die ersten Stadt- und Außenaufnahmen von Köln: eine Kölner Hauptstraße und eine Protagonistin, die vor einer Kneipentür steht und ihrer türkischen Freundin aus Scham nicht hinein folgen kann. Die Dämmerung bricht herein, und wir sehen aus dem Hintergrund den Zuhälter Aida (Jürgen Prochnow) ins Bild laufen, der versehentlich mit Shirin zusammenstößt. Ein kurzer Dialog ergibt, dass er einen Mahmud kennt, sich aber wundert, warum sie ihn kenne. Er nimmt sie mit hinein, und es stellt sich heraus, dass der Mann im Lokal nicht Shirins Mahmud ist. Aida tanzt mit Shirin, die sich in der Kneipe sichtlich unwohl fühlt. Ihre Schüchternheit und Scham animiert Aida und er lädt sie zu einem Martini ein. Später übergibt sich Shirin auf der Toilette und verlässt daraufhin das Lokal. Die Sequenz endet mit Aidas Kommentar, er habe es ja nur »jut jemeint«.

Aufgrund der Rezession von 1973 verliert Shirin ihre Arbeit in der Fabrik. Keine Arbeit bedeutet auch den Verlust des Wohnheimplatzes, weshalb sie bei ihrer griechischen Freundin einzieht, deren Ehemann noch Arbeit hat. Das Arbeitsamt vermittelt ihr einen Putzjob. Während dieser Zeit lässt sie sich die Haare blond färben, um - so der Wortlaut einer Werbebroschüre - »etwas aus ihrem Typ zu machen «; sie legt das Kopftuch ab. Es folgt die positivste Sequenz im Film, eine Feier bei der griechischen Familie anlässlich des Sturzes der Militärdiktatur (1967-1974) Griechenlands. ${ }^{103}$ Die Griechen und eingeladenen Türken feiern zusammen und für Shirin ist es nach eigener Aussage der schönste Tag ihres bisherigen Lebens. ${ }^{104}$ Dieser Zustand hält jedoch nicht lange an. Am nächsten Tag wird Shirin während ihrer Arbeitszeit von einem betrunkenen Deutschen vergewaltigt. Sie kündigt, das Arbeitsamt kann sie daraufhin nicht mehr vermitteln und die Beamtin warnt sie vor einer möglichen Abschiebung, sollte sie in Kürze keine Arbeit gefunden haben. ${ }^{105}$ Shirin entgegnet, dass sie nun aber ebenso wenig in die Türkei zurückkehren könne, da sie nun keine Jungfrau mehr sei.

(1995): S. 114. Dabei übersieht sie, dass Sanders-Brahms sehr viele Türkinnen ohne Kopftuch und in Jeanshosen zeigt. Zudem entspricht ihre verdrehte nationale Zuschreibung nicht wirklich der territorialen Logik des Films. In ihm stehen regionale Rahmungen und Prägungen im Vordergrund, wie die Unterscheidung von Land und Stadt, Darstellung und Nennung von provinziellen Gegenden wie Kırşehir oder Städten wie Istanbul und Köln. Hinzu kommt, dass der deutsche Protagonist Aida mit kölnischem Akzent spricht.

103 Siehe hierzu: GRAF, Rüdiger (2010): Europäische Zeitgeschichte seit 1945, Berlin: Akademie, S. $154 \mathrm{f}$.

104 Dass die Figur Shirin sich in Sanders-Brahms Film mit Griechinnen und Griechen anfreundet, ist den türkischen Liedermachern Metin Türköz und Adnan Varveren ein besonderer Makel der Protagonistin. Siehe hierzu: ÖZTürk/CANBolat (2020).

105 Gastarbeiterinnen und Gastarbeiter aus Nicht-EG-Ländern haben betriebsgebundene Einjahresverträge erhalten. Wurde ihnen der Vertrag gekündigt wurde, konnten Sie wieder in ihr Her- 
Bei ihrer erfolglosen Arbeitssuche trifft sie in einer Kneipe erneut auf Aida. Er betritt - wie der Dorfverwalter zu Beginn des Films - mit einer Kopfverletzung die Kneipe, lädt Shirin zum Essen ein und bietet ihr an, für ihn zu arbeiten. Er könne sich um ihren Aufenthaltsstatus »für Jeld « kümmern. Shirin erhält von Aida einen gefälschten türkischen Pass mit Aufenthaltsgenehmigung. Jetzt beginnt der Teil des Films, der auf Helma Sanders-Brahms' Recherchen und Assoziationen im Zusammenhang mit ihrem Dokumentarfilm DIE INDUSTRIELLE RESERVE-ARMEE sowie der Berichterstattung über die Ermordung einer türkischen Prostituierten in der Nähe eines Arbeiterwohnheims beruhen. Die Zuhälter schleusen Shirin und zwei weitere Frauen nach Pfortenschluss der Wohnheime über die Kellerfenster in die Männerwohnheime. Für 70 DM gehen die Frauen von Bett zu Bett und befriedigen ihre Kunden in den Sechsmannzimmern. Shirins allererster Kunde ist Mahmud, den sie so lange gesucht hat. Er erkennt sie nicht, da Shirin einen geradezu assimilatorischen Kleidungs- und Verhaltenswandel durchgemacht hat ${ }^{106}$ - oder eine Integration in umgekehrter Richtung: Shirins Migration führt zu keinem sozialstrukturellen Aufstieg, sondern zu einem sozialstrukturellen und moralischen Abstieg in die Illegalität. Aber auch dieser Abstieg wird als eine Assimilationsgeschichte erzählt, denn Shirin wird der Rhetorik des Films zufolge zu einer Deutschen. ${ }^{107}$ Auch Ibrahim, der zu Beginn des Films DöNüŞ von Türkay Şoran fleißig, moralisch, verliebt in seine Frau und in das von ihr gepachtete Stück Land dargestellt wird, entspricht nach seiner ersten Rückkehr aus Deutschland diesem Bild nicht mehr. Wir sehen ihn im Dorf nur noch im Anzug mit seinem Transistorradio unter dem Arm.

Dass dieser Wandel ein äußerlicher bleibt und keiner inneren Logik folgt, erzählen beide Filme allerdings auch. Shirin bleibt auf der sozialen Ebene sehr solidarisch. Sie überweist auch weiterhin den Großteil ihres Gehalts an die Frau in Istanbul, die sie aufgenommen hatte, ohne sie zu kennen. Eine Sequenz bei der Post zeigt Shirin mit langen blonden Haaren und einem Pelzmantel. Sie über-

kunftsland zurückgeschickt werden. Vgl. HERBERT (2001): S. 226. Siehe auch HunN (2005), S. 142. 106 Auch Gülcan aus dem Film DöNÜŞ erkennt ihren Ibrahim bei seiner Rückkehr aus Deutschland nicht wieder, als sie ihn in einem gelben Anzug, einem Tiroler Hut auf dem Kopf, mit einem Fotoapparat und einer Armbanduhr erblickt. Mit ihren Händen bedeckt sie schockiert ihre Augen, blickt dann durch zwei Finger hindurch und umrundet danach Ibrahim, um sich zu vergewissern, ob er es denn auch wirklich ist. Siehe hierzu auch: KulaoĞLU (2017): S. 28. Diese Begegnung bereitet Ömer Alkın filmanalytisch sehr präzise auf. Siehe hierzu: ALKIN (2020): S. 381-388.

107 Tatsächlich benennen auch Türköz und Varveren in ihren drei Deutschlandliedern die ,Hure/Hündin‘ (kaltak) Shirin zu ,Helga' um, weil sich keine Türkin je so verhalten würde wie sie. Siehe hierzu: ÖZTÜRK/CANBOLAT (2020): S. 69f. 
weist das Geld in die Türkei und begegnet hier dem Mann ihrer griechischen Freundin Maria. Sie sei eine schöne Frau geworden und habe jetzt viel Geld, spricht sie Janis, der Grieche, freundlich an. Ja, entgegnet ihm Shirin: Sie habe ihren Mahmud gefunden und werde in der kommenden Woche heiraten. Er ist enttäuscht weil er nicht eingeladen wurde und fragt Shirin nach ihrer neuen Adresse, die kurzerhand beschämt die Post verlässt, ohne zu antworten. Erst später, als seine Frau Maria nach der Kündigungswelle mit den Kindern nach Griechenland zurückgekehrt und er selbst ins Wohnheim gezogen ist, erfährt Janis von Shirins heimlicher Tätigkeit. Obwohl er sie vor dieser gefährlichen Arbeit warnt, bittet er sie, auch mit ihm zu schlafen, da er Maria nur einmal im Jahr sehe. ${ }^{108}$ Das könne sie nicht tun, da Maria ihre Freundin sei. Daraufhin umarmen sich beide und der Grieche sagt: »Viel schlimmes Land«. Mit der Zusammenführung von körperlichen Bedürfnissen und emotionalen Bindungen setzt der letzte Abschnitt des Films ein.

Shirin verlässt nachts das Wohnheim, das im Industriegebiet liegt, und beobachtet, wie Aida von einem kriminellen Kollegen erstochen wird. Shirin eilt ihm zu Hilfe, der mit den Worten stirbt, er habe von Anfang an gewusst, dass sie ein gutes Mädchen sei. Weitere Prostituierte kommen hinzu, werden jedoch von den anderen Zuhältern wieder ins Auto gedrängt. Sie zwingen die Frauen, über den Mord zu schweigen und lassen sie irgendwo in der Dunkelheit aussteigen, um weiterzuarbeiten. Die Frauen laufen im Dunkeln über Wiesen entlang einer Autobahn und einer Fabrik. Irgendwann bleibt Shirin stehen, dreht sich um und sagt, sie wolle zurück nach Hause. Sie dreht sich um, läuft zurück, rennt am Auto der Zuhälter vorbei, einer steigt aus und schießt ihr in den Rücken. Sie stirbt und der Beginn des Films wiederholt sich: Man hört Shirins Stimme, die sagt: »Jetzt bin ich tot«.

Helma Sanders-Brahms hat den Tod der blonden Türkin mit der Sorge des Heimleiters zusammengeführt. Shirins Tod rahmt den Film und ihre Aussage »Jetzt bin ich tot« verbindet den unbehaglichen düsteren und trostlosen Ort am Rande einer Kölner Autobahn mit der steinigen Landschaft in einem türkischen Nirgendwo. ${ }^{109}$

108 Diese Passage in SHIRINs Hochzeit verdeutlicht noch einmal, neben dem Fokus auf die soziale Frage in diesem Film, den körperlichen bedürfnisorientierten. Auch die erste wissenschaftliche empirische Studie zum Leben der Gastarbeiter in Wohnheimen hebt diesen Aspekt im Zusammenhang mit der Frage der Integration besonders hervor. Siehe hierzu: BINGEMER, Karl/MEISTERMANN-SEEGER, Edeltrud/NEUBERT, Edgar (1970): Leben als Gastarbeiter. Geglückte und mißglückte Integration, Köln: Westdeutscher Verlag, S. 19.

109 An einer ähnlichen Stelle, nahe einer Autobahn, verstirbt auch Recep, der Freund des Ich-Erzählers Yüce, in Bekir Yıldız' autobiografischem Roman Türkler Almanyada. Siehe hierzu: YILDIZ (1966): S. 138. 


\section{4 „Die Suche nach dem unauffindbaren Partner»}

Wie bereits erwähnt, fiel die Rezeption des Films sehr unterschiedlich aus. ${ }^{110}$ Interessanterweise spiegeln diese Vielfalt und Widersprüchlichkeit auch die Motivationen und Zielvorstellungen der deutschen Regisseurin und der türkischen Schauspielerin. Die Schauspielerin Ayten Erten wollte mit ihrer Rolle als Shirin den deutschen Zuschauern »Denkanstöße geben « und zwischen beiden Kulturen vermitteln. Sie wollte zeigen - darauf insistiert sie -, dass es sich um ein »Zeigen « und nicht um ein »Darstellen « handelt -, »wie türkische Frauen in der Bundesrepublik ausgebeutet werden«. An einer anderen Stelle hält sie fest, dass für sie die Rolle der Frau im Allgemeinen im Vordergrund gestanden habe, "gleichgültig welcher Nationalität «. ${ }^{111}$ Eine ähnliche heterogene, disparate und widersprüchliche Motivationsstruktur zwischen spezifisch interkultureller und existenziell-allgemeiner Ebene finden wir auch bei Helma Sanders-Brahms. Als sie die ersten Ideen und Vorstellungen für ihren Spielfilm hatte, war ihr nächster Schritt »zu den Türken« zu gehen, „um zu erfahren, wie sie lebten in meinem Land«. Zur Vorbereitung verbringt sie zwei längere Aufenthalte in einem türkischen Dorf. Wenn ihre ethnografischen Beobachtungen und ihre Herangehensweise als Rahmung für den Film insgesamt auf eine interkulturelle Vermittlung zu zielen scheinen, hält sie dem entgegen ein weiteres zentrales Ergebnis für ihren Film fest: dass dieser eigentlich die »Suche nach dem nicht auffindbaren Partner und nach Kommunikation in der Isolation unserer Städte« zeige, und in dieser Suche »begegnen sich unsere Erfahrungen «. ${ }^{112}$ Das Verhältnis zwischen türkischer Frau und der Frau als Mensch im Allgemeinen, das Verstehen der türkischen Kultur durch Aufenthalte in türkischen Dörfern und die existenzielle Einsamkeit des modernen Menschen in modernen Industriestädten steht für eine kontroverse Logik und einen Verknüpfungstyp in Sanders-Brahms' Film, der kulturelle und soziale Entitäten fragil ineinander verschränkt. Dieser komplizierten Doppelbesetzung der Figur Shirins, einerseits als türkische Dörflerin, andererseits als isolierter moderner Stadtmensch, setzt Sanders-Brahms’ Film eine einfache stabile Erzählstruktur entgegen.

110 Siehe hierzu auch: SchenK (2020): S. 39-45.

111 SANDERS-BRAHMS (1980): S. 168.

112 Uмвасн, Klaus (1976): „Viel schlimmes Land. ১Shirins Hochzeit` TV-Spiel von Helma Sanders«. In: DER SPIEGEL, 19.01.1976, S. 120. Diese allgemein-existenzielle Aussage von Sanders-Brahms fügt sich ein in die Diktion der Definition von Eingliederung als Integration. Zur Eingliederungspolitik erläutert der leitende Beamte des BMA, dass diese »Hilfen zum Zurechtfinden in einer fremden Umgebung und zur Überwindung des Alleinseins bereitstellen sowie einen Beitrag zum gegenseitigen Verständnis leisten. ১Sie [die Eingliederungshilfen] verhindern die Isolierung des ausländischen Arbeitsnehmers und eine Ghettobildung und dienen ebenso dem Abbau von Spannungen und Vorurteilen.« SCHÖNwÄLDER (2001): S. 507. 
Als äußerst solide erweisen sich in diesem Film nämlich kausale und gesellschaftlich bedingte Unterdrückungsmechanismen, die an fast allen Orten und in allen Tätigkeitsfeldern wirken. Angefangen vom türkischen Dorf über die Verbindungsstelle, den Arbeitsplatz in Köln bis hin zur Arbeit als Prostituierte ist dieser Film von einer um sich greifenden Repression durchdrungen. Aufgrund der topologischen Struktur des Films wäre es zu kurz gedacht, die Ursache der Repression einfach in der Welt der Männer zu verorten. Sicher gehört SHIRINS HochzEIT dem ideologischen Horizont der Frauenbewegung der 1970er Jahre an, zumal es diese zeitgleich in der Türkei gab. ${ }^{113}$ Einige Notizen der Regisseurin stützen diese These. Sie hält in ihren Aufzeichnungen als Gegenkonzept zur Herrschaft des Mannes in der industrialisierten Welt das türkische Dorfleben der Frauen fest. Nach Sanders-Brahms habe dieses im positiven Sinne »mehr mit der Frauenbewegung zu tun, wie es sich jetzt zu entwickeln scheint, als mit der ganzen repressiven Familienideologie des Abendlandes«. Sie sind nicht wie in Europa oder mittlerweile auch in türkischen Städten und Großstädten auf »den einen Mann angewiesen « und müssen nicht »um jeden Preis alle seine Launen ertragen«. Im Gegensatz findet sie auf ihrer Recherchereise im türkischen Dorfleben eine »verlorengegangene Heimat« wieder. Die Welt der Männer ist dort von der der Frauen getrennt. ${ }^{114}$

Als ich mich zu den Männern setzte, hockten sich fünf Frauen zum Schutz hinter mich. Geste voller Einfühlung und Zärtlichkeit. Die Männer erzählten nur. Später ging ich dann zu den Frauen, da war es lustiger. Sie tanzten. [...] Die Frauen waren sehr zärtlich zueinander, auch zu ihren Kindern, voller Erfahrungen, voller Spaß, ohne Rivalität, die eine der anderen gegenüber, es war eine Geborgenheit da, wie in meiner Kindheit bei meiner Mutter. ${ }^{115}$

Und dass Frauen und Männer im Dorf nur dann das Bett teilen, wenn es um den geschlechtlichen Akt zum Zwecke der Fortpflanzung geht und sonst nicht, hält Sanders-Brahms aufgrund der Differenz zwischen Mann und Frau für richtig. Beides, körperliche Zärtlichkeit und Fröhlichkeit durch Tanz, übernehmen in der Markierung von Differenz im Film in den Sequenzen im Arbeiterwohnheim eine wichtige Funktion. Als Shirin das erste Mal ihr Bett im Wohnheim macht, schrei-

113 Siehe hierzu auch die Romane von Aysel Özakın aus den 1970er Jahren, besonders Alninda Mavi Kuşlar (Blaue Vögel auf deiner Stirn) von 1978. Der Erzählrahmen dieses Romans ist das Taksim-Massaker aus dem Jahr 1977, bei dem 34 Menschen starben und 134 in Istanbul bei den 1. Mai-Kundgebungen der Revolutionären Arbeitergewerkschaften verwundet wurden.

114 Diese Einstellung gleicht der von Verena Stefans in ihrem autobiografischen Roman Häutungen sehr. Sie hält darin nach Beziehungsversuchen mit Männern auch fest, dass die Frau den Mann zur Selbstfindung und zum Glücklichwerden nicht brauche. Siehe: STEFAN, Verena (1975): Häutungen, Frankfurt a. M.: Fischer.

115 SANDERS-BRAHMS (1980): S. $109 \mathrm{f}$. 
tet die deutsche Heimleiterin ins Zimmer, schnautzt sie in faschistoidem Ton an, dass sie ihr Bett falsch bezogen habe, und wir sehen in der nächsten Einstellung einen Flashback Shirins, wie sie im Dorf zärtlich an andere Frauen geschmiegt einschläft. Als ein Großteil der türkischen und griechischen Frauen aus dem Wohnheim ihren Arbeitsplatz verlieren, folgt zwar eine zunächst sehr traurige Sequenz, die jedoch mit einem Tanz der Frauen endet, der auch die Heimleiterin emotional berührt, die ihre Trauer darüber bekundet, dass nun alle gehen müssen.

Auch der Schichtführer in der Fabrik wird sich gegenüber den Gastarbeiterinnen solidarisch zeigen, als diese ihre Arbeit verlieren. Er reicht ihnen - nachdem sie ihre Kündigung erhalten haben - auf sanfte und solidarische Art die Hand und kommentiert, nun auch nicht zu wissen, wie es mit ihm weitergehen solle, weil auch ihm gekündigt wurde. Bedürftig und zugleich zärtlich bittet auch er Shirin darum, mit ihm zu schlafen. Diese Sequenzen, in denen es vor allem Frauen sind, die Shirin immer wieder helfen, zeigen eindeutig, dass hier eine solidarische Struktur den patriarchalischen und im Kern kapitalistischen Gesellschaften gegenübersteht und aufgebaut wird. Dennoch geht es in diesem Film nicht zentral um die Gleichberechtigung von Mann und Frau. Denn Zärtlichkeit und Bedürfnis sind zwei zentrale politische Kategorien. Auch die männlichen Gastarbeiter sind ohnmächtig, und es ist eine Frau, die Shirin mit dem Zuhälter Aida bekannt macht und sie in die Prostitution einführt. Weniger die geschlechtliche Unterscheidung strukturiert den Film als vielmehr eine vorangehende Trennung der Innen- von der Außenwelt, die Michael Rutschky der Bundesrepublik in den 1970er Jahren in seinem vielzitierten und bekannten Essay attestiert. Heute würden wir von einem epistemischen Code sprechen. Dementsprechend ist die Gesellschaft in ihrem Kern zweigeteilt: »drinnen ist das Positive, draußen das Negative. Übergänge, Zusammenhänge gibt es nicht. Die Außenwelt ist kalt und böse ${ }^{116}$

Dieser Bruch zwischen Innen und Außen durchzieht Sanders-Brahms’ Film und verleiht ihm eine unbestimmte und dilemmatische Struktur: zwischen allgemeiner städtischer Entfremdung und der national-kulturellen Verortung, zwischen Differenz und Ähnlichkeit, zwischen kultureller Zuschreibung und Vermittlung auf der einen und körperlichen und existenziellen Bedürfnissen auf der anderen Seite; eine dilemmatische Struktur, die auch der Dialog aus dem Off zwischen Shirin und der Regisseurin offenlegt, der den gesamten Film durchzieht. $\mathrm{Zu}$ Beginn scheint die Regisseurin Shirin deutlich überlegen, besserwisserisch.

116 Rutschкy, Michael (1980): Erfahrungshunger. Ein Essay über die siebziger Jahre, Frankfurt a. M.: Fischer, S. 41. 
Sie korrigiert Shirin mehrfach. Beispielsweise als sie ihr erklärt, dass das Land (Dorf) nicht ihr, sondern dem Agha (Ağa) gehöre. Doch dieses Verhältnis verkehrt sich im Laufe des Films und die akzentfreie Stimme aus dem Off wird falsche Aussagen machen, die nun Shirin richtigstellt. ${ }^{117}$ Am Ende ist es ein Prozess des wechselseitigen Erziehens zwischen der Migrierenden und der Alteingesessenen. ${ }^{118}$ Es ist sicher richtig, dass der Film zu Beginn paternalistisch wirkt und das Verhältnis zwischen einer deutschen und einer offensichtlich (durch den deutlichen Akzent) ausländischen Stimme, der grammatikalische Fehler unterlaufen, den Eindruck erweckt, dass hier die deutsche Seite die Geschichte bestimme. ${ }^{119}$ Doch dieses scheinbar hierarchische Verhältnis wird nicht nur durch den sich wandelnden Dialogverlauf konterkariert, sondern ebenso durch die erzählerische Struktur. Diese zeichnet sich zum einen durch eine Mischung aus Dokumentation und Liebesfilm aus. Zum anderen bieten der lose Anfang und das lose Ende keine Grundlage für eine auktoriale Erzählform.

Auch die deutsche Erzählerstimme aus dem Off weiß nicht mehr als Shirin über die Umstände und Folgen der Migration. Shirin aber wird über die eigene Herkunft und die nicht mögliche Ankunft hinausgehen - wie sie es selbst aus dem Off formuliert. Sie kommt weder mit Mahmud zusammen, noch kehrt sie in ihr Dorf zurück oder erfährt eine stabile Form der Sozialisation in der Bundesrepublik. Das Sujet der Migration scheint in SHIRINS HochzEIT verlorenzugehen. In den Vordergrund drängt sich nicht eine Erzählung, die durch konsistente Bindung von Anfang, Mitte und Ende gelingt. Im Zentrum steht vielmehr die Aussagekraft und Glaubwürdigkeit der einzelnen Situationen, welche die Verhaltensweisen der Akteurinnen und Akteure betonen. Diese Situationen tragen den Film. Es geht nicht um die Frage nach Anfang und Ende der Geschichte, nicht nach der Macht und Ohnmacht ihrer Akteurinnen und Akteure. ${ }^{120}$ Vielmehr geht es um die Frage nach den Verhaltensweisen, um Praktiken, die ein Ankommen oder ein Zurückkehren ermöglichen könnten. Diese Grundstruktur bestimmt auch die Narration des Films und eine Identitätspolitik, die wir in den politischen Thematisierungen des Ausländers im Deutschland der 1960er und 1970er Jahre finden.

117 Auch Schenk macht in Sanders-Brahms Film gegen Brauerhochs Interpretation auf einen Dialog im Off zwischen Shirin und der deutschen Regisseurin aufmerksam, in dem nicht die Deutsche die türkische Dörflerin als »dumm« beschreibt, sondern umgekehrt und die Deutsche dem zustimmt. Siehe hierzu: ScHENK (2020): S. $50 f$.

118 Siehe hierzu: BraUERHOCH (1995): S. 110f.

119 Vgl. Neubauer (2011): S. 179.

120 In diesem Zusammenhang fehlte der feministischen Kritik in Sanders-Brahms Film „die ideologische Schärfe“ und ein politisch offener Charakter. Siehe hierzu: FISchetTI, Renate (2000): Das neue Kino. Acht Portraits von Regisseurinnen, Dülmen-Hiddingsel: Tende, S. 123. 
Evident ist in SHIRINS HocHzEIT zunächst das eigensinnige Verhältnis zwischen Fiktion, Emotion und Dokumentation und die Abfolge bzw. Struktur des Films. Der Film beginnt mit dem Ende, mit dem Tod der Protagonistin und ist so gesehen eine einzige Flashback-Erzählung. ${ }^{121}$ Dieser Kunstgriff desavouiert eine chronologische Erzählform. ${ }^{122}$ Der Einstieg erfolgt mit einem persischen Liebesmärchen. Daran schließen sich der von Anfang an intim geführte Dialog aus dem Off zwischen der Protagonistin und der Regisseurin und die dokumentarische Darstellung des Dorflebens, die mit der Dominanz von halbtotalen und halbnahen Einstellungen nicht einzelne Individuen, sondern Gruppen in den Vordergrund rückt. Wir sehen keine Nahaufnahmen der einzelnen Akteure im Dorf, keinen Dialog mit Schuss- und Gegenschussaufnahmen. In Einzelaufnahmen werden in den ersten Sequenzen Wohnräume, Decken, Kopftücher, Tischtücher und vieles andere gezeigt, was Shirin für ihr Leben mit Mahmud - so die Protagonistin aus dem Off - genäht und gestickt hat. Neben dieser Materialität werden die Brüder des Vaters und ihre Frauen, das gemeinsame Essen und der Abschied der Frauen von Shirin in Gruppenaufnahmen gezeigt, und es gibt dabei kaum Schnitte. In solchen Einstellungen sind später auch die Wohnheim- und Fabrik-Sequenzen fotografiert.

Parallel wird der intime Dialog aus dem Off weitergeführt und das Märchenmotiv wieder aufgenommen. Beispielsweise äußert Shirin als Prostituierte später aus dem Off, dass sie nun weit über den Berg, über Mahmud hinaus sei. Die Gleichzeitigkeit von Liebesgeschichte, intimem Dialog, ethnografischem Dorfbericht und Dokumentation der Arbeitsmigration gibt diesem Film eine heterogene Struktur, die von keiner der genannten Aspekte einheitlich in einem dritten Raum durch einen Metacode geschlossen oder aufgelöst wird. ${ }^{123}$ Das Verhältnis der einzelnen opponierenden Narrative ist ephemer. Das hierarchische Verhältnis zu Anfang des Dialogs zwischen der Regisseurin aus dem Off und der Protagonistin als Miterzählerin und Beobachterin kippt nicht selten in sein Gegenteil. Das faschistoide Auftreten der deutschen Heimleiterin und das herrisch-maskuline Verhalten des deutschen Schichtführers in der Fabrik kippen beide in Positionen der Empathie. Und umgekehrt kippt der immer verständnis- und gefühlvolle Grieche, Marias Mann, indem er nach Sex mit Shirin verlangt. Aber selbst in seiner sexuellen Bedürftigkeit zeigt Helma Sanders-Brahms den Gastarbeiter nicht zudringlich, sondern zärtlich, denn Deutschland ist »viel schlimmes Land«.

121 Vgl. BRAUERHOCH (1995): S. 110.

122 Eine lineare Zeitstruktur impliziert auch Robert Ezra Parks Integrationstheorie.

123 Schenk reduziert diese Vielschichtigkeit von Sanders-Brahms Film ausschließlich auf die Verschränkung von Märchen und Dokumentarischem in SHIRINS HochzeIT, die er mehr der unterschiedlichen Rezeption und Interpretation des Films entnimmt als einer eigenständigen Filmanalyse. Siehe hierzu: ScHENK (2020). 
Die sich nicht vereinheitlichende, schließende Mehrebenenstruktur des Films zeigt sich auch in der Verhandlung kultureller, Differenz generierender Kennzeichen. So ist Shirins Kopftuch kein Kennzeichen für die Türkei, sondern typisch für das Dorfleben. Der Forderung ihrer modernen türkischen Freundin, ihr Kopftuch abzulegen, entgegnet sie, man würde es bei ihr im Dorf so tragen. Die Aussage, man würde es in der Türkei so tragen, wäre in dieser Situation inkonsistent und würde auch einer gewissen Komik nicht entbehren. Diese regionale und nicht nationale Reichweite impliziert im Film auch eine mäßige kulturelle Repräsentationskraft als muslimisches Kennzeichen. Es ist weniger ein Abstraktum der Differenz oder der Verständigung als ein brauchbarer oder nicht brauchbarer Gegenstand, der sich zum Schutz oder der Steigerung der Attraktivität einsetzen lässt. Dieser Einsatz ist wichtiger als die Repräsentation. Dies zeigt sich auch darin, dass Shirin das Kopftuch ganz unterschiedlich trägt. Man sieht mal mehr, mal weniger Haare. Sie hält es häufig in der Hand, wir sehen sie beim Anziehen des Kopftuchs, und der Schichtführer wird auch einmal unbedarft daran ziehen, als Shirin versucht, ihn zu necken. Eine allegorische Wirkung bekommt es hingegen im Lokal nach dem Tanz und dem Alkoholkonsum mit Aida, wenn sich Shirin auf der Toilette übergibt und wir im Spiegel sehen, wie ihr das Kopftuch vom Kopf rutscht. Doch diese Allegorie verliert sich wieder. Shirin trägt es, wenn sie beispielsweise Mahmud auf dem Kölner Bahnhof sucht, der sonntags von unzähligen Gastarbeitern bevölkert ist. ${ }^{124}$ Und kurz bevor sie sich die Haare blondiert, wird sie das Kopftuch bereits abgelegt haben, wobei dieses Verschwinden nur noch bedingt auffällt. Wenn das Kopftuch überhaupt eine Funktion erfüllt, dann eine schützende, die die schüchterne Art der Protagonistin noch verstärkt. Die offenen Haare der türkischen Schauspielerin Türkan Şoray als Gülcan in DöNÜŞ stehen am Ende des Films für ihre Desintegration im Dorf, aber nicht für eine explizit kulturelle. Denn es sind Schuld- und Besitzverhältnisse, die diese Dynamik auslösten.

124 Mit der Bahnhofssequenz, in der Shirin Mahmud sucht, nachdem sie ihn im Lokal nicht gefunden hat, folgt Sanders-Brahms ihrer dokumentarischen Richtlinie des »Zeigens« in diesem Film. In Karen Schönwälders Buch zur Einwanderung und ethnischen Pluralität in Deutschland finden wir repräsentativ für viele andere Debattenbeiträge aus dem Jahre 1971 die folgende Einschätzung: „Vielleicht haben wir bisher den heimlichen Wunsch genährt: irgendwann werden sie wieder nach Hause gehen, dann werden wir wieder mehr Platz und Ruhe haben, und unsere Innenstädte und Hauptbahnhöfe werden an Sonntagnachmittagen nicht mehr wirken wie Kundgebungen nach dem gescheiterten Turmbau zu Babel. Aber solche Hoffnungen trügen.« »Die Bundesrepublik muß sich auf ein Leben mit den Gastarbeitern einrichten «, heißt es resignativ in einem Zeitungsbeitrag. Siehe hierzu: SCHÖNwäLDER (2001): S. 614. Auch Max von der Grün hält in Leben im gelobten Land fest, dass Bahnhöfe für Gastarbeiter »Kommunikationszentren « seien und ihnen so die Moschee ersetzen würden. Siehe hierzu: vON DER GRÜN (1975): S. 22. 
Im Unterschied $\mathrm{zu}$ den Migration thematisierenden Filmen der späteren Dekaden ist die Reichweite kultureller Kennzeichen hier gering. ${ }^{125}$ Exemplarisch zeigt sich dies auch in der Miniatur des Kölner Doms und später auch in der einer Moschee - ein Wecker -, den eine Gastarbeiterin vom Tisch räumt, als alle gekündigten Gastarbeiterinnen das Wohnheim verlassen müssen. Zwischen Gebrauch und Repräsentation sind kulturelle Kennzeichen in SHIRINS HocHzEIT in einem unbestimmten und willkürlichen Wandel begriffen, wie die Hauptakteurin selbst, deren neuer Kleidungsstil zwar eine evidente Veränderung darstellt, jedoch keinen expliziten Übergang von einer spezifisch türkischen zu einer spezifisch deutschen Kultur zeigt. Vielmehr ist es ein Übergang, der im äußeren Erscheinungsbild eine Veränderung von einem dörflich-traditionellen zu einem städtischen Auftritt dokumentiert. Ein Übergang vom unwirtlichen Dorf in eine unwirtliche große Stadt. ${ }^{126}$

Die übrigen Übergänge in SHIRINS HochzeIT sind aus einer klassischen integrationstheoretischen und narrativen Perspektive prekär und problematisch, da weder der Ausgangspunkt des Films, seine Mitte, noch der Schluss, Shirin einen Ort der Zugehörigkeit weisen. Das Dorf gehört dem Agha, das Wohnheim den Fabrikbesitzern und die Straßen Kölns den Zuhältern oder der Polizei. Nur der Kölner Bahnhof wird in SHIRINS HochzEIT zu einem herrenlosen Versammlungsort der Gastarbeiter. ${ }^{127}$ Das klassische Narrativ vom Auszug, vom Meistern der Prüfungen, von der Rückkehr oder der Ankunft kann hier nicht greifen. ${ }^{128}$ Auch die dörfliche, türkische kulturelle Bindung vom Beginn stellt für Shirin keine stabile soziale Einheit dar. Selbst ihre Verwandten halten sich nicht an die kulturellen Codes bzw. die Tatsache, dass Shirin Mahmud versprochen war. Da der Verwalter mehr

125 Diese zeigt sich ebenfalls in den zeitgleich entstehenden türkischen Produktionen Отовüs (1974), dem bereits angesprochenen Film, in dem die Migration türkischer Dörfler nach Schweden thematisiert wird, wie auch im Roman Gurbet Yavrum (1975), in dem die Tochter eines türkischen Gastarbeiters sich auf die Suche nach ihrem verlorenen Vater in Kanada macht. Siehe: Tunç, Okan (1974): Otobüs, Spielfilm, Türkei, Pan Film Türkiye; ÖzAKIN, Aysel (1975): Gurbet Yavrum, Istanbul: Can Yayınları.

126 Siehe zur Unwirtlichkeit der Städte die einflussreiche Publikation von Alexander Mitscherlich Die Unwirtlichkeit unserer Städte $(1965,2008)$.

127 Rita Chin macht in ihrer Arbeit auf die ikonografische Funktion der Aufnahme des einmillionsten Gastarbeiters Rodrigues de Sá auf dem Motorrad am Kölner Bahnhof Köln-Deutz aufmerksam. Siehe hierzu auch: VON DER GRÜN (1975): S. 22. In der amerikanischen Arbeit Sius über die chinesischen Gastarbeiter in New York stellen Wäschereien einen vergleichbaren Versammlungsort dar.

128 Siehe zum klassischen Narrativ, das besonders im Bereich des Films durch das Kino Hollywoods ab den 1950er Jahren große Verbreitung fand und heute weiterhin als eines der wirkmächtigsten im Bereich des Films gilt, KRÜTZEN, Michaela (2011): Dramaturgie des Films. Wie Hollywood erzählt, Frankfurt a. M.: Fischer, S. 36f. 
zahlen kann, bekommt er Shirin, obwohl er ihren Bruder ins Gefängnis gebracht hat. In Şorays Film DöNüş entlässt der Großgrundbesitzer den Dorfverwalter aus seinen Schulden, wenn dieser ihm hilft, an Gülcan ranzukommen, die aber schon verheiratet ist. In Deutschland regiert das Geld ebenso wie in der Türkei, und solidarische Strukturen sind nicht per se gegeben, sondern können bestenfalls unter guten Bedingungen entstehen. ${ }^{129}$

So ist SHIRINS HochzEIT aufgrund des Mangels stabiler kultureller und sozialer Einheiten weder explizit ein Film zu kultureller Differenz, noch ein Film über eine gescheiterte Integrationsgeschichte in einer Mehrheitsgesellschaft. Stattdessen wirft er die soziale Frage auf, weil Shirins Bindungen von Anfang an in Auflösung begriffen sind. Das Soziale wird dabei »durch die überraschenden Bewegungen von einer Assoziation zur nächsten ermittelt «. ${ }^{130}$ Wie in Milton Gordons Integrationstheorie ist das zentrale Anliegen in Helma Sanders-Brahms' Film, über Antidiskriminierung neue soziale Gruppenkonstellationen zu ermöglichen. Der große Unterschied zu Gordon ist hier nur, dass es in SHIRINS HocHZEIT keinen Raum, keinen Ort gibt, weder in der Türkei noch in Deutschland, der eine Äquivalenz zwischen Gruppe und Territorium, zwischen Gruppe und Kultur schaffen und die schwachen Bindungen in starke und stabile übersetzen könnte. So ist das Soziale in diesem Film keineswegs von einer dichotomen Unterscheidung zwischen Kollektiv und Individuum bestimmt, von Unterscheidungen wie religiöser Fanatismus vs. westliche Lebensweise, wie Bevormundung vs. Freiheit oder wie Tradition vs. Moderne und Türkei vs. Europa, wie es die Forschung nicht müde wird, derart falsch die ersten Produktionen zur Migration nach Deutschland zu klassifizieren. ${ }^{131}$

Auch wenn diese seit den 1980er Jahren klassischen interpretatorischen Unterscheidungen zu Phänomenen der Migration in Sanders-Brahms' Film nicht greifen und das Sujet der Migration aus dieser Beobachtung heraus in SHIRINS HocHzEIT nicht konsistent ist, handelt es sich bei diesem Film dennoch um einen Klassiker der deutsch-türkischen Migration. Spätestens jetzt stellt sich die Frage, was diesen Film zusammenhält und ihn zu einem umstrittenen, aber doch erfolgreichen Film werden ließ. Die Liebesgeschichte ist es nicht. Es ist auch nicht der dokumentarische Wert des Films, denn hierfür überwiegen wiederum zu sehr die fiktionalen Elemente.

129 Vgl. LEFEBVRE (2006): S. 338.

130 Latour, Bruno (2010): Eine neue Soziologie für eine neue Gesellschaft, Frankfurt a. M.: Suhrkamp, S. 424.

131 Neubauer (2011): S. 175. Siehe auch GöктÜRк (2000b): S. 331. In meinem Aufsatz Von der interkulturellen zur kulturellen Kompetenz von 2009 unterlag ich mitunter ebenfalls diesem voreiligen Trugschluss. Siehe hierzu: EzLI (2009). 
Anders gefragt: Welche Referenzen in diesem Film stehen jenseits von Kultur, Mehrheitsgesellschaft und Minderheit im Vordergrund und geben dem Film über den ästhetisch-erzählerischen Rahmen hinaus eine stabile und konsistente Struktur? Welche Narrative sind es, die über den Film hinausgehend eine gesellschaftlich anschlussfähige Erzählung ermöglichen konnten, trotz ihrer aus heutiger Perspektive widersprüchlichen Rezeption zwischen Kultur und Sozialem? Und wirken vielleicht trotz des Mangels an stabilen gesellschaftlichen Einheiten wie Gruppen und Familien hier Ideen und Vorstellungen von Assimilation, Integration und Sozialem, die jenseits gegebener stabiler gesellschaftlicher Ordnungen ausbuchstabiert werden müssen? Die Frage ist, was an unartikuliertem Wissen mitgeteilt wird, das "stillschweigend auf einen Fundus an sensorischen und praktischen Erfahrungen Bezug « ${ }^{132}$ nimmt, um in der Zone zwischen Alltag, Kunst und Politik Wahrscheinlichkeiten zu artikulieren. Und in welchem Verhältnis stehen erzählerische Offenheit und kulturprägende Narrative? Was das Anliegen und die Bewegung ästhetischer Texte, Filme und Theorien betrifft, werden wir sehen, dass Aneignungen des öffentlichen Raums eine Grundbewegung darstellen, auch wenn ihre Protagonisten passiv und schematisch auftreten.

Um diese Fragen und Themen mit der bisherigen Interpretation von SHIRINS HochzeIT und mit einer gewissen Repräsentativität und Breite beantworten und untermauern zu können, werden in den folgenden zwei Unterkapitel die zuvor genannten Texte und Filme aus den 1960er und 1970er Jahren in eine analytische Relation zur SHIRINS HochzEIT gebracht. Zunächst folgt die Analyse des Poems Was will Niyazi in der Naunynstraße aus dem Jahre 1973 des türkischen Autors Aras Ören; der erste breit rezipierte Text deutsch-türkischer Literatur, der für Rita Chin den Beginn eines »multicultural Germany« markiert. Hier wird es neben den bereits aufgeworfenen Fragen auch darum gehen, aufzuzeigen, inwieweit sich die deutsche (Sanders-Brahms) von der türkischen Perspektive (Ören) auf die Anfänge und Folgen der türkischen Migration nach Deutschland unterscheidet und worin sie sich ähneln. In diesen Zusammenhang werden auch Güney Dals Roman Wenn Ali die Glocken läuten hört (der zweite bekannte Text deutsch-türkischer Literatur der 1970er Jahre) sowie Bekir Ylldız' autobiografischer Roman gebracht.

Die Interdependenz und Ähnlichkeit zwischen Filmen, Texten und gesellschaftspolitischen Narrativen werden in ihrer heterogenen und dilemmatischen Struktur zeigen, dass es sich bei Filmen und Texten, die in diesem Einstiegskapitel zur Disposition stehen, weder um einfache Opfer- oder Tätergeschichten handelt, wie bislang in der Forschung konstatiert wird, noch umgekehrt um

132 Koschorke, Albrecht (2012): Wahrheit und Erfindung. Grundzüge einer allgemeinen Erzähltheorie, Frankfurt a. M.: Fischer, S. 38. 
Ermächtigungsnarrative. Im Zentrum steht eine Verhandlung und Bearbeitung von Integration und Desintegration, die die Jahrzehnte des Umbruchs ${ }^{133}$ (1960er) und der Transformation ${ }^{134}$ (1970er) als Sozial- und Kulturgeschichte die Herkunfts- und Ankunftsgesellschaften geprägt hat.

\section{5 «Wir wollten alle Amerikaner werden«: Aras Örens Gastarbeiter erfolglos auf dem Weg in den Westen}

Halime, eine türkische Gastarbeiterin im ersten Band von Örens Poem-Trilogie Was will Niyazi in der Naunynstraße (1973), ${ }^{135}$ wohnt Anfang der 1970er Jahre in einem Mehrparteienhaus in der Berliner Naunynstraße. Sie kommt, wie ihre ältere deutsche Nachbarin Frau Kutzer in der Mitte des Poems berichtet, »abends manchmal mit Männern nach Haus «. ${ }^{136}$ Frau Kutzer fragt sich, da ihre türkische Nachbarin »es ganz offensichtlich in dem einzigen Zimmer [, das sie hat], mit den Kerlen treibt«, wo währenddessen ihre kleinen Kinder sind und was sie machen. ${ }^{137}$ Ein wenig später treffen sich Halime und Frau Kutzer im Treppenhaus.

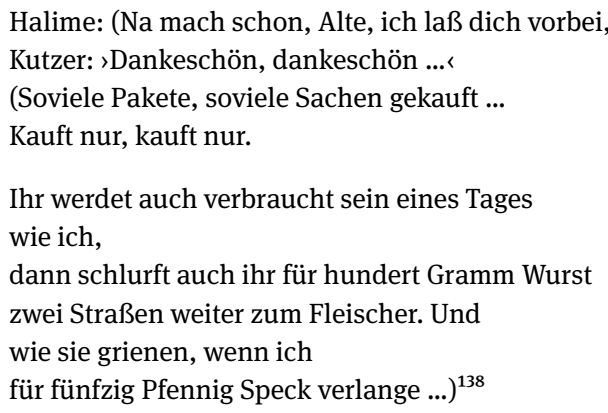

Beide Szenen im ersten Band des Poems (die erste finden wir in der Mitte und die Treppenhausszene gegen Ende des Textes), deuten eine Begegnungsstruktur zwischen Alteingesessenen und Zugewanderten an, die sich hier nicht aus

133 Vgl. SCHILDT (2009): S. 179-244.

134 Ebd, S. 245-330. Und siehe auch ReICHARDT, Sven (2014): Authentizität und Gemeinschaft. Linksalternatives Leben in den siebziger und frühen achtziger Jahren, Frankfurt a. M.: Suhrkamp, S. 82-86.

135 Der zweite Band der Trilogie, Der kurze Traum von Kağthane, erschien 1974, und abgeschlossen wurde sie mit dem dritten Band Die Fremde ist auch ein Haus 1980.

136 ÖREN (1973): S. 31.

137 Ebd.

138 Ebd., S. 56f. 
ethnisch-kultureller, sondern aus körperlicher, räumlicher und sozialer Diversität konstituiert. Eine türkische Frau mittleren Alters lebt mit mehreren Kindern in einer Einzimmerwohnung - ihr Mann sitzt wegen Blutrache in der Türkei im Gefängnis -, eine 67 Jahre alte deutsche Frau lebt hingegen allein in einer Zweizimmerwohnung. Das sind zunächst Informationen für eine klassische Migrationsforschung, die auf statistische und repräsentative Ergebnisse aus ist; zumal Anfang der 1970er Jahre verstärkt das öffentliche Interesse aufkommt, zu wissen und $\mathrm{zu}$ erfahren, wie die Gastarbeiter und Gastarbeiterinnen in Deutschland wohnen und untergebracht sind. ${ }^{139}$

Aus interpretatorischer Sicht ist dies nur die eine Seite der beiden zitierten Passagen. Verweise auf Alter, Familie und Wohnungsgröße sind die Rahmungen der Situationen, in denen besonders die unterschiedlichen körperlichen Bedürfnisse erzählerisch akzentuiert werden. Halime hat Sex und kommt mit vollen Einkaufstüten nach Hause, weil ihr Körper will und kann; eine alte deutsche Frau, die auf ihren eigenen Körper referierend, nichts mehr braucht und nicht mehr verzehren kann als 100 Gramm Wurst und Speck für 50 Pfennig pro Woche. Dabei wird sie bei ihrem Einkauf von deutschen Verkäufern belächelt. Weitaus mehr als die türkische Gastarbeiterin wird hier die alte deutsche Frau als Desintegrierte dargestellt. ${ }^{140}$

Dass Aras Örens Poem trotz dieser sozialen Mehrebenenstruktur, die sich über körperliche Bedürfnisse ergibt und nicht über nationale, religiöse oder kulturelle Zuschreibungen, in den zeitnahen Besprechungen als erste gelungene literarische Chronik des Zusammenlebens von Deutschen und Türken ${ }^{141}$ und somit als »erste Reflexion ${ }^{142}$ über das Leben der arbeitenden Türken in Deutschland bewertet wurde, ist keineswegs eine kulturalistische Fehlinterpretation. Es ist eine Deutung, die, zum einen, in einem gesellschaftspolitischen und narrativen Zusammenhang der 1960er und 1970er Jahre steht. Zum anderen hängt die Tatsache, dass Örens

139 Siehe hierzu: ZIERIs, Ernst (1971): So wohnen unsere ausländischen Mitbürger. Bericht zur Wohnungssituation ausländischer Arbeitnehmerfamilien in Nordrhein-Westfalen, Düsseldorf. Siehe hierzu auch: Siegfried-Hagenow, Monika (2006): Als die Gastarbeiter ins Fernsehen kamen. Collage von Archivbeiträgen des Fernsehens über Gastarbeiter in der Bundesrepublik, Dokumentation, Deutschland, Erstes Deutsches Fernsehen. Vgl. auch: ScHöNwÄLDER (2001): S. 497. 140 Mit einer vergleichbaren Struktur der Desintegration einer Alteingesessenen arbeitet auch Rainer Werner Fassbinder in ANGST ESSEN SEELE AUf (1973). Dort ist es die alteingesessene und sich in einem vergleichbaren Alter wie Frau Kutzer befindende deutsche Frau Emmi Kurowski, die von ihren Nachbarinnen und ihren Kindern ausgeschlossen wird, nachdem bekannt wird, dass sie den viel jüngeren Gastarbeiter Ali, der aus Marokko stammt, heiraten will. Siehe hierzu: FASSBINDER, Rainer Werner (1973): Angst essen Seele auf, Spielfilm, Deutschland, Arthaus.

141 Vgl. SubERGER, Ulf G. (1974): »Wir machen szammen Geld für die Fabrika Direktor ... «. In: Deutsche Volkszeitung, S. 17.

142 PATAKI, Heidi (1975), »Review of Der kurze Traum aus Kağtthane«. In: Neues Forum 22, S. 66. 
Poem ohne ein kulturelles oder religiöses Differenzierungsnarrativ konsistent und in der Sprache der Zeit »authentisch « wirkt, zuallererst von seinem eigenen narrativen Verlauf ab. Es ist vor allem der Beginn und zugleich der Zugang, den Was will Niyazi in der Naunynstraße wählt und beschreitet, der eine weiterführende Struktur der Beschreibung von Differenz und Ähnlichkeit zwischen Deutschen und Türken vorgibt, die die Szenen in ihrer sozialen Dimension auf Einwanderer und Alteingesessene »authentisch « und plausibel wirken lässt.

Im Prolog des Poems schneit es in Berlin. ${ }^{143}$ Die Naunynstraße in Kreuzberg, auf und in der sich alles in diesem Stück abspielt, ist zugefroren. Der Protagonist und Gastarbeiter Niyazi, mit dem Nachnamen Gümüşkılıç (»Silberschwert«), ist bereits in den ersten Zeilen auf dieser Straße unterwegs; in die Fabrik zur Arbeit, zur Nachtschicht. Gebrochen wird der für die Migrationsliteratur klassische und schematische Einstieg - kaltes Einwanderungsland, Ausländer arbeiten in der Nachtschicht - bereits mit einem Nebensatz und dem weiteren Verlauf der Erzählung. An der Stelle, wo heutige Migrations- und Integrationsforscher weitererzählen würden, die erste Generation der Gastarbeiter habe der deutschen Gesellschaft Arbeiten abgenommen, die viele deutsche Alteingesessene nicht hatten verrichten wollen, folgt Örens Erzählung einer anderen narrativen Struktur. ${ }^{144}$ Niyazi geht hier mit schnellen Schritten zur Arbeit in die Fabrik Preussag, ganz so wie er auch im Istanbuler Stadtteil Bebek unterwegs gewesen ist; dort zum Blaufischfang. Hier bei Preussag arbeitet er an den »weißglühenden Öfen« der Fabrik. Auf die translokale Verbindung von hier und dort folgt in der dritten Strophe die Anmerkung, dass durch Niyazis Arbeit denjenigen »warm wird [...], die ihre Villen im Südwesten der Stadt bewohnen «. ${ }^{145}$ Danach verlässt der Erzähler Niyazi und wendet sich Frau Kutzer zu, die ebenfalls in der zugefrorenen Naunynstraße wohnt, der allerdings von Niyazis Arbeit nicht warm wird. Denn sie kommt in dieser Nacht "schwer in Schlaf, [...] sie muss ihre blaugefrorenen Füße reiben «. ${ }^{146}$ Der Erzähler kehrt nicht wieder zu Niyazi zurück, um die schwere Arbeit und den beschwerlichen Alltag der Gastarbeiter zu beschreiben. Er bleibt bei Frau Kutzer und erzählt bis zum Beginn des dritten Kapitels (der erste Band der Trilogie besteht aus sieben Kapiteln), die Geschichte, Wünsche und Enttäuschungen von Frau Kutzer und ihrer Familie. ${ }^{147}$

143 Siehe hierzu auch den Film Отовӥs.

144 Siehe hierzu: BADE (1983); EsSER (1980, 1983); ELWERT, Georg (1982): »Probleme der Ausländerintegration. Gesellschaftliche Integration durch Binnenintegration?«. In: Kölner Zeitschrift für Soziologie und Sozialpsychologie 34:4, S. 717-731.

145 ÖREN (1973): S. 5.

146 Ebd.

147 Ebd., S. 13. 
Diesen Exkurs zu Frau Kutzer und ihrer Familie leitet der Erzähler wie folgt ein: »Ihr kennt doch alle Frau Kutzer / oder doch ihren Mann: / Er hat bei Borsig gearbeitet, / dort verschraubte er die Vorderachsen der mächtigen Lokomotiven «. ${ }^{148} 37$ Jahre lang ging er dieser Tätigkeit nach, war in der Weimarer Zeit Mitglied der KPD, beugte jedoch »seinen Kopf ohne Widerstand dem System «, als die Nationalsozialisten die Macht an sich rissen. Und auch wenn sie damals schon in der Naunynstraße wohnten, wird ihr "schwindlig ", wenn sie in ihre Vergangenheit blickt, denn die »Jahre sind wie Schluchten, die ich hinter mir hab «. ${ }^{149}$ So erscheint ihr ihre eigene Geschichte fragil und surreal: »Es ist nicht so einfach zurückzusehen nach 67 Jahren: / Pinguine in der Wüste, / Vogel Strauß auf dem Eis. / So laufen die Gedanken / an ihre Jugendjahre ${ }^{150}$ Alles andere als fragil erweist sich jedoch ihr Traum, den sie hat, als sie schließlich einschläft - ein Wunschtraum, den sie schon immer hatte: durch »die Kristalltüren des Adlon zu schreiten«. Aber was sie mit ihrem Mann im wirklichen Leben kennenlernt, ist »das >Bayrische Zelt in der Friedrichstraße ${ }^{151}$ Als Resultat ihrer Gedanken und Träume hält Frau Kutzer fest, dass Arbeit und Jugend im Leben ihr Ende haben. Das habe sie gelernt. Denn diese »auffällige Welt [...] blendet uns die Augen«. Und es ist »dieses von Etage zu Etage leben, ohne dahinter zu kommen, in welcher Etage man ist «. Aber letztlich möchte der Mensch "gern wie ein ganz anderer leben, über seine Verhältnisse hinaus «. ${ }^{152}$

Auf diese Erkenntnis folgt das zweite Kapitel, in der Ören die bis ins 19. Jahrhundert reichende Familiengeschichte Kutzers, ihrer Eltern und Großeltern erzählt, die ebenfalls von Migration geprägt ist. Diese kam 1844 von Ostpreußen nach Berlin als Franz Naunyn Bürgermeister wurde. Die Naunynstraße war damals nicht die Naunynstraße, sondern »irgendeine

Die Familie Brummel / faßte Fuß in dieser Straße. / Lange nach dem Umzug bekam der Großvater, / Heinz Brummel (er war auch Schlosser, / und dazu Schmied), für die Familie / die Bürgerrechte Berlins, / amtlich registriert im Jahre 1894. / Rotes Wachs siegelte die Urkunde. ${ }^{153}$

Erst nach 50 Jahren wurden die Brummels Bürger der Stadt Berlin. Und Frau Kutzer, geboren 1905, erinnert sich bis 1918 an Hausarbeiten wie Sticken, Stricken und Kohlkochen. Ouvertüren von Léhar-Operetten hörten sie ab und an mit dem

148 Ebd., S. $5 f$.

149 Ebd., S. 7.

150 Ebd., S. 8.

151 Ebd., S. 9.

152 Ebd., S. 10.

153 Ebd., S. 14. 
Grammophon. Doch waren die Geschichten der Operetten eine »Welt« für sie mit »verhängte[n] Türen [...], die fremd blieb und geheimnisvoll«. ${ }^{154}$

Der Erste Weltkrieg bringt den deutschen Soldaten dann »vier Jahre im Regen / von Schrapnells, Blut, Knochen / und Stahl / durchnäßt / bis in den Kopf / und in die Herzen« ein. Auf der Potsdamer und Friedrichstraße in Berlin warten »die Nutten auf sie «. ${ }^{155}$ Das Jahr 1923 bringt der Familie Brummel den ökonomischen Ruin, der Vater stirbt 1924 und kurz darauf heiratet Elisabeth Brummel »neunzehnjährig [...] den jungen Monteur Gustav Kutzer «. ${ }^{156}$ Als die Arbeitslosigkeit in der Weimarer Zeit gegen Ende der 1920er immens ansteigt, arbeitet Frau Kutzer als Putzfrau im Haus eines »Kriegsgewinnlers in Neukölln«. »Das erstemal in ihrem Leben / für andere zu arbeiten, / hat ihr sauer geschmeckt. / Das Taftkleid war verschossen / und das Grammaphon längst verkauft. « ${ }^{157}$ Auch wenn sie die Dame des Hauses nicht ausstehen kann, möchte sie doch wie sie werden, und sie war »in Gedanken immer bei der reichen Dame in Neukölln «. ${ }^{158}$

Die Zeit des Nationalsozialismus in Deutschland wird kurz gestreift. Es ist eine Zeit des familiären Rückzugs, die Tochter wird geboren, und die Zeit, als Gustav als Linker vor dem gefährlichen neuen politischen System Angst hatte. Gustavs Soldatenjahre im Zweiten Weltkrieg werden kurz erwähnt. Es folgen die Bombennächte und die fremden Soldaten, die sich in Berlin »mit Konserven, Bonbons, Schokolade [...] Frauen« kaufen, und an Straßenecken in Berlin werden heimlich »Lebensmittelkarten getauscht«. 1959 erliegt Gustav Kutzer einem Herzanfall und stirbt nach »siebenunddreißig Jahren « Arbeit an »mächtigen Lokomotiven«. Niyazi kommt von der Nachtschicht zurück und Frau Kutzer beendet ihre Geschichte in ihrem Gespräch mit dem Erzähler: Der Tod ihres Mannes habe in der Naunynstraße »niemanden ein Haar bewegt«. Es folgten Formalitäten und danach »abends wieder das warme Blubbern vom Kochtopf / und ab und zu / das Kopfwiegen der Nachbarn / und ihre unehrlichen Worte «. ${ }^{159}$ Erst nach diesem seitenlangen Exkurs folgt die Geschichte der türkischen Gastarbeiter; und damit folgt die türkische Migration auf die deutsche Migration in die Naunynstraße. Dabei handelt es sich um eine vergleichbare Bindung von deutsch und türkisch, wie sie Sanders-Brahms in SHIRINS HocHzEIT mit den ersten Einstellungen vom Acker in einem türkischen Dorf als trockenes Land des Grundbesitzers zeigt und beschreibt und ihren Film mit dem Niemandsland neben einer Autobahn

154 Ebd.

155 Ebd., S. 15.

156 Ebd., S. $15 f$.

157 Ebd., S. 17.

158 Ebd., S. 18.

159 Ebd., S. 20. 
in Köln beschließt. Deutsche und Türken haben identische Triebe, ein ähnliches Begehren und wenn sie nicht zu den Besitzenden gehören, sind sie auch ähnlich ortlos. Äußerst eindrücklich wird diese Konstellation in Şorays Film DöNÜş gezeigt. Als Ibrahim vom Biertrinken aus »pokalgroßen Gläsern« im Beisein von Frauen in der Zivilisation schwärmt, folgt als nächste Sequenz in diesem Film, der ausschließlich in einem unbestimmten türkischen Dorf spielt, wie der Großgrundbesitzer (Ağa) mit zwei attraktiven Frauen und zwei seiner Mitarbeiter gemütlich Alkohol trinkt. Und ähnlich wie im ersten Text zur türkischen Migration nach Deutschland Türkler Almanyada wird in Örens Poem und in Şorays Film ebenfalls durch die narrative Abfolge der jeweilige Titel der Produktionen zum Teil konterkariert. Geht es in Örens Poem um Frau Kutzer oder um Niyazi und mit ihm um die Türken in Deutschland? Und von wo kehrt eigentlich Ibrahim zurück, wenn doch der türkische Großgrundbesitzer genauso lebt wie die Deutschen und wenn es sich bei Wasser, Strom, Alkohol und Miniröcke um elmentare, flüchtige Dinge und mobile Gegenstände handelt?

Die behandelten ästhetischen Erzählungen der 1960er und 1970er Jahre folgen einer assoziativen Struktur, die Dinge ebenso wie Personen beinhalten. Im vierten Kapitel von Aras Örens Poem, „Frau Kutzers Nachbarn«, werden die Frauen Atifet und Halime sowie der fleißige Gastarbeiter Kazım Akkaya vorgestellt. Im Vordergrund steht nicht wie, sondern warum sie nach Deutschland gekommen sind. Das Wie wird hingegen karikiert. »Ein verrückter Wind eines Tages / wirbelte den Schnurrbart eines Türken, / und der Türke rannte hinter seinem Schnurrbart / her und fand sich in der Naunynstraße. ${ }^{160}$ Zunächst zieht, in der »Mitte seines Lebens«, irgendein Türke im Stockwerk unter Frau Kutzer ein. Er ist zurückhaltend, weiß sich zu benehmen, isst nichts, trinkt nichts und spart. Nach Jahren ist er wieder weg und es ziehen andere seiner Landsleute ein, wie Niyazi, der ledig, 41 Jahre alt ist und seit sieben Jahren in Deutschland lebt. Er wohnt ein Stockwerk über Frau Kutzer, spricht gut Deutsch und achtet sehr auf »sein Äußeres«. ${ }^{161}$ Dazu gehört, dass er »Koteletten bis unter die Ohren« hat.

160 Ebd., S. 21.

161 Tatsächlich haben türkische und spanische Gastarbeiter, als sie in die Bundesrepublik migrierten von den Regierungen der Entsendeländer jeweils einen Leitfaden erhalten, in dem verlangt wird, dass sie als Vertreter ihrer Länder in der Bundesrepublik sich gut verhalten, nicht auffallen und sich gut kleiden sollten. Siehe hierzu: ERYILMAZ/YAMIN (1998): S. 24. Und siehe auch: DOMIT (2005): Projekt Migration. Katalog zur Ausstellung im Kölner Kunstverein, Köln: Dumont, S. 33. Es gibt sehr viele Aufnahmen, die die Gastarbeiter bei ihrer Ankunft am Münchener Hauptbahnhof mit Krawatte und Anzug zeigen. In Şerif Görens Film ALMANYA, ACI VaTAN macht sich ein routinierter türkischer Pendler zwischen der Türkei und Deutschland darüber lustig, dass die Türken kurz vor der Ankunft an der deutschen Grenze ihre Krawatten anlegen. Siehe hierzu: GöREN, Şerif (1979): Almanya, Acı Vatan, Spielfilm, Türkei, Gülşah Film. 
Wie Frau Kutzer zieht Niyazi »Bilanz« seines bisherigen Lebens, das ähnlich fragil und heterogen wirkt. Zwei Leben habe er gehabt, zwei tief in ihm drin. Diese beiden Leben sind jedoch nicht Ergebnis seiner transnationalen Migration, sondern haben ihren Ursprung in der Binnenmigration in Istanbul, wobei Ören an keiner Stelle erwähnt, woher Niyazi ursprünglich stammt. ${ }^{162}$ Auch in Okans Отовӥs wissen wir nicht, woher die Türken kommen; in DöNüş ist die einzige Koordinate irgendein Dorf und ein einziges Mal fällt das Wort »Almanya«, ansonsten nur »Medeniyet« (»Zivilisation«) und die Namen von Dingen wie »Radyo» oder »Teyp« (Aufnahmegerät), die Ibrahim von dort mitbringt. Für Niyazi in Örens Poem war es die Schönheit des Bosporus, die sich wie eine »bunte Ansichtskarte [...] in die Mitte [seines] Lebens « hineingeklebt hat und die Lebensweise der Wohlhabenden, wie die des Ölkaufmanns Tarık Hakkı oder die der Amerikaner Williams und Miss Collins, die »Angestellte im PX« waren, im Istanbuler Stadtteil Bebek. ${ }^{163}$ Sie alle leben wie Amerikaner in Istanbul. ${ }^{164}$

Den Unterschied zwischen einem amerikanischen und einem türkischen Leben in der Türkei, den Vergleich von verschiedenen Lebensweisen kannten Niyazis Eltern noch nicht. Seiner Meinung nach waren sich die »Paschafamilien« (Adel), die Geschäftsleute und »die Armen [...] noch nicht so fremd, sie grüßten sich mit Respekt, unterhielten sich «. ${ }^{165}$ Alles begann 1946, als die »grünen Dollars«, Kaugummis, Whiskeys, Filme und Schallplatten kamen und mit ihnen eine neue Lebensweise. Da traten an die Stelle »der alten Herrenhäuser und Ufervillen« »die Betonblocks«. Niyazi ist migriert, um die Grenze zwischen denen aufzuheben, »die Süßigkeiten und Pasteten und denen, die unreife Melonen essen«. Warum er dies tue? Weil er ein Recht und einen Anspruch darauf habe und das, „was man Zivilisation nennt, übereinandergelegt die Summe der Arbeitskraft« aller sei, gleich welcher Herkunft. ${ }^{166}$ Wenn Frau Kutzer mit ihrem Alter gelernt hat, dass Jugend und Arbeit enden, so lehrt Niyazi die Migration, dass er ein Recht auf ein anderes und besseres Leben hat, weil er dieses bessere Leben aus den Filmen kennt.

162 Durch die beschleunigte Mechanisierung der Landwirtschaft setzte innerhalb der Türkei schon Mitte der 1950er Jahre eine große Binnenmigration ein. »Anfang 1958 lebten bereits etwa 522000 Bewohner der beiden Metropolen Istanbul und Ankara in illegalen Behausungen«. Bis zu einem gewissen Grad bildete die Arbeitsmigration ab 1961 nach Deutschland »die Fortsetzung der Binnenwanderung, da der größte Teil der Migranten außerhalb der türkischen Ballungsräume geboren war«. Siehe hierzu: Kreiser/Neumann (2009): S. 428 und S. 440. Siehe hierzu: KREISER/NEUMANN (2009): S. 428.

163 Ebd., S. 24.

164 Ören (1973): S. 25. Siehe hierzu: Kreiser, Klaus/Neumann, Christoph (2009): Kleine Geschichte der Türkei, Stuttgart: Reclam, S. 416.

165 Ebd.

166 ÖREN (1973): S. 27. 
In ähnlicher narrativer Diktion erzählt Ören von den Gastarbeiterinnen und Gastarbeitern Atifet, Halime, Kazım Akkaya, Sabri San und auch vom deutschen Arbeiter Klaus Fleck, die ähnliche Unterscheidungsmerkmale aufweisen wie die Figuren in Ylldiz' autobiografischem Roman. Atifet, die seit 1969 eine Freundin Niyazis ist und an Arbeiterdemonstrationen in Berlin teilnimmt, hat als politischer Mensch ein schwieriges Leben hinter sich. Nach Örens Beschreibung leidet sie auch unter dem gesellschaftlichen und politischen Wandel in der Türkei durch ihre Amerikanisierung und den Militärputsch 1960. Ohne Aussicht auf eine bürgerliche Arbeit verdient sie ihr Geld in Istanbul zwischen 1961 und 1965 als Prostituierte. Zu ihren Stammgästen gehören auch Amerikaner, 1967 wird sie Gastarbeiterin, arbeitet bei Siemens in Berlin und wohnt, »wo die Naunynstraße in den Oranienplatz mündet«. ${ }^{167}$ In einem bilanzierenden Selbstgespräch hält sie fest, dass sie sich in jungen Jahren an den Fotos der Filmstars orientiert habe, im Spiegel ihre »Pfirsich-Brüste« besah und im Spiegelbild zu den Fabrikbesitzern sprach: Sie hätten zwar Fabriken, sie aber Schenkel, und der Körper sei schließlich »was zum Anfassen «. ${ }^{168}$ Jetzt sei sie aber dran, »wie ein Boss, dem die Fabrik abgerannt ist«; mit dem großen Unterschied, dass ihr Körper nicht versichert sei und sie für ihn keinen Kredit aufnehmen könne. Sie ist nicht »zurückzubekommen, die Frische des Fleisches « ${ }^{169}$ Halime, eine direkte Nachbarin von Frau Kutzer, mit ihren »ungezogenen Kindern« wird als nächste beschrieben. Sie arbeitet bei Telefunken, ihr Mann sitzt angeblich wegen Blutrache in der Türkei im Gefängnis. Sie erhält einen Monatslohn von 500 Mark, schickt davon 75 Mark an ihren Mann, an ihre Mutter und an drei Schwestern. Sie ist 27, »klein und dick« und bringt dennoch Männer mit nach Hause. Wenn der Akt mit diesen vorbei ist, ziehen die Männer »ihre Mützen ins Gesicht und gehen mit Gepolter über die Treppe [...] Halime klemmt sich ein Handtuch in die Spreize / und rennt zum Abort, / in der Hand einen Henkeltopf mit warmem Wasser «. ${ }^{170}$

Kazım Akkaya, der letzte, der im dritten Kapitel vorgestellt wird, und neu in die Naunynstraße zieht, ist bei der Arbeit »der Liebling des Meisters«, wie er selber sagt. Über ihn wird eine Reportage gedreht, die der Fernsehreporter Fritz Zimmermann auch wirklich realisiert. ${ }^{171}$ Wenn die anderen ihre neun Stunden pro Tag arbeiten, arbeitet er elf und »redet nicht mal davon«. Die Deutschen sind für ihn zu bequem, hochnäsig und der Überfluss hat ihnen die »Köpfe verschmiert«. Er ist gekommen, weil die Arbeit in der Türkei weniger wurde und der Wert des

167 Ebd., S. 28.

168 Eine hierzu analoge Filmszene gibt es auch in SHIRINS HocHzeIT.

169 ÖREN (1973): S. 30.

170 Ebd., S. 31.

171 Ebd., S. 32. 
Geldes immer mehr fiel. Werften wurden zu Friedhöfen und auch die Busagentur, die er Anfang der 1960er gründete, musste nach drei, vier Wochen der stärker gewordenen Konkurrenz weichen. Dabei wurden »störrische Agenturbesitzer sogar mit Kugeln um die Ecke gebracht «. ${ }^{172}$ Am 7. Mai 1971 ist er nach Berlin in die Naunynstraße gekommen. »Ich habe vor, einen Bus zu kaufen oder einen LKW. Ob das oder das, in dieser Frage habe ich mich noch nicht entschieden $«{ }^{173}$ Dem Fernsehreporter sagt er zum Schluss, dass er nächste Woche kommen solle, um seine Wohnung zu filmen. Dann werde er wieder von seinem Leben erzählen, das wie ein Film selbst sei, und »ihr dreht Bilder von mir, auf denen ich mich gut mache «. ${ }^{174}$ Im zweiten Band des Poems Der kurze Traum von Kağthane wird Kazim Akkaya gekündigt und ehemalige Kollegen von ihm treffen ihn in der Straßenbahn gebeugt nach Weinbrand riechend. ${ }^{175}$

Mit Sabri San, dem letzten türkischen Gastarbeiter, der vorgestellt wird, verhält es sich anders. In Gesprächen mit Niyazi, macht dieser ihm klar, dass das ganze Sparen für die Zukunft nichts bringe. »Denn die Räder dieses Systems / drehn sich nicht für uns, [...] Was wir gespart haben, / ohne zu essen, ohne zu trinken, ohne was zu erleben, / wird in die Taschen von anderen fließen. ${ }^{176}$ Es kann nur noch darum gehen, im Kampf die eigenen Rechte zu erweitern, um am Glück dieser Welt zu partizipieren. Obwohl Sabri San nicht genau begreift, was ihm Niyazi deutlich zu machen versucht, »[frißt] sich ein verrosteter Bohrer / durch seinen ganzen Körper / von der Schädelkammer / bis zur Herzmitte«. Er verliert die Orientierung, will nicht mehr arbeiten, lässt sich krankschreiben und läuft tagsüber von Straße zu Straße, ganz »ohne Ziel«. Schließlich erkrankt er an Tuberkulose und steht am Ende des vierten Kapitels wie »eine Pappel, kummerbeladen« am Flussufer des Berliner Landwehrkanals.

Von einer Sinnkrise wird auch der Deutsche Klaus Fleck heimgesucht, der letzte Arbeiter, der im ersten Band dieses Poems vorgestellt wird. Wie bei allen anderen wird auch seine Biografie im Wechselspiel zwischen auktorialer und personaler Erzählweise wiedergegeben. Im Unterscheid zu Sabri ist sein Leben von Jugend an von Konsum bestimmt, vom Kaufen von Mofas, Motorrädern, später kommen mit der Ehe dann Geschirrspülmaschinen, Kühlschränke, Einbauküche dazu und erste Familienurlaube »mit dem Flugzeug «. ${ }^{177}$ Dies alles drückt Klaus Fleck aber die »Luft ab«. An seinen Freitagabenden in der Eckkneipe grölt und flucht er, ob das

172 Ebd., S. 33.

173 Ebd., S. 34.

174 Ebd., S. 34.

175 ÖREN, Aras (1974): Der kurze Traum von Kağıthane, Berlin: Rotbuch, S. 22.

176 ÖREN (1973): S. 40.

177 Ebd., S. 46. 
denn alles sei, »wofür wir leben«? »Unsere freiheitlich-demokratische-Ordnung schützen«, heißt es in der Presse und in den Medien immer wieder. Klaus Fleck dagegen, "von wegen Demokratie / von wegen Recht «. ${ }^{178}$ Was kümmert es ihn. Bier, hinterher Kirschlikör und nochmal Bier. „Das ist das Leben. « Als Gesprächspartner für die Kneipenabende holt er sich Ali, »seinen Freund«, von der Straße hinzu, der eigentlich unterwegs ist von der Arbeit zu seiner Frau Nermin. Zuvor hat Ali ein paar Faustschläge von seinen Vorarbeitern erhalten, weil er nach der Arbeit die Mülltonnen nicht hinter das Fabrikgebäude bringen wollte. Ali schwört sich, erwische er die beiden oder einen anderen Deutschen einmal in seinem Dorf Acıbayram, dann werde es für sie kein Entkommen geben. Nun sitzt er vor Klaus, der sich frustriert in Rage redet und Ali anschnauzt, er könne »ja nicht mal richtig quatschen«, er sei ein »dreckiger Ausländer« und was er denn überhaupt hier wolle. Dabei schlägt Klaus Ali mehrmals ins Gesicht. ${ }^{179}$ Später wird die Polizei Alis Frau Nermin darüber benachrichtigen, dass ihr Mann verletzt im Krankenhaus liege und einen Deutschen, Klaus Fleck, totgeschlagen habe. »Der Totschlag sprach sich schnell rum / in der Naunynstraße. / Alles fiel über die Türken her. « ${ }^{180}$ Und es »schneit in der Naunynstraße. Die winzigen Blutspuren / auf dem Gehsteig / sind längst gefroren ${ }^{181}$

Diesem fremdenfeindlichen Ausbruch von Gewalt und Gegengewalt folgt in den abschließenden Kapiteln 6 und 7 in Was will Niyazi in der Naunynstraße eine heterogene Abfolge von zwischenmenschlicher Distanz, existenzieller und solidarischer Nähe zwischen Alteingesessenen und Zugewanderten. So überlegt sich Frau Meier lange, ob sie in ein neu eröffnetes türkisches Geschäft gehen solle, denn eigentlich findet sie, dass die Türken »nach Hause gehen sollen und da ihre Läden aufmachen. Unsere schließen und die machen auf «. ${ }^{182}$ Der Verkäufer Mehmet überredet sie, einzutreten. Er denkt sich, dass sie sich doch nicht so zieren solle, diese Deutschen seien sowas von geizig, "sind unsere doch leichter bei der Hand «. ${ }^{183}$ An diesen Kontakt zwischen Alteingesessenen und Migranten schließt sich das Gespräch zwischen Kazim und einem anderen Gastarbeiter an, in dem es um mögliche freiwerdende Wohnungen geht, weil die alten Deutschen - »die Alte auf meiner Etage macht's nicht mehr lange« - bald sterben und ihre Wohnungen frei werden.

178 Die politische Lösung Willy Brandts »mehr Demokratie wagen« aus seiner Regierungserklärung vom Oktober 1969 ist Anfang der 1970er Jahre für die Bundesrepublik in Medien und Debatten ein sehr wirkmächtiges Narrativ. Siehe hierzu: Wolfrum, Edgar (2006): Die geglückte Demokratie. Geschichte der Bundesrepublik von ihren Anfängen bis heute, Stuttgart: Klett-Cotta.

179 ÖREN (1973): S. 48.

180 Ebd., S. 53.

181 Ebd.

182 Ebd., S. 57.

183 Ebd., S. 58. 
In diesen Dialog zwischen Kazim und seinem Freund mischt sich der Erzähler und Chronist dieses Poems ein. „Was für ein Vorgang ist das, / daß wir einer auf des anderen Leiche steigen, / um zu bestehen? / Wer weiß, wieviel Leute das / gleiche wollen und doch, / ohne es zu merken, / gräbt einer das Grab des andern. « ${ }^{184}$

Die wechselseitige soziale Kälte, die sich hier mit moralischer Intervention im vorletzten Kapitel ausdrückt, wird mit dem letzten Kapitel wieder zurückgenommen. Denn kurz vor ihrem Tod kritisiert Frau Kutzer sich selbst: Es sei ein Trugbild gewesen, so leben zu wollen, wie die reiche Dame aus Neukölln, denn diese habe sicher nie an sie gedacht. Und für sich allein könne man nicht leben, ohne eine Beziehung zu anderen $\mathrm{zu}$ haben. Was sie sich nun wünsche, sei Macht, »das alles so zu verändern, wie ich es will, / aber so, dass diese Veränderung / nicht auf Kosten der anderen geht «. Das war, so denkt sie, auch der Kampf ihres Mannes. ${ }^{185}$

So wie es für Frau Kutzer zwei Seiten zwischen Konsumwünschen und Solidarität gibt, gibt es sie auch für den Eingewanderten. Die Häuser in der Naunynstraße drehen zwar mit der Vorderfront den Migranten den »Hintern zu, wie stumpf gewordene Transportarbeiter«. Wenn sie aber in die Hinterhöfe treten, »dann fühlst du, dann schmeckst du, dann riechst du was in der Luft liegt. [...] dass hier die Klasse ist, die die Regeln dieser Gesellschaft zerschlagen / und neu bauen wird «. ${ }^{186}$ Mit Horst Schmidt, dem Nachbarn von Frau Kutzer, plant Niyazi diese Klasse zu schaffen. Sie müssen sich zusammentun und allen zeigen, »wie es heute ist und morgen, wie wir frei werden«. Das einzige Problem sieht Niyazi darin, dass die Türken aus der Türkei einen anderen Klassenbegriff haben als die Deutschen, denn »viele fühlen sich / noch nicht mal als Arbeiter«. In ihren Dörfern haben sie "geschuftet wie Vieh« für den Großgrundbesitzer. ${ }^{187}$ Man müsse ihnen erst einmal zeigen, »wie sie zu dem kommen, was ihr Recht ist. / [...] Überall, wo man ihnen das Recht wegnimmt, das ihnen zusteht«, hält eine eigene Aussage Niyazis Horst Schmidt fest. Mit zwei Briefen eines griechischen und eines türkischen Gastarbeiters aus der Naunynstraße endet Was will Niyazi in der Naunynstraße. Der erste Brief ist an den Herrn Senator für Arbeit und Soziales von Berlin und der zweite an Herrn Hoffmann vom Arbeitsamt II gerichtet. Darin werden Wohnungen für Gastarbeiter und ein anderes Verhalten ihnen gegenüber gefordert. ${ }^{188}$ Denn wie »jedes Tier einen Unterschlupf«, brauche auch der Mensch eine Wohnung und da man ebenso wie jeder andere Arbeiter zusammen für

184 Ebd., S. 59.

185 Ebd., S. 56.

186 Ebd., S. 64.

187 ÖREN (1973): S. 66. Siehe hierzu auch folgende türkische Filme: YıLMAZ, Atif (1978): Kibar Feyzo, Spielfilm, Türkei, Arzu Film; EĞILmEz, Ertem (1980): Banker Bilo, Spielfilm, Türkei, Arzu Film.

188 ÖREN (1973): S. 67-69. 
die Reichen Geld mache, verstehe man nicht, warum der Gastarbeiter schlecht behandelt werde. ${ }^{189}$

So unterschiedlich, wie die Rezeption zu Sanders-Brahms’ Film SHIRINS HocHZEIT ausfiel, so sehr unterscheiden sich auch die wissenschaftlichen Reflexionen zu Aras Örens Poem von den 1980ern bis heute. In Schreiben gegen Vorurteile hält Monika Frederking fest, dass die bipolare Dichotomie von Recht und Unrecht sowie der Fokus auf die ökonomischen Umstände dominiere. Ören betone die »ökonomischen Verhältnisse gegenüber den Charaktermerkmalen einer Figur«, und die Ursachen für »falsche Bewusstseinsvorgänge lägen in den jeweiligen ökonomischen Verhältnissen «. ${ }^{190}$ Aufgrund dieser für Frederking spezifisch »sozialistischen Weltanschauung « und politischen Diktion, erfolgen auch die Kontakte und »Annäherungen« von Alteingesessenen und Zugewanderten kontingent und nebenbei. So gebe Örens Literatur zwar den deutschen Lesern »Anregungen zu Problemen der Migranten«, trage insgesamt aber »nicht zu einer Vorstellung eines deutsch-ausländischen Miteinanders bei «. ${ }^{191}$ Ebenso könne die gesamte Trilogie nicht als Identifikationsangebot für Örens »Landsleute« dienen, da die drei Bände ausschließlich auf Deutsch erschienen seien. ${ }^{192}$

Im Gegensatz zu dieser Einschätzung sieht Irmgard Ackermann in ihrem programmatischen Text Integrationsvorstellungen und Integrationsdarstellungen in der Ausländerliteratur Aras Örens Poem als hochintegrativ an. Obwohl der Begriff »Integration« darin gar nicht auftauche, sei Was will Niyazi in der Naunynstraße implizit davon durchdrungen. ${ }^{193}$ Die Integration macht sie jedoch nicht am Austausch oder an einer ganzheitlichen Konzeption des Zusammenlebens fest, sondern an der Aneinanderreihung von Einzelschicksalen, wie sie es nennt, von Niyazi über Sabri San bis Halime. Ihr Zugang verläuft also nicht entlang des Austauschs und Kontakts

189 Ebd., S. 68f.

190 Frederking, Monika (1985): Schreiben gegen Vorurteile, Berlin: Express Edition, S. $64 \mathrm{f}$.

191 Ebd., S. 129.

192 Aras Ören hat Was will Niyazi in der Naunynstraße zunächst auf Türkisch verfasst und dann im Rotbuch-Verlag auf Deutsch 1973 publizieren lassen. Die Übersetzung hat er selbst mitbetreut. Die türkische, ursprüngliche Fassung des Textes erschien nach der Vollendung der Trilogie mit Die Fremde ist auch ein Haus (1980, Rotbuch) 1980 im Istanbuler Verlag Remzi Kitabevi als Berlin Üclemesi (»Berliner Trilogie«). Siehe: ÖREN, Aras (1980): Berlin Üçlemesi, Istanbul: Remzi Kitabevi. Aras Örens literarisches Schaffen war keineswegs allein für den deutschen Buchmarkt gedacht. Dies zeigt auch, dass fast alle seine Texte zur türkischen Migration nach Deutschland in der Türkei ebenfalls erschienen sind. Siehe hierzu: http://www.arasoeren.de/veroeffentlichungen/veroeffentlichungen-auf-tuerkisch/ (17.08.2016). Dies gilt ebenfalls für die Autoren Yüksel Pazarkaya, Güney Dal und seit den 2000er Jahren auch für Zafer Şenocak.

193 ACKERMANN, Irmgard (1984): »Integrationsvorstellungen und Integrationsdarstellungen in der Ausländerliteratur «. In: Zeitschrift für Literaturwissenschaft und Linguistik 56, S. 23-39, hier S. 32. 
zwischen Alteingesessenen und Migranten, sondern anhand der biografischen Skizzierungen, die im Wandel sind. Diese würden auf verschiedene Stufen der Integration verweisen, letztlich nach Ackermann auf eine Form der »Prozessintegration«. Denn kaum eine Person im Poem sei noch dieselbe, nachdem sie »die Türkei verlassen hat «. Nach Ackermann lernen und denken die Personen in Örens Poem um, sie durchleben einen Bewusstseinswandel, »der auf der persönlichen Ebene doch nichts anderes bedeutet als eine Prozessintegration «. ${ }^{194}$ Der Wandel, den Ackermann in ihrer Analyse konstatiert, wird als derjenige begriffen, dass die Personen sich bewusst werden, dass sie Rechte haben. Integration ist demnach zu verstehen als »eine selbstständige Interessenvertretung einer multikulturellen Gesellschaft bei weitgehendem Spielraum in der persönlichen Anpassung «. ${ }^{195}$

Ob der Wandel, der in Örens Poem mehr programmatisch und pädagogisch als bewusstseinsfördernd dargestellt wird, und ob die Gemengelage von sozialem Zusammenhalt und sozialem Ausschluss in Was will Niyazi in der Naunynstraße so stabil ist, dass von geschlossenen Einzelschicksalen und zugleich von einer allgemeinen Interessensfindung gesprochen werden kann, ist äußerst fraglich. Wohin die Prozessintegration eigentlich führen soll, lassen Ackermann und das Poem selbst offen. Diese Bewegung konstatiert auch Bekir Yıldız für sich selbst und seine Gastarbeiter Mitte der 1960er, und er lässt sie, wie Ören und Ackermann, ebenfalls offen. ${ }^{196}$ Zwanzig Jahre nach Ackermanns Interpretation meint die amerikanische Historikerin Rita Chin, dass sich in Aras Örens Poem-Trilogie eine »broader reconceptualisation of West German Identity and culture itself [...] « artikuliere. ${ }^{197}$ Diese Konzeptualisierung gelinge Ören, weil die Migrantenfiguren in seinem Poem im Unterschied zu zeitgleich entstandenen Texten und Filmen, wie in Heinrich Bölls Gruppenbild mit Dame (1970) oder in den Filmen Rainer Werner Fassbinders Katzelmacher (1969) und ANGST ESSEN SeELE AuF (1973) keine »abstract figures with no individual identities « seien. Im Gegenteil zeige er mit Niyazi und Sabri Figuren »with specific histories, dreams, plans, and disappointments«. Dadurch gelinge ihm - so Chin - die Kopplung von »ethnic tensions within West Germany's diverse working class «; ${ }^{198}$ eine Kopplung, die bei Fassbinder angeblich nicht zu finden sei. Für Chin entwirft Ören mit seiner Literatur der 1970er Jahre, bevor der Begriff des Multikulturalismus überhaupt

194 Wir werden sehen, dass dies mitnichten der Fall ist, ohne dass dieser Befund diese Literatur abwerten würde. Eine vermeintlich stabile Innerlichkeit ist in kaum einer Literatur oder Filmproduktion Ende der 1960er und 1970er gegeben.

195 Ebd., S. 33.

196 Siehe hierzu: YiLdiz (1966): S. 39.

197 CHIN (2007): S. 84f.

198 Ebd., S. 71. 
Eingang in Forschung und Literatur erhält, die erste Imagination und Reflexion eines »distinctly German mode of multiculturalism «. ${ }^{199}$

Diese voneinander abweichenden Interpretationen von Aras Örens Text und die damit verbundenen Perspektivierungen auf Vermittlung oder Nicht-Vermittlung, auf repräsentative Einzelschicksale, auf Integration oder die Darstellung einer multikulturellen Gesellschaft durch Akteure mit Migrationshintergrund sind, wie in diesem Buch noch gezeigt wird, besonders den Narrativen „Wie lebt es sich als Türke in Deutschland?“ der 1980er Jahre und „Was lebst Du?“ der ersten Dekade des 21. Jahrhunderts in ihrer bestätigenden wie auch kritisierenden Form eigen. Die Stärken des Poems und letztlich sein Erfolg - es war der »secret Bestseller « der deutsch-türkischen Literatur der 1970er, aus dem der SFB zwei TV-Dokudramas und Hörspiele realisiert hat - haben meiner Meinung nach andere Grundlagen als die des Kontakts, Austauschs, der Integration oder der Darstellung einer multikulturellen Gesellschaft im Sinne der späteren Dekaden. Was will Niyazi in der Naunynstraße hängt in seiner narrativen Struktur mit Sanders-Brahms' Film, mit Fassbinders ANGST ESSEN SEELE AUf und ebenfalls mit Heinrich Bölls Gruppenbild mit Dame zusammen.

Um diese Grundlagen genauer zu untersuchen, hilft es, zunächst einen Blick auf die zeitnahe Rezeption von Aras Örens Poem selbst zu werfen. Diese sieht in Örens Text im Unterschied zu Frederking sehr wohl eine Form der Vermittlung und des Kontakts zwischen Alteingesessenen und Migranten, jedoch keine der Einzelschicksale, auch keine der Integration (Ackermann) oder eine Darstellung einer multikulturellen Gesellschaft (Chin). Dekaden später und vor allem heute wird das Stück als erste literarische Chronik zum Zusammenleben von Deutschen und Türken, ${ }^{200}$ oder als Darstellung des türkischen Lebens in Deutschland ${ }^{201}$ begriffen. Das Zusammenleben wird jedoch in den 1970ern anders ausbuchstabiert als in der Diktion der 1980er, wo es um das Verstehen geht, oder wie heute, wo die Darstellung und Verhandlung von Diversität im Vordergrund stehen. In den Rezeptionen der 1970er Jahre ist die Rede vom Verweben und Verbinden zweier Seiten. Es sei bewundernswert, »wie ein Schriftsteller aus Istanbul voller Souveränität, Ironie und einfühlsamer Kenntnis etwa im Lebensbild einer Berliner Proletarierwitwe und Kleinbürgerin, Niyazis Vermieterin ${ }^{202}, 60$ Jahre deutscher wie türkischer Geschichte

199 Ebd., S. 85.

200 STUBERGER, Ulf (1974): »WWir machen szammen Geld für die Fabrika Direktor ...«. In: Deutsche Volkszeitung, 17.01.1974.

201 Drewitz, Ingeborg (1973): »Poem von den Kreuzberger Türken«. In: Der Tagesspiegel, 16.12.1973.

202 Wie oben dargestellt, handelt es sich bei Frau Kutzer nicht um Niyazis Vermieterin, sondern um seine Nachbarin. 
und Geschichten miteinander verwebt «. ${ }^{203}$ Oder der Dokumentarfilmer Friedrich Zimmermann, der aus Aras Örens Poem die zwei Dokudramen für den SFB realisierte - eines über Frau Kutzer und eines über Kazım Akkaya ${ }^{204}$ - hält zur literarischen Vorlage fest: diese kreise keineswegs nur um das »Türkenproblem «, sondern auch um die »Sorgen und Nöten alter Leute, mit ihrer Einsamkeit am Rande unserer Wohlstandsgesellschaft ${ }^{205}$ Auf diese Weise verbinden auch die beiden Dokudramen mit den Titeln Frau Kutzer und ANDERE BEWOHNER DER NAUNYNSTRASSE (1973, 51 Min.) und KAZIM AKKAYA UND DIE BEWOHNER DER NAUNYNSTRASSE (1975, 58 Min.) zwei unterschiedliche Zugänge in die Naunynstraße. Örens Literatur wird eher als eine verbindende, denn als vermittelnde begriffen. So ist es auch möglich, ihn zugleich als Poet der Arbeiter und als Poet der Gastarbeiter zu begreifen. Weder der Begriff der Integration noch der der multikulturellen Gesellschaft taucht in der Rezeption der 1970er auf. Nicht weil sie unbedingt fehlen würden, sondern weil man sie nicht brauchte. Das Poem Was will Niyazi in der Naunynstraße wird als ein Text über Türken und Deutsche, letztlich als »Zeitgeschichte« begriffen. ${ }^{206}$ Den letzten Satz in Friedrich Zimmermanns erstem Dokudrama spricht die Schauspielerin Dorothea Thieß, die Frau Kutzer verkörpert und deren Leben bilanziert: »Die Jahre sind wie Schluchten, die ich hinter mir hab, / wenn ich mich umsehe, wird mir schwindlig ${ }^{207}$

\subsection{Integration als Orientierung}

Die Fragilität von Biografie und Historie in Örens erstem Band, die narrative Abfolgelogik, dass es vor der Migration der Türken in die Naunynstraße eine andere, eine deutsche Migration in die Berliner Naunynstraße gab und die Ähnlichkeit und Vergleichbarkeit der Bedürfnisstrukturen auf deutscher wie auf türkischer Seite, prekarisieren nationale und kulturelle Zuschreibungen, wie dies bereits in Helma Sanders-Brahms' SHIRINs HochzEIT der Fall war. Ebenso wie

203 BeCKer, Peter von (1974): »Türken in Deutschland. Kurzer Traum vom langen Abschied. Aras Ören: ein Dichter unserer größten Minderheit«. In: DIE ZEIT, 29, 15.07.1974, S. 38, Hervorhebung im Original.

204 Die beiden Dokumentarfilme würde man heute als »Docufictions« bezeichnen.

205 Sieben, Irene (1973): »Frau Kutzer und Niyazi aus Istanbul. Filmszene aus Kreuzberg: Wie leben Deutsche und Türken zusammen?«. In: Berliner Morgenpost, 25.05.1973. R. W. Fassbinder hält als eines seiner Hauptanliegen für ANGST ESSEN SEELE AUF fest, Empathie für beide seiner Protagonisten zu empfinden. Siehe hierzu: GöKTÜRK u. a. (2009): S. 277.

206 Olic, Ivika (1973): »Die Dame von der Naunynstraße«. In: Der Tagesspiegel, 30.09.1973.

207 SIEBEN, Irene (1973): »Frau Kutzer und Niyazi aus Istanbul. Filmszene aus Kreuzberg: Wie leben Deutsche und Türken zusammen?«. In: Berliner Morgenpost, 25.05.1973. 
im Film sind es in Örens Text erstens ein Wechsel aus dokumentarischer und poetischer Diktion, zweitens das Auftauchen zahlreicher Personen, die kurz biografisch skizziert werden als nicht-einheitliche Gruppe wie in Yıldız autobiografischem Roman, drittens die Sichtbarkeit und Einbindung der Dinge und die mit ihnen verbundenen Bedürfnisse der Akteure, und nicht zuletzt die Dominanz von Transitorten (Straße, Treppenhaus, kleine, enge Wohnungen, Arbeitsplätze, Läden) und bei SHIRINS HochzEIT im Besonderen das Arbeiterwohnheim, die ein Ankommen, auch als ein Zu-Ruhe-Kommen, erschweren. Die Orte im Film und Text sind von einer »Unwirtlichkeit« geprägt, die eine »Kunst, zu Hause zu sein ${ }^{208}$ nicht entstehen lassen.

Das Nicht-Vorhandensein innerer und wohnlicher Räume bei Sanders-Brahms und Ören zeigt sich schon an den Anfangssequenzen und Anfangsstrophen. Auf Niyazis Gang zur Arbeit in die Nachtschicht folgt die existenzielle und biografische Unruhe im Bett bei Frau Kutzer. Auf Shirins Aussage, dass das ihr Land sei, sagt die Stimme aus dem Off, dass es das Land des Großgrundbesitzers, des Aghas (Ağa) sei, das sie und ihre Familie bewirtschaften müssen. Niyazi arbeitet ebenso wenig für sich: Von seiner Arbeit wird den Reichen im Süden der Stadt warm und er ist aus Istanbul weggegangen, weil er nicht so leben kann, wie die wohlhabenden Türken und Amerikaner im Istanbuler Stadtteil Bebek. Niyazi ist auf der Straße unterwegs, Shirin sammelt in den ersten Einstellungen Steine auf dem Feld. Auch in Şorays Film DöNüş wird in den meisten Sequenzen gearbeitet, entweder auf dem Feld, beim Brunnen am Dorfplatz oder in den wenigen Aufnahmen zu Hause.

Obwohl die Einfühlung in die Charaktere in SHIRINS HochzeIT über die VoiceOver-Narration und in Was will Niyazi in der Naunynstraße über die bedürfnisorientierten biografischen Skizzierungen vordergründig zu sein scheinen, wird in beiden Medien dieser Ansatz einer Innen/Außen-Unterscheidung immer wieder von einer sozialstrukturellen und materiellen Oben/Unten-Unterscheidung unterbrochen und gebrochen. Es gelingt weder über eine Liebesgeschichte noch über die Artikulation von Bedürfnissen, einen stabilen Innenraum aufzubauen und mit ihm souveräne Akteure zu setzen, die die soziale und industrielle Welt gegen die soziale Ungleichheit ordnen könnten. Alle Protagonisten in SHIRINS HochzeIT und in Was will Niyazi in der Naunynstraße sind isoliert, auch wenn im Film und im literarischen Text dialogische Modi wie das intime Gespräch (Sanders-Brahms) oder die Ähnlichkeit existenzieller Bedürfnisstrukturen (Ören) zwischen türkischen und deutschen Akteuren bemüht werden.

208 MitsCherLich, Alexander (1965): Die Unwirtlichkeit unserer Städte. Anstiftung zum Unfrieden, Frankfurt a. M.: Suhrkamp, S. 10. 
Shirin ist isoliert, weil außer der solidarischen Frauengemeinschaft, die im Film zerbricht, keine andere stabile soziale Einheit wie Familie oder eine mögliche nationale oder religiöse Identität aufscheint. So wie sich diese solidarische Struktur nicht schaffen lässt, gelingt es bei Ören nicht, dass man irgendwann wie Amerikaner (Niyazi) oder einfach über seine Verhältnisse hinaus lebt (Kutzer). Die Frage, ob ein Neuanfang in der Naunynstraße gelingen wird, beantwortet weder der erste Band der Berlin-Trilogie noch der zweite oder dritte. Im zweiten Band, Der kurze Traum aus Kağithane ${ }^{209}$, stehen im Vordergrund die Beschreibung der Anwerbung und der Umstände und Situationen in den Verbindungsstellen in Istanbul vor dem Anwerbestopp im November 1973. Darin fokussiert Ören, ebenfalls in einer Mischung aus Dokumentation und Introspektion, die türkische Arbeitsmigration nach Deutschland und den »kurzen Traum«, den die Arbeitsmigranten im armen Istanbuler Stadtteil Kağıthane als Herkunftsort oder als Zwischenstation von Deutschland erträumen. Erst im abschließenden dritten Band Die Fremde ist auch ein Haus, der 1980 erscheint, findet die migrationsspezifische Unterscheidung zwischen Heimat und Fremde Eingang in die Literatur Aras Örens. Erst mit diesem letzten Band wird das Poem zu einer Migrationserzählung, in dem die Eltern der Gastarbeiter auch als Eltern beschrieben werden, die Herkunft und Ankunft voneinander trennt und als heimatlose identifiziert. Mit dieser inhaltlichen, erzählerischen sowie topografischen Modifikation werden Bedürfnisse und Praktiken der Akteure verstärkt über die Bestimmungen von Situationen und Verhaltensweisen hinaus, im Übergang vom zweiten zum dritten Band mit nationalen und kulturellen Bindungen gerahmt. Im Zentrum steht dabei besonders das Verhältnis zwischen den Generationen. Damit geht eine zentrale narrative Verschiebung einher, die den Übergang in die Literatur und den Film der 1980er Jahre einleitet, die aber auch die Forschungs- und Debattenstruktur zu Ausländern in Deutschland bestimmen wird, der wir uns im dritten Kapitel »Der Ausländer und sein Volk« widmen werden, das unter dem Narrativ »Wie lebt es sich als Türke in Deutschland? « steht. Şerif Görens Film Almanya, Aci VATAN von 1979 zeigt diesen Übergang als einen Bruch und als eine Kollision zweier gegensätzlicher Orientierungen auf, mit dem ich mich im Fazit dieses Kapitels auseinandersetzen werde.

In SHIRINS HochzeIT und in Was will Niyazi in der Naunynstraße werden Bedürfnisse und Praktiken der Akteure nicht explizit an Herkunfts- oder an Ankunftsgesellschaften gebunden, sondern an Straßen, an andere Akteure oder an Dinge. Beispielsweise wird Shirins Gesicht am Anfang des Films in den Berg, durch den sie sich im weiteren Verlauf des Films versucht, metaphorisch durch-

209 Kağıthane ist ein Stadtteil auf der europäischen Seite der Stadt Istanbul. Kağıthane bedeutet auf Türkisch »Kartenhaus«. 
zugraben, eingeblendet und sie scheinen beide - Berg und Shirin - eins zu sein und zusammen zu gehören. Mit dem topologischen und narrativen Zusammenfall und dem zugleich einsetzenden universellen Liebesmärchennarrativ ist die hier gezeigte Last keine rein kulturelle, sondern auch eine materielle und praxeologische. Diesem fiktiv-erzählerischen Einstieg folgt eine dokumentarische Diktion im Film vom Dorfleben über die Istanbuler Arbeiterverbindungsstelle bis zum Arbeiterwohnheim in Köln. Und erst nach dieser dokumentarischen Abfolge rückt die Protagonistin mit Nahaufnahmen wieder in den Vordergrund. Beides, die »Unwirtlichkeit« des öffentlichen Raums und die isolierten Akteurinnen und Akteure, bestimmen inhaltlich, im Einsatz der filmischen Settings und der Location, auch ein Gros der Filme des Neuen Deutschen Films. Diese reichen von Alexander Kluges ABSCHIED von GESTERN (1966), Volker Schlöndorffs TöRLESS (1966) bis hin zu DeUTsChland IM HeRBst (1978) von Katja Rupé. ${ }^{210}$

Als Struktur impliziert diese Erzählform weder eine Versammlung in der Herkunfts-, noch in der Ankunftsgesellschaft. Es bleibt bei einer Ansammlung, die für die Arbeitsmigranten wie auch für die Alteingesessenen gilt. Hinter dem, was gezeigt wird, gibt es sozusagen keinen Raum, keine Straße. Oder wie Rainer Werner Fassbinder es für seine zeitgleich entstandenen Filme und im Besonderen für Katzelmacher und ANgst essen SEele auf festgehalten hat: »Es ist alles einfach so da, wie es da ist «. ${ }^{211}$ In Sanders-Brahms’ Film, in Örens Poem und in den anderen genannten Produktionen begegnet uns eine narrative Abfolge, die in ihrer Dynamik und Tendenz endogen und immanent strukturiert ist. Äußerst eindrücklich zeigt sich diese endogene Struktur in Türkan Şorays Film DöNüş. Denn es ist nicht nur so, dass der Großgrundbesitzer wie ein Westler lebt, mit lasziv aussehenden Frauen Alkohol konsumiert, sondern auch dieselbe Position hat. Zu Anfang des Films gibt es eine Einstellung, in der wir wieder arbeitende Frauen auf dem Acker sehen, doch im vorderen Teil des Bildes sitzt der Großgrundbesitzer auf einem Pferd und blickt auf die arbeitenden Frauen herunter, im Besonderen auf Gülcan. Von niemandem sehen wir ein Gesicht. In Gülcans Gesicht wird der Großgrundbesitzer jedoch später im Film mehrfach sagen, dass »wir am Ende sehen werden, wem diese Welt gehört, Dir oder mir«. Diese Einstellung und die daran anschließende Auseinandersetzung zwischen dem Großgrundbesitzer und Gülcan ist deshalb von besonderem Interesse, weil sie modifiziert in den 1980er und 2000er Jahren wieder auftaucht, dann allerdings nicht

210 Siehe hierzu: KLuge, Alexander (1965/66): Abschied von Gestern, Berlin/West: Independent Film GmbH. SchlöNDoRfF, Volker (1965/66): Der junge Törless, München: Franz Seitz Filmproduktion. RupÉ, Katja (1977/78): Deutschland im Herbst, München: Project Filmproduktion im Filmverlag der Autoren GmbH.

211 TöTEBERG, Michael (2002): Rainer Werner Fassbinder, Reinbek: Rowohlt, S. 44. 
mehr endogen ausgerichtet. In den 1980er Jahren fehlt bei der Aufnahme von arbeitenden türkischen Frauen im Dorf der Großgrundbesitzer und folglich die Auseinandersetzung mit ihm. An seine Stelle wird die traditionelle repressive türkische Kultur treten, die wir im Gegensatz zum Bild in DöNüş nicht im selben Bild werden sehen können. ${ }^{212}$ Allein, weil sie sich nicht in Personen materialisiert, sondern als ein geschlossenes System vielmehr diese Personen spaltet.

In den 1960er und 1970er Jahren ist die Kritik am Ist-Zustand eine immanente Frage, die sich auch in den soziologischen Reflexionen Lockwoods zeigt. Er beschreibt Integration als einen emergenten Prozess zwischen System- und Sozialintegration. ${ }^{213}$ Und aus heutiger historischer Perspektive sind sie mit dem Ergebnis des Zeithistorikers Sven Reichardt vergleichbar, der das linksalternative Subjekt in den 1970er Jahren als eines beschreibt, das weder ein klares Opfer noch ein klarer Gegenspieler von Machtinterventionen und Konsum, weder ein willenloser Akteur »von Einschreibungsprozessen noch [ein] vollkommen autonomer Akteur des eigenen Lebens « war. ${ }^{214}$ Es ist letztlich diese antipodische Struktur der Akteure in Örens Poem sowie in Sanders-Brahms' Film, die die migrationsspezifischen Narrative von Herkunft und Ankunft nicht stabilisieren lassen. So verweist beispielsweise Shirins letzte Aussage, bevor sie irgendwo im Niemandsland in der Nähe von Köln stirbt, dass sie nach Hause zurück will, auf keine Heimat oder Ankunft, die es wirklich für sie gibt. Der Artikulation von Bedürfnissen entsprechen kaum gesellschaftliche oder soziale Zustände und vice versa. Aus integrationstheoretischer Perspektive ist dieser Mangel an Äquivalenz der Tatsache geschuldet, dass die Grundlage von Integration, nämlich die Migration, offensichtlich nicht erfolgt. Der Migrationshistoriker Jochen Oltmer definiert Migration heute als einen »auf einen längerfristigen Aufenthalt angelegte räumliche Verlagerung des Lebensmittelpunktes von Individuen, Familien, Gruppen oder auch ganzen Bevölkerungen «. ${ }^{215}$ Nach dieser Definition sind der zentrale Aspekt und die Grundlage der Migration die »Verlagerung des Lebensmittelpunktes «. ${ }^{216}$ Weder in Bekir Yıldız' autobiografischem Roman, in Türkan Şorays, Tunç Okans

212 Siehe hierzu: EzLI, Özkan (2013): »Narrative der Integration und Assimilation im Film «. In: Die Integrationsdebatte zwischen Assimilation und Diversität. Grenzziehungen in Theorie, Kunst und Gesellschaft, hg. v. Özkan Ezli, Andreas Langenohl, Valentin Rauer, Claudia Voigtmann, Bielefeld: transcript, S. 187-210, hier S. 197.

213 Vgl. Lockwood, David (1969): "Soziale Integration und Systemintegration«. In: Theorien des sozialen Wandels, hg. v. Wolfgang Zapf, Köln: Kiepenheuer \& Witsch, S. 124-137.

214 Siehe hierzu: REICHARDT (2014): S. 68.

215 Oltmer, Jochen (2013): Migration im 19. und 20. Jahrhundert, München: Oldenbourg, S. 1.

216 Dieser Fokus auf den Lebensmittelpunkt korreliert mit der Konjunktur des Heimatbegriffs, wie er in den letzten Jahren in der Bundesrepublik als eine narrative Reaktion in Politik, Medien und Kunst auf den Flüchtlingsstrom seit 2015 sich konstituiert. 
und Sanders-Brahms' Filmen noch in Örens Poem kann von einem Fokus auf einen Lebensmittelpunkt und auf dessen Verschiebung die Rede sein. Die Perspektive von Literatur und Film ist in den von uns behandelten Produktionen vielmehr auf Orte, Plätze und Gruppen gerichtet, die in Herkunft und Ankunft fremd sind. So stellen neben Milton Gordon auch andere Forscher in ihren Integrations- und Migrationstheorien ab Mitte der 1950er bis in die 1970er Jahre hinein (im Gegensatz zu Robert Ezra Park) die Bedeutung von Ort, Platz, Gruppe und Öffentlichkeit ins Zentrum ihrer Überlegungen.

Als eine "physical transition « beschreibt Shmuel N. Eisenstadt Mitte der 1950er Jahre die Migration. ${ }^{217}$ Rudolf Heberle bezeichnet jeden Wechsel des Wohnsitzes, »und zwar des de-facto-Wohnsitzes, einerlei ob freiwillig oder unfreiwillig, dauernd oder vorübergehend«, als Migration. Norbert Elias und John L. Scotson halten in ihrer bekannten Studie Etablierte und Außenseiter von 1965 fest, dass Migration vor allem eine Änderung der Gruppenzugehörigkeit impliziere. »Was geschieht, scheint [...] nur zu sein, daß Menschen sich physisch von einem Ort zum anderen bewegen. In Wirklichkeit wechseln sie immer von einer Gesellschaftsgruppe in eine andere über. « ${ }^{218}$ Einige Jahre nach der Veröffentlichung von Elias' Studie konstatiert der Zürcher Soziologe Hoffmann-Nowotny, dass Migration »jede Ortsveränderung von Personen« meine, und last but not least hält Günter Albrecht in seiner Soziologie der geographischen Mobilität fest, dass »die Ausführung einer räumlichen Bewegung, die einen vorübergehenden oder permanenten Wechsel des Wohnsitzes bedingt, eine Veränderung der Position also im physischen und im >sozialen Raum « « sei. ${ }^{219}$ So ist das narrative Problem der Integration in den 1960er und 1970er Jahren nicht in erster Linie das Individuum, sondern die Gruppe, die Beziehungen zwischen den Akteuren und ganz besonders der Ort. An dieser Stelle ist es sinnvoll, die theoretische Perspektive ein wenig auszuweiten. Beispielsweise hält Herbert Marcuse in seiner gesellschaftspolitisch äußerst wirkmächtigen Publikation Der eindimensionale Mensch von 1967 fest, ${ }^{220}$ dass es in den westlichen durchindustrialisierten Konsum- und Nachkriegsgesell-

217 Siehe hierzu: EISEnSTADT, Shmuel (1954): The Absorption of Immigrants. A comparative study based mainly on the Jewish community in Palestine and the State of Israel, London: Routledge \& Kegan Paul.

218 Zitiert nach: TreibeL, Annette (2011): Migration in modernen Gesellschaften. Soziale Folgen von Einwanderung, Gastarbeit und Flucht, München: Juventa, S. 19. Ab den 1980er Jahren rückt an die Stelle des Ortes und der Gruppe das Individuum und das System.

219 Ebd.

220 Siehe hierzu: TAZ (2014) »Rote Rosen für Marcuse. Vor 50 Jahren erschien Marcuses >Der eindimensionale Mensch . Das Buch befeuerte die sozialen Bewegungen wie kaum ein anderes«. In: taz, 14.01.2014. http://www.taz.de/!5050926/ (06.07.2017). Die erste Ausgabe erschien 1964 auf Englisch. 
schaften keine Orte mehr gebe, von denen aus das Subjekt Kritik und Negation ausüben könnte. An anderer Stelle spricht er diesbezüglich vom Ende der Utopie. Die Orte der Negation gibt es nicht mehr, an denen sich vielgestaltige Individuen entwickeln könnten. Bevor überhaupt wieder von Individuen die Rede sein kann, gelte es erst, die Orte zu schaffen, die ein Sprechen der Kritik ermöglichen. Hannah Arendt sieht das Hauptproblem hierfür im Verhältnis zwischen dem Privaten und dem Öffentlichen, zwischen denen keine wirkliche Bindung existiere. Nach Arendt müsste das Öffentliche das Private »einhegen «, so dass aus dem Privaten heraus in den öffentlichen Raum hinein Bindungen Einzelner zu Anderen entstehen. Dabei geht es nicht um das Innere dieses privaten Bereichs, »dessen Geheimnis die Öffentlichkeit nichts angeht«, sondern um die »äußere Gestalt«, um dasjenige, "was von außen errichtet werden muss, um ein Inneres zu bergen, was von politischer Bedeutung ist «. ${ }^{221}$ Es ist diese Innen-Außen-Kommunikation, die den bisher behandelten ästhetischen Produktionen zur Migration nach Deutschland eigen sind. Daher kann von einem Wechsel des Lebensmittelpunktes, wie ihn Jochen Oltmer als einen Wechsel von einer zuvor stabilen privaten Lebenswelt in eine andere festhält, in den 1960er und 1970er Jahren aus mehreren Gründen - und eben nicht nur im Feld der Migration und Integration - nicht die Rede sein. ${ }^{222}$

Nach Henri Lefebvre ist die Grundlage für die uns heute gängige Definition von Migration Anfang der 1970er Jahre die »Einsicht, dass das Gelebte, das Konzipierte und das Wahrgenommene sich in der Weise verbinden, dass das 〉Subjektく, das Mitglied einer bestimmten sozialen Gruppe, von einem zum anderen gelangen kann, ohne dabei die Orientierung zu verlieren «. ${ }^{223}$ In den ersten Texten und Filmen zur Migration nach Deutschland und Europa geht es um »Orientierung«, was auch das bedürfnisorientierte Leitnarrativ dieses Kapitels, »Wir wollten alle Amerikaner werden«, impliziert. In den 1960er und 1970er Jahren geht es darum, neue soziale Bindungen und Kontakte zu ermöglichen, die noch jenseits heutiger Migrations- und Integrationsmarker wie individueller, kultureller oder reli-

221 ARENDT, Hannah (1960): »Der Raum des Öffentlichen und der Bereich des Privaten«. In: Raumtheorie. Grundlagentexte aus Philosophie und Kulturwissenschaften, hg. v. Jörg Dünne, Frankfurt a. M.: Suhrkamp, S. 420-434, S. 429.

222 Interessant ist in diesem Zusammenhang auch, dass der erste deutschsprachige Film zur Arbeitsmigration in der Bundesrepublik nicht von den Gastarbeitern selbst handelt, sondern in Klaus Wildenhahns Dokumentarfilm IN DER FREMDE (1967) von süddeutschen Arbeitern, die in einer nordwestdeutschen Provinz ein Getreidesilo errichten. Wildenhahn dokumentiert eindrücklich deren Leben in den Arbeiterbaracken, die sich kaum von denen unterscheiden, die Jahre später für die Gastarbeiter errichtet werden. Siehe hierzu: WiLDENHAHN, Klaus (2010): Filme 1967-1987, Deutschland, DVD Absolut Medien.

223 LEFEBVRE (2006): S. 336. 
giöser Spezifika in Film, Literatur und Theorie gedacht werden. Anders formuliert: Migration und Integration befinden sich zwischen Mitte der 1950er Jahre bis Mitte/Ende der 1970er Jahre selbst in einem wechselseitigen Anpassungsprozess, da Träger dieses Verhältnisses dieser Zeit die Ökonomie ist und nicht ein kulturelles Setting. Narrative der Orientierung wie »der Gastarbeiter von heute ist der Europäer von morgen«, die Gastarbeiteranwerbung als europäisches Integrationsprojekt oder Niyazis für viele andere Türken repräsentative Aussage, warum er gekommen sei, sind von Konsum, Wirtschaft und Arbeit bestimmt, aber nicht von staatsbürgerlicher Zugehörigkeit und Praxis. Die letztgenannten sind hingegen wichtige Themen von Migration und Integration in der Bundesrepublik seit dem Ende der 1990er Jahre bis heute. .24 $^{22}$

Und doch: Trotz des Mangels dieser heutigen zentralen Migrationsspezifika von Herkunft, Ankunft, Lebenswelt und Kultur sind SHIRINS HochzEIT und Was will Niyazi in der Naunynstraße die zwei bekanntesten und am stärksten als künstlerische und zugleich dokumentarische Reflexionen rezipierte Werke zur türkischen Migration nach Deutschland in den 1970er Jahren. Mein Befund für dieses interessante und paradoxe Phänomen, das wir auch bei ANGST ESSEN SEELE AUF werden feststellen können, ist, dass die stabilisierenden Elemente für diese Rezeption nicht an erster Stelle die Migration und ihre Folgen sind, sondern eine Logik von Bedürfnissen, bestimmten Situationen und schließlich von sozialen Zuständen. Auch wenn Migration dokumentiert wird, sind die zentralen Themen die Artikulation und Verhandlung körperlicher Bedürfnisse und der Umgang mit diesen mittels spezifischer Verhaltensweisen. Es herrscht ein Mangel an Reprä-

224 Siehe hierzu: SchäUBLE, Wolfgang (1999): „Doppelte Staatsbürgerschaft fördert nicht die Integration, sondern behindert sie«. In: Deutschlandfunk, 11.01.1999, http://www.deutschlandfunk.de/doppelte-staatsbuergerschaft-foerdert-nicht-die-integration.694.de.html?dram:article_ id=57477 (10.07.2017). Siehe zur Staatsbürgerschaftsdebatte zwischen 1999 und 2004: GöKTÜRK u. a. (2011): S. 234-237, 240-243 u. 473f. FAIST, Thomas (2004): „Staatsbürgerschaft und Integration in Deutschland. Assimilation, kultureller Pluralismus und Transstaatlichkeit«. In: Integration von Migranten. Deutsche und französische Konzepte im Vergleich, hg. v. Yves Bizeul, Wiesbaden: Deutscher Universitätsverlag, S. 77-104. YuRdAKUL, Gökce/ÖzvATAN, Özgür (2017): »Doppelte Staatsbürgerschaft. Ethnie und Diversität?«. In: Tagesspiegel Causa, 11.01.2017, https://causa. tagesspiegel.de/politik/doppelte-staatsbuergerschaft-wie-exklusiv-ist-deutschsein/doppelte-staatsbuergerschaft-ethnie-oder-diversitaet.html (10.07.2017). Siehe auch: AugstEIn, Jakob (2017): »Türken rein! Türkischer Wahlkampf in Deutschland? Vergesst Verbote und Polizeieinsätze. Kümmert euch lieber um mehr Integration und schafft die doppelte Staatsbürgerschaft wieder ab«. In: DER SPIEGEL, 16.03.2017, http://www.spiegel.de/politik/deutschland/tuerken-rein-doppelte-staatsbuergerschaft-weg-dafuer-mehr-integration-kolumne-a-1139081.html (10.07.2017). FAZ (2017): »Merkel verteidigt doppelte Staatsbürgerschaft«, 29.04.2017, http://www.faz.net/ aktuell/politik/inland/doppelpass-merkel-verteidigt-doppelte-staatsbuergerschaft-14993080. html (10.07.2017). 
sentation, wodurch die Praktiken und Verhaltensweisen der Akteure in den Vordergrund der Beobachtung rücken. Besonders im deutsch-deutschen Konnex ist dies eine zentrale Frage der 1960er und 1970er Jahre, da mit der Frage nach der Zivilisiertheit der Anderen zugleich die Frage an die eigene Zivilisiertheit gestellt wird. ${ }^{225}$ Dieser Befund erhärtet sich, wenn wir im Folgenden, bevor wir dieses Kapitel mit der Filmanalyse von Fassbinders ANGST ESSEN SEELE AUF abschließen, einen Blick auf die narrative Struktur der Thematisierung des sozialen Wandels, des Eigenen und Fremden mit dem Begriff des Gastarbeiters in Debatten, Politik und Forschung werfen und uns auch den Fragen zuwenden, was in dieser Zeit unter gelingender und nicht gelingender Integration verstanden wurde und wen, was und wo hinein es eigentlich $\mathrm{zu}$ integrieren galt.

\subsection{Zivilisation als unbestimmte Soziokultur}

Was die Frage der Integration betrifft, sind nicht nur die migrationsbezogenen Filme, Texte und Theorien der 1970er von kultureller Unbestimmtheit geprägt von Bewegungen ohne Ankunft -, sondern auch soziologische und politische Beobachtungen. Die in den 1960er und 1970er Jahren mehrfach veröffentlichte Studie Über den Prozess der Zivilisation von Norbert Elias besagt, dass man »nie mit Bestimmtheit werde sagen können, dass die Menschen einer Gesellschaft zivilisiert sind«. Wenn wir überhaupt eine gesamtgesellschaftliche Aussage treffen können, dann die, dass eine Gesellschaft unter bestimmten Bedingungen zivilisierter geworden ist, man aber nicht als unveränderbaren Zustand festhalten kann, dass sie zivilisiert sei. ${ }^{226}$ Für Elias gibt es keine wirklichen Ruhezustände von Menschen und Gesellschaften, da sie immer irgendwie unterwegs sind und »Wandlungen zu den normalen Eigentümlichkeiten einer Gesellschaft gehören «. ${ }^{227}$ Diese sind wiederum äußerst interdependent, was die Interaktion zwischen individuellen und sozialen Strukturen angeht, die voneinander über den Blick auf die Verhaltensweisen nicht zu trennen sind. Sie sind auch deshalb nicht zu trennen, weil es nach Elias nicht möglich ist, Triebkontrollen von Triebimpulsen abzuspalten, da die ersteren »nicht die Gestalt eines Gefäßes« haben,

225 Was den Zusammenhang von Kultur und Bewusstsein betrifft, hält Alexander Kluge für seinen Film ABSCHIED von GESTERN von 1966 fest, dass sich eine Kultur in Deutschland in dieser Form noch gar nicht habe situieren können.

226 ELIAS, Norbert (1969): Über den Prozess der Zivilisation. Soziogenetische und psychogenetische Untersuchungen - Erster Band, Frankfurt a. M.: Suhrkamp, S. XX.

227 Ebd., S. XI. 
das die letzteren »in seinem Inneren enthält«. ${ }^{228}$ Die prozessorientierte Perspektive auf Gesellschaftsgeschichte ergibt sich bei Elias besonders daraus, dass im Zentrum seiner Untersuchungen die Verhaltensweisen von Menschen stehen, die sich aus Triebimpulsen und Triebkontrollen konstituieren. ${ }^{229}$ Diesem Fokus auf öffentliche und auch private Interaktionen an Orten wie Fahrstühlen, dem familiären Esstisch und verkehrsreichen Straßen folgt auch Erving Goffman in seiner mikrosoziologischen Arbeit Relations in Public Anfang der 1970er Jahre und sieht in der Beschreibung dieser Praktiken die Berührungskultur westlicher Gesellschaften arbeiten. ${ }^{230}$

Dieses an Bedürfnissen, an Affektregulierung, privaten und öffentlichen Interaktionen orientierte Interdependenzgeflecht findet sich argumentativ in einer der ersten prominenten Studien zur Gastarbeit in Deutschland wieder: Leben als Gastarbeiter. Geglückte und missglückte Integration von 1970. ${ }^{231}$ Ausgangspunkt sind wie bei SHIRINS HocHzEIT Gewaltverbrechen, neunzehn an der Zahl, die sich in Köln zu Beginn des Jahres 1966 im Zusammenhang mit ausländischen Gastarbeitern ereignen. Kurz darauf gibt die Stadt Köln die genannte Studie bei der Deutschen Gesellschaft für Sozialanalytische Forschung in Auftrag, die die »Ursachen dieser Häufung « der Gewaltdelikte von Gastarbeitern klären soll. ${ }^{232}$

Anhand »tiefenpsychologischer Exploration" sind die Grundannahmen und zugleich das Ergebnis der Studie, dass soziale Integrationsprozesse, wie sie auch Elias in seiner Soziologie der Zivilisation aufzeigt, eng mit personalen zusammenhängen. »Ein integrierendes Ich muss Veränderungen der Umwelt mit den stets vorhandenen eigenen, inneren Konflikten abstimmen und die entstehenden Spannungen harmonisieren. « ${ }^{233}$ So gelingt Integration vor allem in der Bewältigung von Spannungen und Situationen. Spannungen, herausfordernde

228 Ebd., S. LXIII.

229 Ebd., S. LXVII.

230 Siehe: GofFMAN, Erving (1982): Das Individuum im öffentlichen Austausch. Mikrostudien zur öffentlichen Ordnung, Frankfurt a. M.: Suhrkamp, S. 92-97.

231 Verstärkt gesellschaftspolitisch gewendet argumentiert Herbert Marcuse in seinem für die 1968er-Generation äußerst einflussreichen Buch Der eindimensionale Mensch, dass auch die Artikulation der Bedürfnisse, die die eindimensionierende Entwicklung einer durchökonomisierten Gesellschaft - wie die Bundesrepublik als fortgeschrittene Industriegesellschaft in den 1960ern - stören und »sprengen« könne. Nach Marcuse muss die bestehende Gesellschaft negiert werden. Erst aus dieser Negation werden sich die Voraussetzungen ergeben, um neue, emanzipative menschliche Bedürfnisse zu entwickeln. Eine Transformation, die jenseits einer traditionellen Moral durch das Verlangen und Begehren nach Glück und ihrer Realisierung durch Technik und Kunst das kapitalistische System, das nur auf Akkumulation ausgerichtet ist, erschüttert. Siehe hierzu: MARCUSE (1967): S. 17.

232 Siehe: Bingemer/Meistermann-SeEger/Neubert (1970): S. 19.

233 Ebd., S. 18. 
Situationen - oder, wie es in der Studie heißt, "Zustände von Desintegration « -, können nach Auffassung der Autoren der Studie nur innerhalb familiärer oder in freundschaftlichen Bindungen zu Anderen kompensiert werden. Dies gilt - nach Ansicht des Studienleiters - für Gastarbeiter ebenso wie für Alteingesessene. Während »normale Erwachsene [...] Zustände von Desintegration« innerhalb der Familie oder im Gespräch mit Freunden kompensieren können, bleiben dem Gastarbeiter, weil Familie und Freunde fehlen, diese Möglichkeiten der Kompensation und Entlastung verwehrt. In derartiger Isolation erlebt er "grenzenlose Ohnmacht und die Vergeblichkeit « seines Einsatzes und seiner Arbeit. ${ }^{234}$ Es geht - wie es auch Marcuse in Der eindimensionale Mensch festhält - um unbefriedigte Wünsche allgemein. ${ }^{235}$ Diese führen zu unbewussten Aggressionen, die durch das isolierte Leben der Gastarbeiter angefacht werden und zum Ausbruch kommen. So sei es auch kein Wunder, resümieren die Autoren der Studie, »dass die Lösung einer Notlage in der Affekthandlung liegt, die die Türken selbst am meisten befürchten. Sie sind frustriert und zum Aufstauen von Affekten gezwungen «. ${ }^{236}$ Dabei spiele auch die Beschränkung ihrer Sexualität aufgrund der Wohnverhältnisse eine wichtige Rolle, wie es auch Yıldız anhand der Arbeiterbaracken, Tunç Okan mit dem engen nichtprivaten Raum des Busses, Sanders-Brahms im Arbeiterwohnheim und Ören in den kleinen Wohnungen in der Naunynstraße aufzeigen. Gegen ein monistisches und ein pluralistisches Verständnis von Integration, das jeweils ein kulturelles wäre, favorisieren die Autoren (wie auch Milton Gordon) ein interaktionistisches Modell, aus dem idealiter eine gemeinsame Lebensform aus Minderheit und Mehrheit entstehen könnte. ${ }^{237}$ Aber auch bei der interaktionistischen Integrationsform geht es wie bei der monistischen oder der pluralistischen um Anpassung. ${ }^{238}$ Woran man sich jedoch in der Logik der Interaktion anpassen soll, lässt die Studie offen: weder die Annahme einer vorausgehenden Einheit (Monismus) noch die Annahme, es gebe vorausgehende unterschiedliche prozessresistente kulturelle Prägungen (Pluralismus) bieten Lösungen, und auch die Personen sind nicht unveränderbar bestimmt. ${ }^{239}$

Dahingegen sind die Ursachen der Isolation klar formuliert. Abgesehen von der Wohnsituation und der daraus resultierenden Kontaktarmut ist es das »affektive« Verhältnis der Deutschen zu den Gastarbeitern, das ein zentrales

234 Ebd.

235 Siehe hierzu: MARCUSE (1964): S. 25.

236 Bingemer/MeistermanN-SEEGER/NEUbERT (1970): S. 60.

237 Ebd., S. 19f.

238 Ebd., S. 20.

239 Wahrscheinlich leitet sich daraus auch die Formulierung der »geglückten« oder »missglückten Integration« ab. 
Problem darstellt. Die Deutschen begreifen die Gastarbeiter als eine soziale Schicht noch unterhalb der deutschen Unterschicht. Diese Form der Abwertung hängt mit der »Verdrängung des historischen Kapitels der Zwangsarbeiter im 2. Weltkrieg « zusammen. Die Abwertung der Gastarbeiter hilft, »Schuldgefühle« zu verleugnen. ${ }^{240}$ Daraus resultiert ein hochexplosiver Verdrängungskomplex, der die »unbewussten Motive der Deutschen im Verhalten gegenüber den Gastarbeitern « darstellt. ${ }^{241}$ In der Zeitgeschichte wird darüber hinaus der Übergang von den 1950ern über die 1960er zu den 1970er als eine Zeit beschrieben, in der sich die Schamkultur zur Schuldkultur gewandelt habe. »Die Angst der bürgerlichen Kultur der fünfziger Jahre war keine Gewissensangst, sondern die Angst vor sozialer Isolation. [...] Die Linksalternativen kennzeichnete dagegen [...] eine von Innerlichkeit und Läuterung bestimmte Haltung«, die mit Schuldgefühlen zusammenhing. ${ }^{242}$ Ausgehend von dieser Gemengelage (zwischen anständigem Verhalten und Schuld) sind auch die Ausländerdebatten der 1970er Jahre nicht von Fragen nach der Ordnung und Organisation gesellschaftlicher Vielfalt geprägt, sondern wesentlich von Fragen nach dem Umgang mit den Gastarbeitern. In den sozialpolitischen Schriften des Deutschen Städtetags hält dessen Präsident, der Bremer Bürgermeister Hans Koschnick, 1971 fest, dass die deutsche Bevölkerung »noch nicht in ausreichendem Maße gelernt [hat], mit anderen Völkern in einem partnerschaftlichen Verhältnis, frei von Über- und Unterordnungstendenzen, zu leben «. ${ }^{243}$ Daher treten als notwendige und mögliche verlässliche »Partner« für die Eingliederung der Gastarbeiter in der Studie Leben der Gastarbeiter Institutionen wie die Ausländerbehörde oder das Arbeitsamt auf. Die Dominanz von Begriffen mittlerer Reichweite wie »Partner«, »Situation«, »Zustand « oder »Entlastung« bestimmt auf einer deskriptiv-explorativen Ebene nicht nur die Studien explizit und inhaltlich, Film und Literatur narrativ, sondern auch die Gastarbeiterdebatten insgesamt. ${ }^{244}$ Beispielsweise entstammt

240 Siehe hierzu: Schönbach, Peter (1970): Sprache und Attitüden. Über den Einfluß der Bezeichnungen »Fremdarbeiter« und »Gastarbeiter« auf Einstellungen gegenüber ausländischen Arbeitern, Stuttgart: Huber, S. 57.

241 Ebd., S. $38 \mathrm{ff}$.

242 Siehe hierzu: REICHARDT (2014): S. 203. Siehe auch: HERBERT, Ulrich (2014): Geschichte Deutschlands im 20. Jahrhundert, München: Beck, S. 690-697.

243 Koschnick, Hans (1971): »Deutscher Städtetag. Hinweise zur Hilfe für ausländische Arbeitnehmer«. In: Sozialpolitische Schriften des Deutschen Städtetags, (Nr. 6), Köln, S. 1-5, hier S. 2.

244 In ihren Anfängen (1975-1978) verfolgte beispielsweise die Interkulturelle Woche - damals noch Tag des ausländischen Mitbürgers (TAM) genannt -, das Ziel, Begegnungen und Gespräche zwischen der deutschen Öffentlichkeit und den ausländischen Arbeitnehmern zu ermöglichen. Da aufgrund der hohen Arbeitslosigkeit des Jahres 1975, bei ausländischen Arbeitnehmern doppelt so hoch wie bei deutschen, die Sorge groß war, dass der Einsatz der Gastarbeiter für die 
das bekannte Zitat Max Frischs zur Arbeitermigration nach Europa in den 1950er und 1960er Jahren, man habe Arbeitskräfte gerufen, doch es kamen Menschen, aus seiner Essaysammlung, die im Kern ihrer Reflexionen die Öffentlichkeit ebenfalls als Partner begreifen will. ${ }^{245}$ Getragen wird diese komplexe und ersehnte Bindung von Öffentlichkeit, Institution und Partnerschaft durch eine Sprache der Sorge um den Anderen, aber auch um sich selbst, die von der einzelnen mikrologischen Situation bis zum Narrativ der europäischen Integration reicht.

In einer Spiegel-Serie über benachteiligte Gruppen in der Bundesrepublik aus dem Herbst 1970 zeigt sich diese komplexe Bindung beispielsweise sehr eindrücklich. Die zwölfseitige Reportage »Komm, Komm, Komm - Geh, Geh, Geh« zu Gastarbeitern in Deutschland gibt ein Beispiel für dieses »karitative Sentiment «. ${ }^{246}$ Der Tenor des Artikels: Man müsse den Gastarbeitern helfen. Als Beispiel wählt man die Stuttgarter Landessparkassen-Zentrale, die mittels eines italienischstämmigen Bankangestellten (Adriano Piccolini) den Gastarbeitern das Sparen beibringen soll. Man könne - so der Abteilungsleiter der Bank - diese »Leute nicht mehr Tausende von Mark in der Jackentasche herumtragen lassen «. ${ }^{247}$ An anderer Stelle wird auf eine Aktion westdeutscher Warenhäuser aufmerksam gemacht, bei der an Informationsständen vor Karstadt Hamburg beispielsweise von Hostessen Lebensmittel-Fibeln in italienischer, spanischer, griechischer und türkischer Sprache an die Gastarbeiter verteilt werden. ${ }^{248}$ »Wir müssen diesen Leuten

Entwicklung des bundesrepublikanischen Wohlstands in Vergessenheit geriete. Über Kontakte, Gespräche und gesellige Formate sollte mit dem TAM die entstandene Polarisierung zwischen Deutschen und ausländischen Arbeitnehmern aufgehoben werden. Zentrale Begriffe dieser ersten Interkulturellen Wochen waren Isolation, Arbeits- und Wohnverhältnisse, Freizeit, Alltag und Solidarität. Als wichtige Akteure fungierten Organisationen, wie beispielsweise die größte Einzelgewerkschaft IG Metall, die dezentral organisierte Arbeiterwohlfahrt (AWO), die kirchlichen Wohlfahrtsverbände Diakonie und Caritas - die großen Spitzenverbände, die ausländischen Arbeitnehmern Anlaufstellen boten. Diese betrieben eine Vertretungspolitik für die ausländischen Arbeitnehmer gegenüber dem Bund und den Kommunen und stellten ihnen Räumlichkeiten im Rahmen des TAM zur Verfügung. Mittels Folklore sollten Vorurteile abgebaut werden. In den Diskussionen standen vor allem die Lebensbedingungen der Gastarbeiter im Zentrum, der Begriff Kultur spielte hingegen keine Rolle. Siehe hierzu: EzLI, Özkan (2020).

245 FRISCH, Max (1970): Öffentlichkeit als Partner, Frankfurt a. M.: Suhrkamp, S. 56-67.

246 Der SPIEgel (1970): »Komm, Komm, Komm - Geh, Geh, Geh. Spiegel-Report über sozial benachteiligte Gruppen in der Bundesrepublik (II): Gastarbeiter«. In: DER SPIEGEL, 19.10.1970, S. 51-74, hier S. 52. (http://www.spiegel.de/spiegel/print/d-43801107.html) (17.08.2016). Zu den benachteiligten Gruppen gehörten in dieser Spiegel-Serie auch Obdachlose und Behinderte. Siehe hierzu auch: GöKTÜRK u. a. (2011): S. 61.

247 DeR SPIEgEL (1970): S. 51.

248 Über 40 Jahre später heißt es in der Welcome-App auf den Informationsseiten zum Leben in Deutschland für die Flüchtlinge unter der Rubrik »Umgangsformen«: »Zu lautes Reden, wildes Gestikulieren oder gar Schreien während eines Gespräches ist in Deutschland unüblich und wird eher 
beim Einkauf behilflich sein«, wird in diesem Zusammenhang der KarstadtGeschäftsführer Albrecht Uenk zitiert. ${ }^{249}$ Und der damalige FAZ-Mitherausgeber Karl Korn fügt hinzu, dass die Gastarbeiter »potentielle Vermittler von Verstehen und Verständigung « seien. ${ }^{250}$ Interessant an dieser ausführlichen Reportage ist auch die Fotostrecke zum Text. Wir sehen in halbnahen und halbtotalen Aufnahmen Gastarbeiterinnen und Gastarbeitern in Wohnheimen, am Bahnhof, auf der Straße, am Arbeitsplatz, bei der Freizeit oder beim Einkauf. ${ }^{251}$ Wie in den analysierten literarischen und filmischen Produktionen werden sie stets in Gruppen, in öffentlichen Räumen, bei der Arbeit oder bei anderen sozialen Handlungen gezeigt.

Bereits zehn Jahre vor der Der Spiegel -Reportage hält der Unternehmensberater Ludwig Kroeber-Keneth in dem FAZ-Artikel »Die ausländischen Gastarbeiter und wir« (1961) fest: Man müsse den Begriff »Gastarbeiter« sehr ernst nehmen und die Menschen zuvorkommend behandeln. »Ein besonders feines Ohr für die Zwischentöne ausländischer Mentalität war bekanntlich noch nie unsere starke Seite«, und es komme - so Kroeber-Keneth - sehr darauf an, ob die Deutschen »die richtige Einstellung finden ${ }^{252}$ Giacomo Maturi, der Anfang der 1960er Jahre Referent des Deutschen Caritasverbandes für die Betreuung ausländischer Arbeiter ist, macht ebenfalls auf den zentralen Aspekt des Umgangs mit und der Einstellung gegenüber den Gastarbeitern aufmerksam. ${ }^{253}$ Für beide liegt die Differenz zwischen den Deutschen und den Gastarbeitern in der südländischen Mentalität, an ihrer »Sensibilita«; ein Begriff, der nach Ansicht beider Autoren »nicht zu übersetzen ist «. ${ }^{254}$ Die Andersartigkeit des Gastarbeiters liegt bei Kroeber-Keneth darin, dass sie "Sensibilita« haben und bei Maturi, dass sie eine andere Einstellung zur Arbeit haben als Deutsche, wobei er in seinem Artikel zugleich

als respektlos empfunden. Wenn man etwas von jemandem möchte, sollte man häufig `Bitte und >Danke`sagen. Viel Wert legen die Deutschen auf Manieren bei Tisch. In der Öffentlichkeit benutzt man bei allem Essen das passende Besteck und nimmt nur selten die Hände. Schlürfen und übertriebenes Kauen ist nicht gern gesehen. « Siehe hierzu: SPECHT, Frank (2017): »Wie die Abschiebung gelingen soll«. In: Handelsblatt, 13.03.2017, https://www.handelsblatt.com/politik/deutschland/ umgang-mit-fluechtlingen-wie-die-abschiebung-gelingen-soll/19511032-all.html (zuletzt 07.04.2019). 249 Der SPIEgEL (1970): S. 51.

250 Ebd., S. 52.

251 Siehe hierzu: ebd., S. 51-74.

252 KROBER-KENETH, Ludwig (1961): »Die ausländischen Arbeitskräfte und wir«. In: FRANKFURTER ALLGEMEINE ZEITUNG, 03.06.1961, S. 5.

253 Vgl. MAtURI, Giacomo (1961): »Die Eingliederung der südländischen Arbeitskräfte und ihre besonderen Anpassungsschwierigkeiten«. In: Ausländische Arbeitskräfte in Deutschland, Düsseldorf: Econ, S. 121-127, hier S. 121.

254 KROBER-KENETH (1961): S. 6. 
festhält, dass sich dies grundlegend geändert habe. Beide Autoren, der eine aus der Wirtschaft, der andere aus dem öffentlich-sozialen Bereich, beschreiben und empfehlen in ihren Artikeln Verhaltensweisen und Praktiken, über die der richtige Umgang, die richtige Einstellung und eine integrierende Verständigung erlernt werden könnten. In diesem Zusammenhang wird auch nicht von »Integration «, sondern von »Eingliederung in die Gesellschaft « gesprochen. ${ }^{255}$ Spannend an diesen Texten ist: Die Juxtaposition von vermeintlich unveränderbarer südländischer Mentalität und der gleichzeitige Befund, dass viele Gastarbeiter ihr Verhältnis zur Arbeit bereits grundlegend verändert hätten. So impliziert der Begriff der Eingliederung eine grundsätzliche Anpassung des Fremden in das gesellschaftliche System. Die Historikerin Karin Hunn verweist in ihren Beiträgen zur Geschichte der Arbeitsmigration in Deutschland auf Arbeitgeberberichte, in denen es heißt, dass der Türke sehr gut arbeiten könne, »wenn man weiß, wie man ihn anzupacken hat «. ${ }^{256}$ Maturi rät hingegen den Deutschen und besonders den Arbeitgebern - ähnlich wie Kroeber-Keneth - eine »menschlichere Behandlung« der Südländer und nicht zu viel des Kommandierens. ${ }^{257}$ Dabei geht es nicht - wie heutzutage - um die Sprechweisen, sondern um Verhaltensweisen, die »Wärme, Kontakt, Umsorgung und Freundlichkeit « vermitteln. Sprachschwierigkeiten sind hier »kein entscheidendes Hindernis«. »Man braucht nicht viel zu reden, es genügt freundlich zu sein, etwas mehr zu lächeln. Das kann man nie genug betonen. ${ }^{258}$ Daher spielt der Aspekt des zärtlichen Verhaltens nicht nur im Zusammenhang mit den Gastarbeitern eine zentrale Rolle. Sie bestimmt auch die innerdeutschen Themen. Heinrich Böll beschreibt beispielsweise die Protagonistin und Heldin in seinem Roman Gruppenbild mit Dame als ein Genie der Sinnlichkeit und der Zärtlichkeit. ${ }^{259}$ Und in Volker Schlöndorffs DiE VERLORENE EHRE DER KATHARINA BLUM von 1975 ist die Unterscheidung von zudring-

255 Vgl. SCHÖNWÄLDER (2001): S. 182.

256 Siehe hierzu: HERBERT, Ulrich/HunN, Karin (2000): „Gastarbeiter und Gastarbeiterpolitik in der Bundesrepublik. Vom Beginn der offiziellen Anwerbung bis zum Anwerbestopp (1955-1973)«. In: Dynamische Zeiten. Die 60er Jahre in den beiden deutschen Gesellschaften, hg. v. Axel Schildt, Hamburg: Christians, S. 273-310, hier S. 280.

257 Ebd., S. 7.

258 MATURI (1961): S. 126. Die gesprochene Sprache wird dabei nicht als zentrales Instrument einer gelingenden Eingliederung oder Integration verstanden, wie sie heute beispielsweise begriffen und aktuell in der Frage der Integration der Flüchtlinge in Deutschland verhandelt wird. Siehe hierzu auch Filmaufnahmen aus den 1960er Jahren in der Zusammenstellung Paul Scheffers. RoElofs, René (2013): Gelobte Länder, Dokumentarfilm, Niederlande. Siehe hierzu auch: https://www.filmdienst.de/film/details/546022/gelobte-lander (zuletzt 07.04.2019).

259 Siehe hierzu: BölL, Heinrich (1970): Gruppenbild mit Dame, München: dtv, S. 13. 
lichem und zärtlichem Verhalten eine im sozialpolitischen Sinn äußerst zentrale. ${ }^{260}$ Nicht das Verstehen einer anderen Kultur, sondern veränderte Praktiken, Verhaltensweisen und Berührungen sind hier der Motor sozialen Wandels.

Dass Integration nicht auf der Ebene der Sprachkompetenz angesiedelt wird, sondern auf der Ebene der Verhaltensweisen und Praktiken, zeigt auch der autobiografische Roman Türkler Almanyada (»Türken in Deutschland«) von Bekir Yıldız. Während seines Urlaubsaufenthaltes in Istanbul, die Stadt erscheint ihm fremd, fällt Yüce besonders das zärtliche Zusammensein eines Paares auf, das er als besonders erstrebenswert charakterisiert. Wenn ein türkisches Ehepaar aus dem Dorf sich aufgrund ihres körperlichen Erfahrungsmangels nicht so verhalten könne, so mangele es den Frauen in Deutschland an einem gewissen Anstand, da sie nicht zärtlich genug seien. ${ }^{261}$ Auch dass Männer und Frauen in Deutschland zusammen unbeschwert Bier trinken, empfindet er als eine äußerst zivilisierte Handlung. Hier entscheiden bereits mikrosoziale Beobachtungen von Praktiken im öffentlichen Raum über Integration und Desintegration wie auch in den soziologischen Reflexionen (Elias, Goffman) und in den Debattenbeiträgen zur Arbeitsmigration nach Deutschland. Und ähnlich wie hier die Beobachtungen mit großen zivilisatorischen Fragen verbunden sind, beginnt auch Bekir Yıldız' Roman unbestimmt universell-zivilisatorisch. »Dort wo Wasser und Erde verbraucht sind, migrieren die Menschen weg. Dies kann auch ganze Völker betreffen. ${ }^{262}$ Er verweist weiter auf umfangreiche Migrationsbewegungen in Asien, die große Zivilisationen hervorgebracht haben. Allerdings ähnelt die Bewegung vom Sirkeci-Bahnhof in Istanbul keineswegs den zivilisatorischen Großleistungen, die aus Migrationen hervorgegangen sind. Der Grund hierfür liegt in den Umständen der türkischen Arbeitsmigration nach Deutschland. ${ }^{263}$

An die Stelle der Frage nach der Zivilisation rückt im weiteren Verlauf des Romans die Frage und Beobachtung der Zivilität der Deutschen, aber insbesondere der Türken auf dem Weg nach Deutschland und in Deutschland, wie bereits zu Beginn des Kapitels festgehalten. Die Kritik am zivilen oder nichtzivilen Verhalten von Deutschen und Türken bestimmt diesen Text. Ein Aspekt, der als sehr spezifisch auftaucht, ist das unmenschlich anmutende Arbeitsethos der Deutschen, unter dem die türkischen Gastarbeiter leiden. Allerdings ist dies wiederum eine Frage der Praxis, die verändert werden kann. Denn auch diese deutsche Eigenschaft wird erst von Szene zu Szene geschildert und dann durch andere, widersprechende

260 ScHLÖNDORFF, Volker (1975): Die verlorene Ehre der Katharina Blum, Spielfilm, Deutschland, Kinowelt Home Entertainment 2009.

261 Yildiz (1966): S. 98.

262 Ebd., S. 3.

263 Ebd., S. 5. 
Szenen, aufgelöst. Wie in Örens Poem und Sanders-Brahms Film bricht die Gewalt auch in Yıldız' Roman unerwartet und eruptiv aus, was auf die Fragilität des zivilen Umgangs aufmerksam macht. Seine Figuren kommen wie in den bisherigen künstlerischen Produktionen aus den sozialen Unterschichten. Mit dieser Doppelung der gesellschaftlichen Peripherie, ohne starke Bindung an ein bestimmendes Zentrum, kann die Behandlung der Frage von Zivilisation und Gewalt nur auf einer mikrologischen Ebene, von Situation zu Situation aufgezeigt und bestimmt werden.

Zeitgleich mit Bekir Yıldız' bis heute kaum beachteten Roman legt Ralf Dahrendorf mit seinem einflussreichen Buch Gesellschaft und Demokratie in Deutschland (1966) eine Publikation vor, die ebenfalls zentral den Zusammenhang von Zivilisation und Gewalt thematisiert. Im Gegensatz zu Bekirs Text spielt Migration nach und in Deutschland in Dahrendorfs Buch zur politischen Zustandsbeschreibung der deutschen Gesellschaften überhaupt keine Rolle und findet auch keine Erwähnung. Für Dahrendorf befindet sich die deutsche Gesellschaft in den 1960er Jahre selbst noch auf dem Weg zu einer westlichen Zivilisation. In Gesellschaft und Demokratie in Deutschland fragt er nach dem größten Hindernis auf dem Weg der deutschen Gesellschaft zu einer liberalen Demokratie.

\footnotetext{
Wir wollen die deutsche Geschichte und Gesellschaft an einem allgemeinen Maßstab messen, oder genauer - da das Messen an vorgegebenen Maßstäben nur beschreibende Befunde erlaubt - zu erklären versuchen, warum Deutschland sich der Demokratie in ihrem liberalen Verstande versperrt hat. ${ }^{264}$
}

Der zentrale Grund für diese Sperre ist für Dahrendorf, aber auch für Jürgen Habermas und andere deutsche Intellektuelle jener Zeit, zum einen, dass über die jüngste deutsche Vergangenheit nicht gesprochen wird. Zum anderen liegt die Ursache für dieses im Westen nicht mehr Integriert-seins im Missverhältnis zwischen Lebenswelt, Öffentlichkeit und politischem System. Als Vorbild für die Integration der Bundesrepublik in den Westen zieht Habermas das moderne bürgerliche 19. Jahrhundert heran, in dem sich der Bürger im Ausdruck seiner eigenen Meinungen den öffentlichen Raum aneignete und somit erst Öffentlichkeit generierte. Für Henri Lefebvre steht in diesem Zusammenhang besonders die Aneignung der Stadt im Vordergrund. »In den Stadtzentren ersetzen Büros die Wohnungen«, hält er zeitdiagnostisch fest und fordert in seiner programmatischen Streitschrift von 1968 Le droit à la ville, dass ihre Bewohner

264 DAHRENDORF (1966): S. 26. 
aus den Statistenrollen heraus zu Neuerfindern ihrer Zentren werden, dass sie mit dieser stärker in Austausch und Kommunikation treten. ${ }^{265}$

Dahrendorf bestimmt in Gesellschaft und Demokratie in Deutschland für die deutsche Nachkriegsgesellschaft eine konfliktgeladene Asymmetrie zwischen politischer und gesellschaftlicher Demokratisierung, die in technisch-wirtschaftlicher Hinsicht zwar gelungen ist, jedoch auf der Ebene der Subjektkulturen - nach Dahrendorf die Ebene der privaten Welt - keine affektive Bindung zum politischen System der liberalen Demokratie habe schaffen können, die zur weitergehenden Liberalisierung der deutschen Gesellschaft notwendig gewesen wäre. Für ihn sind die private und soziale Welt der deutschen Gesellschaft der 1960er Jahre weiterhin von hierarchischen Rollenverteilungen, einem strikten Arbeitsethos, sowie einengender Sexual- und Erziehungsnormen geprägt, wie sie strukturell im wilhelminischen Kaiserreich und während der Nazidiktatur vorherrschten und diese Systeme erst ermöglichten. ${ }^{266}$ Es sei die Abneigung gegen Konflikte insgesamt gewesen, die in der deutschen Geschichte immer zu autoritären Lösungen geführt und die Entwicklung einer liberalen Demokratie im privaten Raum verhindert habe. Dahrendorf und auch Habermas verordnen der deutschen Gesellschaft der 1960er im Gegenzug die Austragung der Konflikte über die Sprache, die die Bindung zwischen politisch-liberalen Institutionen und den Akteuren schaffen soll.

Liberale Demokratie kann nur wirksam werden in einer Gesellschaft, in der erstens die bürgerlichen Gleichheitsrechte wirksam durchgesetzt sind, zweitens soziale Konflikte in allen Bereichen anerkannt und geregelt werden, drittens die Eliten in sich die Buntheit und Vielfalt Sozialer Interessen spiegeln und viertens die öffentlichen Tugenden die vorherrschende Wert-Orientierung der Menschen darstellen. ${ }^{267}$

Diese von Dahrendorf dargestellten Grundlagen einer liberalen Demokratie decken sich mit der heutigen Verwendung des Integrationsbegriffs. Was Dahrendorf und viele bundesrepublikanische Intellektuelle von der deutschen Bevölkerung erwarteten, um im Westen anzukommen, sind seit den 2000er Jahren und in der Folge des 11. September 2001 Erwartungen, die an Menschen mit muslimischem Hintergrund gestellt werden. Das Innen des Zuhauses, der Familie, der Moschee in den öffentlichen Raum zu tragen und sich dadurch als ange-

265 Vgl. Lefebvre, Henri (1968): La droit à la ville, Paris: Anthropos, S. 26. Lefebvre wichtige Streitschrift aus den 1960er Jahren wurde 2016 erstmals ins Deutsche übersetzt. Siehe: LEFEBVRE, Henri (2016): Das Recht auf Stadt, Hamburg: Edition Nautilus.

266 Vgl. ebd., S. 43-58.

267 DAHRENDORF (1966): S. 42. 
kommen und integriert auszuweisen. Eindrücklich ist in diesem Zusammenhang die vom Bundesministerium für Inneres und dem Deutschen Kulturrat initiierte Initiative »Kulturelle Integration«, die am 16. Mai 201715 Thesen zum gesellschaftlichen Zusammenhalt und zur kulturellen Integration vorstellte. Im Zentrum stehen in diesen Thesen Zusammenleben, Bildung, Arbeit und eine gelingende Streitkultur. Der Austragungsort für Mehr- und Minderheiten ist der öffentliche Raum. ${ }^{268}$

In den 1960er und 1970er Jahren gehörten zu dieser Gesellschaft einer liberalen Demokratie, zu dieser anvisierten konflikt- und lösungsorientierten, dialogischen und topologischen Struktur zwischen Privatheit und Öffentlichkeit weder der Zustrom der deutschen Vertriebenen seit 1945, noch die in der Peripherie, lokal in Arbeiterwohnheimen, angesiedelten ausländischen Arbeitsmigranten; und dies obwohl vielen Politikern klar war, dass die Folgen der Arbeitsmigration zu einer bundesrepublikanischen Einwanderungsgesellschaft führen könnten. ${ }^{269}$ Wie zuvor gezeigt, wurde der Begriff »Integration« vorwiegend in einem europäisch-ökonomischen Zusammenhang verwendet oder gesamtgesellschaftlich thematisiert als Frage eines endogenen sozialen Wandels, der zwischen Institutionen und Akteuren zu entstehen habe.

In einer weiteren einflussreichen Publikation der 1960er, die wie Dahrendorfs Arbeit bis weit in die 1970er Jahre hineinwirkte, begegnen wir einer weiteren Begriffsverwendung, die Migration in ähnlicher Weise thematisiert wie Yıldız, Şoray, Ören und Sanders-Brahms. Herbert Marcuse begreift Integration in seinem Buch Der eindimensionale Mensch als einen Prozess der Eindimensionierung und Homogenisierung der Gesellschaft, der dieser ihrer Vielfalt und Kritikmöglichkeiten beraube. ${ }^{270}$ Die Konsum- und Industriegesellschaft gleiche durch einen Verähnlichungs- und Anpassungsprozess den Menschen den Dingen und der Arbeit an und zerstöre dadurch die Vielfalt und Freiheit menschlicher Existenz. Im Zentrum seiner Beobachtung steht, dass durch den Markt und die ökonomische Struktur von Angebot und Nachfrage falsche Bedürfnisse entstünden und dadurch ein falsches Bewusstsein. Damit werden der Gegensatz und die Differenz zwischen dem gesellschaftlich Gegebenen und dem gesellschaftlich Möglichen

268 Siehe hierzu: http://kulturelle-integration.de/thesen/ (06.07.2017). Siehe hierzu auch: El-MafaAlani, Aladin (2018): Das Integrationsparadox. Warum gelungene Integration zu mehr Konflikten führt, Köln: Kiepenheuer \& Witsch.

269 Diesen Aspekt hat Karen Schönwälder in ihrer Habilitationsschrift gründlich herausgearbeitet. Darin findet sich auch der Verweis, den beispielsweise der damalige Innenminister Hans-Dietrich Genscher für Integration stark machte, da die Bundesrepublik für ihn 1972 schon ein Einwanderungsland war. Vgl. ScHÖNwÄLDER (2001): S. 172.

270 Siehe hierzu: MARCUSE (1967): S. 71. 
als Utopie, zwischen befriedigten und nicht befriedigten Bedürfnissen neutralisiert. Dieser Prozess der Eindimensionierung dient nach Marcuse besonders der »Erhaltung des Bestehenden «.

Hier zeigt die sogenannte Ausgleichung der Klassenunterschiede ihre ideologische Funktion. Wenn der Arbeiter und sein Chef sich am selben Fernsehprogramm vergnügen und dieselben Erholungsorte besuchen, wenn die Stenotypistin ebenso attraktiv hergerichtet ist wie die Tochter ihres Arbeitsgebers, wenn der Neger einen Cadillac besitzt, wenn sie alle dieselbe Zeitung lesen, dann deutet diese Angleichung nicht auf das Verschwinden der Klassen hin, sondern auf das Ausmaß, in dem die unterworfene Bevölkerung an den Bedürfnissen und Befriedigungen teil hat, die der Erhaltung des Bestehenden dienen. ${ }^{271}$

Um diesem Prozess der allgemeinen Assimilation entgegenzuwirken, reicht es für Marcuse nicht aus, nur über die Ebene der öffentlichen Meinungsbildung (Habermas) oder der privaten und öffentlichen Konfliktaustragung (Dahrendorf) zu gehen. Sprache als alleiniges Ausdrucksmittel reicht hier nicht aus. Vielmehr muss es darum gehen, »richtige« Bedürfnisse zu entwickeln, die andere Verhaltens- und Sprechweisen nach sich ziehen.

Der Begriff »Bedürfnisse« ist ein äußerst zentraler nicht nur in Marcuses Buch, sondern darüber hinaus in den linken Bewegungen der 1960er Jahre sowie in vielen Reflexionen der Frankfurter Schule bei Adorno und Horkheimer. Eine zentrale Aussage in diesem Argumentationsstrang ist philosophisch: Das Ganze als Geschichte und Gesellschaft sei nicht das "Wahre«, wie es Adorno in seiner Negativen Dialektik in Abgrenzung von Hegel festhält. Ein richtiges Leben im Falschen sei nur als ein aporetisches, als eines im Widerspruch möglich. Das Verhältnis zwischen dem System als Industriegesellschaft und dem Individuum sei von Fremdheit und Kälte geprägt und stecke in statischen und sperrigen Kommunikationsverhältnissen fest. Auf unterschiedlichen Komplexitätsebenen finden wir diesen Befund in den bisher analysierten Texten und Filmen ebenfalls. Auch in ihnen zeigt sich ein Leben im Falschen, wenn Konsum oder Arbeit und Sparen das Leben bestimmen. Diese Ausrichtung koppelt Migration ausschließlich an ökonomische und nicht soziale Integration - ein Verhältnis, dass auch die Beziehung von Migration und Integration in den ästhetischen Reflexionen zur Migration nach Deutschland jener Zeit insgesamt bestimmt. ${ }^{272}$ Es ist die den ästhetischen Erzählungen inhärente Störung der Kommunikation.

271 Ebd., S. 30.

272 An dieser Stelle nimmt auch für Marcuse die Literatur eine sehr wichtige Funktion ein, indem sie diese Entfremdungs- und Entortungsprozesse aufzeigt. Dabei spielt interessanterweise wiederum, wie in den hier behandelten künstlerischen Werken, eine nicht-sublimierte Form von Sexualität eine entscheidende Rolle. Siehe: MARcuse (1967): S. 97. 
Migration und Integration bilden hier keine Äquivalenzkette, weil es an der Narration mangelt, wohin die Bewegung der Migration eigentlich führen solle. Hinzu kommt, dass in den 1960ern zwar vielen Intellektuellen und Politikern klar war, dass sich die Bundesrepublik nach dem Zivilisationszusammenbruch mit dem Dritten Reich selbst an den Westen anpassen musste und wollte, völlig unklar aber blieb, wohin auch diese Bewegung die Bundesrepublik genau führen würde. Die Rede von der Europäischen Integration in den 1960er und 1970er Jahren war das unbestimmte Narrativ, das den aporetischen Konflikt zwischen Individuum und gesellschaftlicher Form erzählbar machte. Doch war diese Europäische Integration in erster Linie keine soziale und keine identitätspolitische, sondern eine wirtschaftspolitische. Die intellektuelle Rede von der Ankunft der bundesrepublikanischen Gesellschaft in der liberalen westlichen Demokratie ist auch eine Konsequenz aus den Verwendungskontexten des Begriffs »Integration « in den 1960er und 1970ern. Denn aus einer nicht-ökonomischen, sozialen Perspektive gibt es in den 1960er und 1970er Jahren keinen Ort der Integration. Stattdessen gibt es aber viel materielle und ideelle Migration, wie dies auch Literatur und Film eindrücklich dokumentieren. Es ist die Kluft zwischen Integration und Migration in den 1960er und 1970er Jahren, die gesellschaftspolitische und filmische Narrative prägte und die es unmöglich machte, größere stabile soziale interdependente Strukturen aufzuzeigen und entstehen zu lassen.

Dies zeigen die ästhetischen Erzählungen auf, wenn ein türkischer Dorfacker ebenso für Ortlosigkeit steht wie ein abgelegener Ort am Rande einer Kölner Autobahn oder wenn Gefühle der Akteure auf öffentlichen Plätzen in Stockholm, in Baden-Württemberg und in Istanbul mit ähnlichen Fremdheitserfahrungen und Kameraeinstellungen (Nahaufnahmen und Halbtotalen) eingefangen werden. Integration zeigt sich in diesen Produktionen an den Stellen, wo es um einen ökonomischen Aufstieg geht. Wenn in Örens Werk die beiden Protagonisten, Frau Kutzer und Niyazi, über ein Ankommen sinnieren, so geht es dabei entweder darum, wie ein Amerikaner zu leben oder in sozialer Hinsicht aufzusteigen. Dass der sozialstrukturelle Aufstieg keinen spezifischen Ort hat, macht auch Ören in seinem Werk sehr deutlich. Denn ob die Projektion, wie ein Amerikaner leben zu wollen, sich tatsächlich in den Vereinigten Staaten realisieren soll oder in Deutschland - der Autor bezeichnet Deutschland als »kleines Amerika« - oder in Istanbul, also im Herkunftsland selbst, spielt keine wesentliche Rolle. ${ }^{273}$ Diese Entkopplung von Integration und Migration wird auch in den Filmen von Şoray, Okan und San-

273 Auch der türkische Ministerpräsident Süleyman Demirel hat in den 1960er Jahren der türkischen Bevölkerung versprochen, dass die Türkei irgendwann ein »kleines Amerika« werde (kücük Amerika). Und auch in dem bekanntesten Musical der 1960er Jahre, in der West Side Story, singen puerto-ricanische Gangmitglieder auf den New Yorker Straßen, dass sie in Amerika leben 
ders-Brahms durchgespielt. Sie steht für eine Trennung von Praxis und Fiktion. Da eine ideelle und identifikatorische Integration in den 1960er Jahren nicht möglich ist, rücken körperliche Bedürfnisse, Praktiken, Handlungen, Verhaltensweisen, Situationen, letztlich die interpersonalen Verhältnisse so sehr in den Vordergrund, dass Integration in den 1960er Jahren nur noch in einer Form der Diskretion gelingen kann. Oder wie Hannah Arendt in ihren Reflexionen zum Verhältnis von Privatem und Öffentlichem in den 1960er Jahren festhält, ist die eigentliche politische Aufgabe, durch das Öffentliche »ein Inneres zu bergen«. In dieser Öffentlichkeit muss das Private als etwas »Eingegrenztes « und »Eingezäuntes « erscheinen. Und die Aufgabe und »Pflicht des öffentlichen Gemeinwesens ist es, diese Zäune und Grenzen zu wahren, welche das Eigentum und das Eigenste eines Bürgers von dem seines Nachbarn trennen und gegen ihn sicherstellen «. ${ }^{274}$

Die Bergung eines inneren Raums durch das Öffentliche ist das Thema von Rainer Werner Fassbinders Liebesgeschichte in ANGST ESSEN SEELE AUf. Sie ist die ästhetische Reflexion der 1960er und 1970er Jahre, die die genannten Stränge am konsequentesten zusammenführt und Integration als Diskretion gelingen lässt. In diesem Film zeigt sich eindrücklich, warum die Frage der Integration in der Bundesrepublik in den 1960er und 1970er Jahren vor allem eine Frage nach den interpersonalen und gesellschaftlichen Verhaltensweisen war. Anhand dieses Films werden wir für dieses Kapitel abschließend zeigen können, dass es auch hier weder die Kultur noch die Akteure sind, die bestimmend, prekär oder schematisch sind, wie es die Forschung zu Literatur und Film dieser Zeit bis heute festhält, sondern die zivilisatorischen, sozialen und topologischen Ordnungen. Sie stehen vielmehr für eine Praxis der Diskriminierung, der Verletzung, deren Gegenstück in Fassbinders Film Integration als Diskretion ist. In einem spezifischen Sinne sieht Rainer Werner Fassbinder ebenso wie Milton Gordon die Grundlagen der Integration im prozessualen Abbau von Diskriminierungen. Und ähnlich wie in Gordons Theorie lautet die zentrale Frage auch bei Fassbinder in Zweier- und Gruppenkonstellationen: »what happens `when people meet «??

\subsection{Von außen nach innen oder: Integration als Diskretion}

In seinem 1973 gedrehten Film ANGST ESSEN SEELE AUF erzählt Fassbinder die Geschichte eines ungleichen Paares. Emmi Kurowski, eine alte Putzfrau - in einem

wollen, obwohl sie das praktisch schon tun. Siehe hierzu: RoBbins, Jerome (1961): West Side Story, Spielfilm, USA, MGM.

274 ARENDT, Hannah (1960): S. 429.

275 Siehe hierzu: GoRdon (1964): S. 60. 
vergleichbaren Alter wie Frau Kutzer in Was will Niyazi in der Naunynstraße -, lernt in München in einer Ausländerkneipe abends den jungen marokkanischen Gastarbeiter El Hedi Ben Salem (Ali) kennen, der wiederum im selben Alter ist wie Niyazi. ${ }^{276}$ Wenn diese Personenkonstellation auf Seiten der Alteingesessenen und Arbeitsmigranten in ANGST ESSEN SEELE AUF an Örens Poem erinnert, so setzt der Anfang des Films allerdings gleich eine konstitutive Differenz. Im Unterschied zu den kaum existenten Kontaktszenen zwischen Niyazi und Frau Kutzer steht die Begegnung zwischen Ali und Emmi im Zentrum von Fassbinders Film. Und sie ist nicht einfach eine des sprachlichen Austauschs, weil auf ihren ersten kurzen Dialog innerhalb der ersten Filmsequenzen ihr gemeinsames Tanzen folgt. ${ }^{277}$ Später bringt er sie nach Hause, denn sie hat "gut mit Ali gesprochen«, wie Ali selbst sagt. ${ }^{278}$ Ali verbringt auf Emmis Wunsch die Nacht bei ihr. Sie schlafen miteinander und verlieben sich ineinander. Das soziale Umfeld reagiert auf die sich anbahnende Beziehung mit Ablehnung, Vorurteilen und Diskriminierung. Ihre Freundinnen und Putzkolleginnen reden nicht länger mit Emmi. Ihre Nachbarinnen beklagen sich über den Schmutz, den es neuerdings im Haus gebe. Und als Emmi und Ali heiraten und Emmi ihre Kinder hernach informiert, stößt sie auf radikale Ablehnung. Ali geht es wenig später genauso. Vom Lebensmittelhändler wird er nicht bedient und auf Emmis Beschwerde hin weist dieser sie aus seinem Laden, mit einer Gestik und einem Wortlaut, die an die Heimleiterin in SHIRINS HocHzEIT erinnern. In einer der wenigen Außenaufnahmen, einer verregneten Biergartenszene, wird mitten im Film diese Exklusionsdynamik, die das Paar immer näher zusammenführt, verdichtet dargestellt. Die beiden sitzen allein an einem Tisch, am Eingang des Wirtshauses steht eine Gruppe von Menschen, junge wie alte, die Emmi und Ali wortlos anstarren. In dieser Sequenz versichert sich das Paar in radikaler Abgrenzung zur Gesellschaft, die auch hier als eine lose Gruppe vorgestellt wird, seiner Liebe, auch wenn Emmi bemerkt, dass sie diesem Druck nicht gewachsen sei. Sie flüchten sich in einen Urlaub und hoffen auf Besserung.

276 ANGST ESSEN SEELE AUf hatte bis kurz vor der Veröffentlichung des Films 1974 den Titel ALLE TÜRKEN HEISSEN ALI.

277 Auch in Bekir Yıldız' autobiografischem Roman spielt der Tanz mit deutschen Frauen eine herausragende Rolle. Doch fällt dort die Beschreibung über die Umstände des Tanzes zwischen deutschen Frauen und Gastarbeitern ganz anders aus. Denn als auf der Faschingsfeier die Musik ertönt, beschreibt Yıldız, fallen die schönen deutschen Frauen über unseren Tisch her und nehmen sich die Gastarbeiter zum Tanz, wie sie es gerade wollen und brauchen. Siehe: YILDIZ (1966): S. 54.

278 FASSBINDER, Rainer Werner (1974): Angst essen Seele auf, Spielfilm, BRD, DVD Studiocanal 2007. 
Doch das Verhalten der anderen (des Lebensmittelhändlers, der Nachbarn, von Emmis Kindern und ihren Freundinnen) ändert sich auch nach dem Urlaub kaum; dabei ist allerdings von Anfang an klar, dass Nettigkeiten nur auf Profitdenken beruhen. Paul, Emmis Sohn, entschuldigt sich zwar bei seiner Mutter für sein Verhalten, fragt aber im gleichen Atemzug, ob sie tagsüber auf sein Kind aufpassen könne, bis er einen Krippenplatz gefunden hätte. Die Nachbarinnen begrüßen sie herzlich im Treppenhaus nach dem Urlaub und fragen sie, ob sie in ihrem Keller, da dieser doch so groß sei, etwas verstauen könnten. Und der Kolonialwarenhändler, der sich um den zunehmenden Kundenschwund sorgt, weil viele mittlerweile in Supermärkten einkaufen, verhält sich schließlich auch freundlich gegenüber Emmi, da »wenn es ums Geschäft geht, der Abscheu zurückstehen muss «. ${ }^{279}$ Die Umkehrung der Verhaltensstruktur ist ökonomisch codiert und nicht mehr eindeutig fremdenfeindlich. Eine ähnliche Umkehr und Exklusionsdynamik zeigt auch Şoray in ihrem Film auf. Denn anfangs sind die Dorfbewohner mit dem frischvermählten Ehepaar noch solidarisch, ändern ihre Verhaltensweisen allerdings sukzessive, nachdem der Großgrundbesitzer ihnen droht. ${ }^{280}$

In Fassbinders Film ist es die Abnahme evidenter Diskriminierungen, die die Beziehung zwischen Emmi und Ali verändert. Nachdem der Druck von außen abnimmt, verlagert sich nämlich der Konflikt in die Beziehung. ${ }^{281}$ Emmi will für Ali nicht mehr marokkanisch kochen und in einer Szene, der wir uns später intensiver widmen werden, stellt Emmi Ali ihren Kolleginnen als ein exotisches Wesen vor. Ali nimmt darauf das beendete, rein sexuelle Verhältnis zur Kneipenwirtin Barbara wieder auf, hat dabei jedoch ein schlechtes Gewissen und verhält sich nun so, als ob ihm alles egal wäre. Als sich am Ende des Films beide wieder versöhnen, bricht Ali aufgrund eines durchgebrochenen Magengeschwürs zusammen und kommt ins Krankenhaus. Nach Aussage des Arztes liege die Ursache am besonderen Stress, dem die Gastarbeiter in Deutschland ausgesetzt seien. ${ }^{282}$ Emmi sitzt an Alis Bett und weint.

Auf den ersten Blick haben wir es bei ANGST ESSEN SEELE AUf mit einer sehr einfachen Geschichte zu tun, die wie Aras Örens Poem aufzeigt, wie schwie-

279 Ebd. In Örens Poem wird auch darauf verwiesen, dass die deutschen Kleingeschäfte schließen müssten, dafür aber die Türken neue eröffnen würden. Siehe: ÖREN (1973): S. 54.

280 Siehe hierzu: ŞoRAY (1972).

281 Vgl. » Zu Gunsten der Realität««. Gespräch zwischen Rainer Werner Fassbinder und Hans Günther Pflaum«. In: Film-Korrespondenz, 13.02.1974.

282 Vgl. FASSBINDER, Rainer Werner (1986): „Filme müssen irgendwann aufhören, Filme zu sein«. In: Die Anarchie der Phantasie. Gespräche und Interviews, hg. v. Michael Töteberg, Frankfurt a. M.: Fischer, S. 47-52, hier S. 52. 
rig sich die Situation für randständige Akteure im Deutschland der 1960er und 1970er Jahre darstellt. Aufgrund der fehlenden gesellschaftlichen Akzeptanz von Fremden wird jede intime Bindung mit dem Fremden abgelehnt und geahndet. Die Verortung von Peripherie und Zentrum scheint klar. Allerdings trifft diese fast pädagogische - Analyse, die auch auf Sanders-Brahms' Film passt, nur teilweise zu. Der Film besticht auf der anderen Seite durch eine formale Sprache und eine syntagmatische Struktur, die den simplen Plot in ein weitaus komplexeres Gefüge von Subjekten, Geschichten, Außenstellen und Gesellschaft integriert. An die Stelle der Vermittlung tritt durch das ästhetische Narrativ (wie auch bei Sanders-Brahms' Film und Örens Poem) eine qualitative Transformation der Mitteilung, die zur eigentlichen Umbildung und Spaltung der Akteure führt und die soziale Frage und im Besonderen die Verhaltensweisen damit in den Vordergrund rückt. Der Zugang zu diesen Fragen erfolgt hier über die Bedürftigkeit der Akteure, die körperliche und psychische Bedürfnisse als eine zusammengehörige Struktur begreift.

Wenn Emmi sich zu Beginn des Films individuell, spontan und bedürftig zeigt - sie geht nach der Arbeit alleine in die Ausländerkneipe, tanzt mit Ali, lässt sich nach Hause begleiten, lädt ihn nach einem sehr angenehmen Gespräch im Treppenhaus, auf einen Cognac ein und lässt ihn in ihrer Wohnung übernachten, weil sie ihre wohltuende Begegnung verlängern möchte -, dann wird sie in einer Offenheit und in einem Dialogbedürfnis gezeigt, die die Dynamik des Films insgesamt prägt. Es ist diese ihre bedürftige Offenheit, die sie im Laufe des ersten Teils immer stärker an Ali bindet und stark gegenüber den anderen macht, wohingegen Emmi im zweiten Teil angeschlagen und zerbrechlich wirkt und zwischen kollektiven und individuellen Bindungen pendelt. Ihre Person wird zu einem Umschlagplatz individueller und gesellschaftlicher Kommunikation, ein Interdependenzgeflecht.

Als der soziale Druck auf Ali und Emmi nachlässt, aktualisiert sich indes eine Spannung und eine Fragilität innerhalb der Figuren, die auf Handlungsebene nicht zu erwarten war. Dies ist eindeutig zu sehen in der emotional starken Biergartenszene: Hier wird die Trennung vom randständigen Liebespaar und der beobachtenden, ausschließenden Gruppe offensichtlich. Inwiefern dabei die Ausschließenden eine integrierte Einheit bilden, wird jedoch weder in ANGST ESSEN SEELE AUF noch in den anderen analysierten Produktionen ersichtlich.

Dass Emmi dem gesellschaftlichen Druck nicht wird standhalten können, signalisiert auch ihr Körper. In der genannten Sequenz legt sie müde ihren Körper auf den Tisch. Auch Emmis Umgangston ändert sich. Nach dem Urlaub beschließt sie, kein Couscous mehr für Ali zu kochen, da er sich langsam den deutschen Verhältnissen anzupassen habe. Emmi wird jetzt wieder von ihren Arbeitskollegen aufgenommen, ausgeschlossen wird nun stattdessen die neue ausländische Putz- 
frau Yolanda. Fassbinder verwendet dieselbe Einstellung im Treppenhaus, die er auch für Emmi einsetzte, als sie ausgeschlossen wurde. Auf die Aussage ihrer Kolleginnen, dass Yolanda weniger Geld als die deutschen Putzfrauen bekomme, erwidert Emmi, »die da oben werden ja wissen, wie so was läuft«. Emmi macht hier mehr oder weniger als Teil der Gruppe mit und ordnet sich hierarchisch ein, indem sie die Verordnung von oben nicht hinterfragt.

Als ihre Kolleginnen zu Besuch kommen, führt sie Ali herrisch als einen sich waschenden Marokkaner mit eigenem Kopf vor, doch im Verlauf dieser Sequenz auch mit dem Bewusstsein, dass sie sich mit dieser Vorstellung ihrem Mann gegenüber falsch verhält. Diese Spannung und Fragilität werden in dieser Sequenz eindrucksvoll gezeigt. Die Sequenz davor schließt mit einer Einstellung, in der Yolanda, ausgeschlossen, hinter den Streben des Treppengeländers ihr Pausenbrot isst. ${ }^{283}$ Die nächste Sequenz: Emmis Wohnzimmer, in der wir Ali reglos vor dem ausgeschalteten Fernseher sitzend sehen. Emmi betritt mit ihren Kolleginnen den Raum und sagt zu ihren Kolleginnen gewandt: »Das ist der Ali. (Zu Ali sich wendend): Sag mal schön `Guten Tag`.« Ihre Kolleginnen wundern sich, wie sauber Ali sei, man sei davon ausgegangen, dass Gastarbeiter sich nie wüschen. »Der ja, der wäscht sich. Der duscht sogar, jeden Tag«, erwidert Emmi. Emmi und ihre Kolleginnen umrunden Ali, bewundern seine Muskeln, berühren seinen Bizeps. Während Emmi guter Laune ist, verlässt Ali genervt den Raum. Was er denn habe, wollen die Kolleginnen wissen. Emmi: Er habe manchmal seinen eigenen Kopf, das komme von der fremden Mentalität. Die nächste Einstellung ist eine Tiefenaufnahme: Ali verlässt nach einem kurzen Blickkontakt die Wohnung und Emmi blickt ihm mit einem schlechten Gewissen nach. Nachdem Ali die Wohnung verlassen hat, steht Emmi an der Türschwelle zwischen Flur und Wohnzimmer, sieht ihre lächelnden Kolleginnen an und lächelt zurück und senkt dann ihren Kopf, aus dessen Gesicht das Lächeln verschwunden ist.

Der Übergang von ihrem strahlenden Gesicht $\mathrm{zu}$ ihrem gesenkten Kopf bündelt die Zeit vor dem Urlaub als Außenseiterin mit der Zeit danach als eine anerkannte, gruppenzugehörige Person. So repräsentiert Emmi nicht mehr einfach eine Peripherie, sondern wiederholt vielmehr den Ausschließungsakt der Anderen, der Mehrheit, mit ihrer Handlung und Geste. Allerdings geschieht dieser Ausschluss, und das ist wichtig, in einem tiefen Bewusstsein dessen, dass sie zuvor selbst die Ausgeschlossene war. Diese Nähe von Einschluss und Ausschluss ist bereits in der Exklusionsgeschichte des ersten Teils des Films angelegt. Dort spielt die nationalsozialistische Vergangenheit der deutschen Gesell-

283 Mit der gleichen Einstellung schloss eine Sequenz im ersten Teil des Films, als Emmi ihr Pausenbrot abseits von ihren Kolleginnen aß. 
schaft eine wichtige Rolle. Eine Küchenszene in Emmis Wohnung: Ali will Emmi Geld geben, weil er doch die ganze Zeit bei ihr wohne und seinen Teil beitragen möchte. Emmi reagiert darauf sehr emotional: Sie will das Geld nicht annehmen, weil Geld alle Gefühle kaputt mache und sie Angst habe, ihre Liebe des Geldes wegen zu verlieren. Unmittelbar nach diesem Bekenntnis zu einer reinen Liebe fragt Emmi Ali beiläufig, ob er Hitler kenne. Ja, er kenne Hitler, erwidert Ali. Emmi erzählt daraufhin die Geschichte ihrer Familie und ihres Mannes, der ein polnischer Kriegsflüchtling gewesen sei. Ihre Eltern hätten ihr davon abgeraten, da eine Ehe mit einem Ausländer kein gutes Ende nehme. Denselben Satz äußert Emmis Putzkollegin Paula ihr gegenüber. Ihr Vater, der wie sie Mitglied in der NSDAP gewesen sei, habe große Probleme mit ihrem Mann František gehabt. Mit einer alltäglichen Beiläufigkeit und Wehmut gibt Emmi ihre Geschichte und die Konflikte vor ihrer Beziehung mit Ali wider. Ihre neue Beziehung mit Ali wird ähnlich verlaufen, nur dass an die Stelle ihrer Eltern, die František nicht mochten, ihre Kinder, Nachbarn, Ladenbesitzer und Kneipenbesitzer treten werden. Diese Nähe von Alltag, Familie und Nationalsozialismus wird wenige Sequenzen später (kurz vor der Biergartenszene) wiederholt. Nach der Trauung, zu der Emmi niemanden eingeladen hatte, gehen beide »fein essen «; in Hitlers Lieblingsrestaurant in München, weil Emmi hier schon immer einmal essen gehen wollte.

Die Nähe und Aufeinanderfolge von reiner Liebe und nationalsozialistischer Vergangenheit bündelt Individualität, Kollektivität und die deutsche Vergangenheit, für die auch die Verhaltensweisen von Emmis Kindern, ihrer Nachbarn und Kolleginnen stehen. Diese Nähe bestimmt die kulturelle Dynamik in Fassbinders Film und zeigt nicht nur Emmis Identität mehrfach und teils widersprüchlich codiert. Allerdings findet in der Mitte des Films eine Umkehrung der Verhaltensweisen statt. An die Stelle einer eindeutig fremdenfeindlich verwurzelten Ablehnung Alis treten ökonomische Interessen, die das Verhältnis zum Fremden als ein Kosten-Nutzen-Verhältnis uminterpretieren. Auch diesen Konnex zwischen Profit und Gastarbeit deutet Fassbinder bereits früh im Film auf ungewöhnliche Art und Weise an. In der Einstiegssequenz des Films tritt eine lasziv gekleidete deutsche Frau an die Theke der Ausländerkneipe, stellt sich an Alis Seite und fragt ihn, ob er denn heute Abend kommen werde. Dieser verneint, weil sein »Schwanz kaputt « sei und verbindet mit seiner Antwort Körper und Maschine - eine Verknüpfung, die auch im Begriff des Gastarbeiters steckt. ${ }^{284}$ Daraufhin geht die Frau mit einer

284 Die Verbindung von Maschine und Sexualität spielt auch bei Bekir Yıldız eine besondere Rolle. Dort wird der Mangel an sexueller Kondition zu Anfang bei deutschen Arbeitern, später auch bei türkischen Gastarbeitern, durch den Einfluss der industriellen Fabrikarbeit erklärt. Siehe: YILDIz (1966): S. 78. In Örens Poem ist Halime Gastarbeiterin und für Frau Kutzer die Frau, 
Mischung aus Wut und Enttäuschung an die Jukebox, wählt, nachdem ein arabisches Stück gelaufen war, einen deutschen Walzer der 1930er Jahre und verlangt von Ali, dass er doch mit der alten Frau tanzen solle und die Geschichte nimmt daraufhin, wie oben beschrieben, mit dem Dialog zwischen Emmi und Ali ihren Lauf. Die aufgezeigten, sich different wiederholenden Verdichtungen unterschiedlicher Codes, die von der jüngsten Geschichte Deutschlands über die Wirtschafts- bis zur Ausländerpolitik reichen, werden in ANGST ESSEN SEELE AUF nicht repräsentativ verhandelt, sondern mikrologisch und syntagmatisch über die Akteure und ihre wechselseitigen Beziehungen in die Geschichte zwischen Emmi und Ali verwoben. Und es sind diese Außenstellen und zusätzlichen Codes, mit denen die Verhaltensweisen und die Geschichten der Akteure in einem von Außenverhältnissen geprägten Interdependenzgeflecht zueinander stehen, die ihre eigene und die junge bundesrepublikanische Geschichte unlösbar bindet. Diese Multiplikationen der Bindungen durch Mehrfachcodierungen der Akteure lassen in Fassbinders Film eine Spannung entstehen, die ein komplexes assoziatives Gefüge und wechselseitige Abhängigkeiten generiert, die in ANGST ESSEN SEELE AUF an Grenzverschiebungen zu erkennen sind. ${ }^{285}$ Um dieses Gefüge zwischen individuellen und sozialen Strukturen in seiner Grundstruktur lesen zu können, hilft uns der Blick einerseits auf die Bildkompositionen und andererseits auf die Settings des Films.

Von der Ausländerkneipe über diverse Treppenhäuser, dem Kolonialwarenladen und Hitlers Lieblingsrestaurant dominieren in diesem Film (abgesehen von Emmis Wohnung) wie in den bereits analysierten Texten und Filmen Übergangsorte. Zudem spielen in vielen Szenen Türrahmen und Türschwellen eine wichtige Rolle. Diese Dominanz des Transits verspricht Bewegung. Doch bewegen sich die Akteure in Fassbinders Sequenzen und Einstellungen selbst kaum. Dies hängt unmittelbar mit Fassbinders Bilddramaturgie zusammen, die die Übergangsräume mit Außenstellen und Grenzziehungen besetzt, die weder körperliche noch emotionale Freiheiten gewähren. Denn in ANGST ESSEN SEELE AUF ist in der Bildsprache eine formal sehr interessante Grenzverschiebung zu beobachten. Im ersten Teil des Films beginnt die Beziehung zwischen Emmi und Ali keineswegs intim, da sie während ihres Tanzes von den übrigen Gästen angestarrt werden. Sie sind Teil einer losen Gruppenkonstellation. Fassbinder löst diese

die mehrere Männer mit nach Hause nimmt. Niyazis politische Freundin verdiente ihren Unterhalt, bevor sie nach Deutschland als Arbeiterin migrierte, als Prostituierte. Und Shirins Assimilationsprozess endet ebenfalls in der Prostitution.

285 Mit einer vergleichbaren Logik der Multiplikation arbeitet auch Ören in Was will Niyazi in der Naunynstraße, wenn er an die Biografie und Familiengeschichte von Frau Kutzer und von Niyazi die anderer türkischer Arbeiterinnen und Arbeiter anfügt und sie einander anpasst. 
Sequenz durch Schuss/Gegenschuss-Aufnahmen auf. Nach dieser Szene sehen wir Ali und Emmi im Treppenhaus zu Emmis Wohnung in die Tiefe aufgenommen: sie an einem Ende des Flurs in Nahaufnahme und er - im Hintergrund am anderen Ende vor der Haustür; wir haben das Gefühl, als einziger Zuschauer einem intim-diskreten Dialog beizuwohnen. Allerdings hat Emmis Nachbarin, Frau Karges, das Gespräch belauscht und macht sich gleich darauf bemerkbar, um zu sehen, wen Frau Kurowski mit nach Hause gebracht hat und informiert darüber sogleich die Nachbarin. ${ }^{286}$ Nach der ersten Nacht verabschiedet sich das Paar am Morgen etwas unbeholfen und zärtlich distanziert: sie auf der einen Seite der Straße und er auf der anderen Seite; auch hier glaubt der Zuschauer, der einzige Voyeur zu sein. Doch die Kamera schwenkt nach oben und wir sehen erneut Frau Karges, die die Szenerie beobachtet. Diese Beobachtung durch die Anderen bindet zugleich die Beziehung, die in der besagten Biergartenszene als Trialog ihren Höhepunkt findet. Es gibt stets ein Außen für die Beziehung, das im Kontrast zu ihrer offenen und diskreten Bedürftigkeit steht. Auf eine ähnliche Weise sind der Großgrundbesitzer in DöNüş, der Schichtführer, die Leiterin des Arbeiterwohnheims in SHIRINS HochzeIT und die Polizei in ОтовÜs endogene Teile der Bildkonstellationen. Doch im Unterschied zu den anderen ästhetischen Erzählungen verschiebt Fassbinder diese Konstellation.

Nach dem Urlaub werden die Akteure Ali und Emmi nicht mehr beobachtet, sie werden jetzt einengend in Türrahmen gezeigt. Die Außenaufnahmen verschwinden gänzlich. Wenn es vor dem Urlaub noch ein klares Außen gab, das durch den fast immer vorhandenen sichtbaren Beobachter intensiviert wurde, verlagert sich diese Grenze zwischen Peripherie und Zentrum in die Beziehung und in die Akteure hinein und leitet subtil das äußerst heterogene Spannungsfeld zwischen reinem Herzen und Faschismus in den Innenraum. Die zuvor beschriebene Szene im zweiten Teil des Films, in der Emmi ihren Mann vorführt und am Ende mit schlechtem Gewissen auf der Türschwelle steht, während ihr Mann die Wohnung enttäuscht verlässt, sie auf der einen Seite ihren Kolleginnen zulächelt und danach den Kopf senkt, ist der Höhepunkt dieser Grenzverschiebung, die das komplexe Assoziationsgefüge dieser Sequenz nur im Übergangsbereich der Schwelle festhalten kann. Emmi teilt sich selbst, alle bisherigen Außenstellen des Films bündelnd, etwas mit. So haben wir es hier mit einem problematischen Feld zu tun, »das durch die Entfernung zwischen heterogenen Ordnungen bestimmt wird «. ${ }^{287}$ Dieses problematische und problematisierende Feld zeigt sich impli-

286 Eine vergleichbare Nachbarschaftsszene haben wir auch in der Mitte von Örens Poem nur mit dem Unterschied, dass Frau Kutzer es nicht einer weiteren Nachbarin mitteilt, dass die Gastarbeiterin Emine wieder Männer mit nach Hause gebracht hat.

287 Deleuze, Gilles (1997): Differenz und Wiederholung, München: Fink, S. 311. 
zit in den Akteuren, das dadurch den Kontakt- und Grenzbereich ausweitet. Die implizite Kommunikation funktioniert nicht mehr und wird in einen Zustand von Kopplung überführt, »die deren innere Resonanz gewährleistet«. ${ }^{288}$ Dieser derart geschaffene Raum generiert eine Vieldeutigkeit und Vielsprachigkeit, die beispielsweise in einer zeichentheoretischen Sprache (Signifikant/Signifikat) nicht mehr angemessen gebündelt werden kann. Ist Emmi fremdenfeindlich oder nicht? Diese Frage lässt sich nicht beantworten, weil Fassbinders Struktur der Person über solche Markierungen hinausreicht, die somit zugleich als gesellschaftlich bedingte zu lesen sind. Dies unterscheidet Fassbinders Film von Yıldız' Roman, Şorays, Okans, Sanders-Brahms sowie von Örens Poem. Wenn die zuletzt genannten mit zwei Dimensionen operieren, generiert Fassbinder eine dritte.

Nach dem russischen Kulturtheoretiker Jurij Lotman ist die Person eine semiotische Grenze, ein Sammlungspunkt unterschiedlicher Codes. ${ }^{289}$ Und wenn die Personen wie in ANgst ESSEN SEELE AUf mehrfach codiert sind, reichen die Assoziationen, die mit ihnen und ihren Aussagen verbunden sind, weit ins Gesellschaftliche hinein, ohne dabei jedoch bei einer Entität wie Gesellschaft überhaupt ankommen zu können. Dies ist vor allem deshalb so, weil die Gruppen wie die Akteure in den behandelten Texten und Filmen nicht fest zusammengehören, sondern lose miteinander verbunden sind. Es ist nicht klar, wofür sie stehen und damit auch nicht klar, was sie repräsentieren, welche vermeintlich vorhergehende soziale Einheit sie vertreten. Die Lösung dieses dilemmatischen Zustandes sieht Fassbinder daher auch nicht in der Wiederherstellung einer Einheit unter der Diktion, dass wir doch alle Menschen seien. Sein Vorschlag geht hinsichtlich der Grundlagen von Integration noch weitaus basaler vor, was sich am Ende des Films eindrücklich zeigt.

Denn trotz der aufgezeigten Grenzverschiebungen in ANGST ESSEN SEELE AUF, der Gleichzeitigkeit von Heterogenitäten und der Spaltungen der Akteure und Gruppen durch das Gesellschaftliche und Historische siegt am Ende des Films die intime Beziehung zwischen Emmi und Ali, die mit der Darstellung ihrer Bedürfnisse und Einsamkeiten im ersten Teil geschaffen wurde. Emmi und Ali finden anders als Shirin und Mahmut, anders als Ibrahim und Gülcan und anders als Niyazi und Frau Kutzer wieder zueinander. Wie zu Beginn und in der Mitte des Films vor ihrer Hochzeit und nun am Schluss des Films tanzen sie in Barbaras Ausländerkneipe, wo sie sich zum ersten Mal begegnet waren. Ihr Tanzen am Anfang, in der Mitte und am Ende des Filmes gibt der Erzählung eine besondere

288 Vgl. ebd.

289 Vgl. Lotman, Jurij (2010): Die Innenwelt des Denkens. Eine semiotische Theorie der Kultur, hg. v. Susi Frank, Cornelia Ruhe, Alexander Schmitz, Berlin: Suhrkamp, S. 184. 
konfigurative Struktur. Während des letzten Tanzes führt das Paar das folgende Gespräch:

Ali: Ichk schläft mit anderer Frau, aber ...

Emmi: Das ist doch nicht wichtig, Ali. Das ist überhaupt nicht wichtig.

Ali: Ichk nicht will, aber immer ichk bin so nervös.

Emmi: Du bist doch ein freier Mensch. Du kannst doch machen, was Du willst. Ich weiß doch, wie alt ich bin. Ich sehe mich ja jeden Tag im Spiegel. Ich kann Dir doch nichts verbieten.

Wenn wir zusammen sind, dann müssen wir gut sein zueinander, sonst ist das ganze Leben nichts wert.

Ali: Ichk will nicht andere Frau, ichk liebe nur Dichk.

Emmi: Ich liebe Dich auch, zusammen sind wir stark.

Danach bricht Ali unter starken Schmerzen zusammen und kommt, wie schon erwähnt, wegen eines bei Gastarbeitern häufig auftretenden, durch Stress bedingten Magengeschwürs ins Krankenhaus. Auch wenn er wieder gesund werden würde, läge er in einem halben Jahr wieder da, prognostiziert der Arzt.

Vor dem körperlichen Zusammenbruch Alis wird bei der Versöhnungsszene das Spannungsfeld, das der Film zwischen reinem Herzen und Faschismus aufgebaut hatte, durch die Bindung zwischen Emmi und Ali in einem Verhältnis offener Diskretion geschlossen. Und Diskretion ist nach Lotman die Grundbedingung für eine dialogische Offenheit, die er als einen Kontakt vor dem Kontakt beschreibt. Der Kontakt vor dem Kontakt beinhaltet eine Dialogbedürftigkeit vor der Dialogsituation, eine Kommunikation des Bedarfs und des Begehrens, die vor der sprachlichen steht und als "notwendig und wünschenswert empfunden werden« muss. ${ }^{290}$ Die Voraussetzung der Bedürftigkeit, die besonders in peripheren Grenzbereichen sichtbar werden kann, ist auch das, was Emmi und Ali zueinander führt und sich selbst als strukturell ähnliche Menschen erkennen lässt. Ein Kontakt, der auch in SHIRINs HochzeIT, in Was will Niyazi in der Naunynstraße und in Bekir Yıldız' Türkler Almanyada als Kommunikation von Bedarf, Begehren und Sorge vom Wohnheimleiter der Fordwerke, von Shirin, Aida, dem griechischen Freund Shirins, von Frau Kutzer, von Niyazi und Halime artikuliert und gesucht wird, jedoch als Integration neuer sozialer Bindungen nicht gelingt, weil allein das Aufzeigen ähnlicher Bedürfnisstrukturen, Interdependenzstrukturen,

290 Lotman, Jurij (2010): »Die Mechanismen des Dialogs«. In: ders: Die Innenwelt des Denkens, S. 191-202, hier S. 198. 
Entlastung und Bewältigung von Situationen und Zuständen nicht ausreichen. Soziale Zustände und Situationen müssen in Prozesse überführt werden. Denn es muss auch immer jemanden geben, der wie Emmi Kurowski den arbeitenden Gast nach einer wohltuenden Begegnung zu sich nach Hause einlädt und den begonnenen Dialog weiterführen will.

\subsection{Fazit zu »Wir wollten alle Amerikaner werden«}

Das zentrale Thema der ästhetischen Bearbeitung der Migration nach Deutschland und ihrer Folgen ist in den 1960er und 1970er Jahren - im Unterschied zum authentischen Subjekt der 1980er, zum hybriden Subjekt der 1990er und zum Cultural Broker der 2000er Jahre - die soziale Frage. Sie bleibt in den von uns analysierten Werken als Frage bestehen. Auf unterschiedlichen Komplexitätsebenen - in ästhetischer wie auch in dokumentarischer Form - bestimmt sie die politische Epistemologie dieser Zeit. Ihr Träger ist die undefinierbare Gruppe. Wo hinein die Gruppen sich integrieren könnten, wird in keiner von mir analysierten ästhetischen Produktion, Debatte oder wissenschaftlichen Arbeit genauer beantwortet. Vielmehr wird Integration in unterschiedliche Richtungen als Kontroverse entfaltet. Die Probleme werden sozial beschrieben, sie werden aber sozial nicht erklärt, weil zum einen, das System als System, das die Probleme verursacht - die Akteure verletzt - nicht sichtbar ist und nicht gezeigt wird. Zum anderen, weil die Bindungen aller Akteurinnen und Akteure zu Beginn, in der Mitte und am Ende der Erzählungen in Auflösung und nicht in Versammlung begriffen sind, mit Ausnahme der Schlusssequenz in Fassbinders Film. ${ }^{291}$ Die kontroverse und paradoxe Struktur in den Erzählungen ist folgende: Auch wenn die türkischen, ausländischen und deutschen Akteure sich in ihren Bedürfnisstrukturen ähneln und Helma Sanders-Brahms' Film, Bekir Yıldız' Roman, Aras Örens Poem und Fassbinders Film von einer Hinwendung zur Ähnlichkeit geprägt sind, setzt weder ein sozialer Wandel ein noch gelingt eine soziale Kohäsion. Es fehlt hierfür eine bestimmbare und darstellbare Gesellschaft, die die Bedingungen für die Entstehung eines zweiten Bewusstseins, den einer nicht-familialen Zugehörigkeit, schaffen könnte.

Diese Bedingungen fehlen aus zwei Gründen: Mit dem Konflikt- und Integrationsforscher David Lockwood Ende der 1960er Jahre gesprochen, kann endogener sozialer Wandel nur gelingen und erfolgen, wenn Akteure und Systeme in

291 Interessanterweise ist diese Schlusssequenz mit dem bekanntesten Film der DEFA aus den 1970er Jahren vergleichbar. Siehe hierzu: CARow, Heiner (1973): »Die Legende von Paul und Paula«. In: Romantische Momente. Die schönsten Liebesfilme der DEFA, DVD Kino Home Entertainment 2007. 
Form von Institutionen in einem prozessorientierten Dialog stehen. In keinem der analysierten Texte und Filme gibt es ein sichtbares und stabiles Akteur-SystemVerhältnis. Es ist vielmehr umgekehrt der Fall, dass ein nicht sichtbares System durch bestimmte Personen wie Großgrundbesitzer oder Schichtführer die Akteure verletzt oder, wie Hannah Arendt es formuliert, die Lebenswelt beschädigt. Repressive Mechanismen werden sichtbar gemacht, jedoch bleiben die Gruppen, um die es geht, undefiniert. ${ }^{292}$

Der zweite Grund, warum es an Gesellschaft fehlt, ist, dass es in keiner der Erzählungen weder real noch imaginär einen Ort für sie gibt. Die Naunynstraße ist eine Sackgasse, Shirins Leben endet am Rande einer Schnellstraße, und in Fassbinders Film bilden die Grundlagen der deutschen Gesellschaft fremdenfeindliches und ökonomisch-strategisches Verhalten. Was fehlt, ist ein die Akteure und Orte verbindendes Narrativ der Integration, das über eine Kritik des Ist-Zustands hinaus auf einen Soll-Zustand verweisen kann. Auf einen sozialen Zustand, eine Form der Versammlung, die die Hinwendung zur Ähnlichkeit zwischen Shirin und Katharina Blum, zwischen Niyazi und Frau Kutzer und schließlich zwischen Ali und Emmi über Gemeinschaftsvorstellungen hinaus in eine stabile Bahn gesellschaftspolitischer Erzählungen überführen könnte. Das zivilisatorische Problem der deutschen Nachkriegsgesellschaft, wie sie Arendt, Dahrendorf, Elias und Marcuse als eines zwischen Akteur und System, zwischen Akteuren und Öffentlichkeit bestimmten, greift auch in den Erzählungen zur Migration, und es ist nicht allein ein innerdeutscher oder ein ausschließlich westlicher Diskurs. Die Erzählungen der Migration und Integration gehen dabei insofern über diese Feststellungen zur deutschen Frage hinaus, als sie neben den genannten gesellschaftlichen Spannungs- und Interaktionsverhältnissen die soziale Frage stärker in den Vordergrund rücken. Dies zeigt uns ein abschließender vergleichender Blick.

Nach Moritz Scheibe verweisen Ralf Dahrendorf und Jürgen Habermas in den 1960ern und 1970ern auf eine gesellschaftliche Problemkonstellation, »dass nämlich eine moderne Gesellschaft auf demokratischen Normen und Verhaltensweisen beruhen musste und dass die Gesellschaft der Bundesrepublik von diesem Ziel noch weit entfernt war «. ${ }^{293}$ Der Weg, der die Kopplung von Innen-

292 Um gesellschaftspolitische Veränderungen herbeizuführen, wird in den 1980ern das Bemühen um Definition auf dieser Ebene in Form von Identitätspolitik jedoch zentral. Siehe hierzu: HABERMAS, Jürgen (1985): »Die Krise des Wohlfahrtsstaates und die Erschöpfung utopischer Energien«. In: ders.: Die Neue Unübersichtlichkeit, Frankfurt a. M.: Suhrkamp, S. 141-163, hier S. 159. 293 Scheibe, Moritz (2002): »Auf der Suche nach der demokratischen Gesellschaft«. In: Wandlungsprozesse in Westdeutschland. Belastung, Integration, Liberalisierung 1945-1980, hg. v. Ulrich Herbert, Göttingen: Wallstein, S. 245-277, hier S. 258. 
und Außenstrukturen schaffen sollte, war nichts anderes als die Ausweitung der Demokratie über die staatlichen Institutionen hinaus in das gesellschaftliche Innenleben der Bundesrepublik. Der Schlüssel für diese Entwicklung ist nach Dahrendorf der Umgang mit Konflikten, nämlich einer der rationalen Kanalisierung, die keiner Autorität bedarf: eine Demokratisierung von unten.

Eine solche Perspektive von unten steht auch im Zentrum in der von mir behandelten Literatur und in den Filmen, jedoch mit einer ganz anderen Bearbeitung der Innen/Außen-Unterscheidung: Sie zielt nicht auf eine Durchdemokratisierung der Gesellschaft, die sich am Ende einstellen soll. Die Bewegungen der Gruppen, Akteurinnen und Akteure sind in Yıldız' Text, Sanders-Brahms' halbdokumentarischem Film, Örens ebenfalls halbdokumentarischem Poem und in Fassbinders Film nicht so klar gerichtet. Das Unten beschreibt in diesen Produktionen nicht eine vermeintlich begrenzte private Welt der deutschen Gesellschaft, sondern vielmehr das Verhältnis zu Peripherien, zu den Randfiguren, den Gastarbeitern, den Frauen und den Alten. Ihre ästhetischen Sprachen stammen aus diesem Grenzbereich, der damals wissenschaftlich noch nicht erschlossen war. Er ist von Überschüssen an Energie, an Bedürfnissen und von »ungerichteten Bewegungsimpulsen « geprägt. ${ }^{294}$ So mögen die analysierten Texte, Filme, Debatten und Theorien von Yıldız über Gordon, Ören, Elias, Habermas, Sanders-Brahms bis hin zu Fassbinder jeweils in sich geschlossen sein und unterschiedliche Herkünfte haben, vom Clash der Agrarkultur mit der städtischen Lebensstruktur, von der Last der Vergangenheit bis zum kolonialistischen Gebaren. Und es gibt auch keine vereinheitlichende Klammer, die alle Ebenen und Produktionen zusammenfügen könnte, wobei die behandelten Texte und Filme auch nicht beziehungslos nebeneinanderstehen. Sie sind auf eine bestimmte Art und Weise miteinander vernäht und verfranst. Mit Rosanvallon gesprochen, bindet alle hier verhandelten Filme und Texte, dass die sozialen Elemente »Ort«, »Kontakte« und »Handlungen« durch eine Gestaltung von Auseinandersetzungen nicht zusammengeführt werden können, deren Bindung auf eine existierende Gesellschaft verweisen könnte. Anders als die politischen Debatten antworten Filme und Texte sensibel und in der ihnen eigentümlichen Komplexität auf die Frage, wie man den Zustand der Ankömmlinge beschreibt, wenn die Ankunftsgesellschaft sich selbst irgendwo anders hinbewegt und die Ankommenden nicht mitnimmt, obwohl diese sich in die gleiche Richtung bewegen.

Zusammenfassend können wir für die 1960er und 1970er Jahre festhalten, dass in Text und Film erstens die Arbeitenden und ihr Verhältnis zueinander das

294 Koschorke (2004): „Codes und Narrative. Überlegungen zur Poetik der funktionalen Differenzierung «. In: Grenzen der Germanistik. Rephilologisierung oder Erweiterung?, hg. v. Walter Erhart, Stuttgart: Metzler, S. 174-185, hier S. 179. 
Thema sind, und dass dieses Verhältnis zweitens von wechselseitigen Begehrens- und Bedürfnisstrukturen geprägt ist, die sich als energetischer Überschuss zeigen. Es gibt einen Kontakt vor dem Kontakt, eine Kommunikation des Bedarfs, die vor der sprachlichen stattfindet. Im Fokus steht dadurch nicht das Verstehen des Anderen - ob deutsch oder türkisch ist nicht ausschlaggebend -, sondern der Umgang und die Situation mit Fremden. Drittens habe ich gezeigt, dass das Verhältnis von Assimilation und endogenem sozialem Wandel ein brüchiges ist, das mit der geringen Repräsentationskraft kultureller und sozialer Zeichen (Individuum, Gruppe und öffentlicher Raum) korreliert. Mit unserer allgemeinen Definition von Integration als Bewegungskonzept können wir festhalten, dass Ist-Zustände problematisiert, jedoch keine Soll-Zustände anvisiert werden. Das öffentliche Sprechen über Migration und ihre Folgen hegen das Private nicht ein. Diese Diskrepanz zwischen dem Reden über Integration und ihren Praktiken aus Alltagskontexten heraus wird uns bis zum Ende dieses Buches, bis zum Beginn des 21. Jahrhunderts in unterschiedlichen Verhältnisgraden zwischen Reden und Handeln als produktive Störungen der Kommunikation begleiten. Und wir werden sehen, dass die Geschichte dieses Verhältnisses wesentlich bestimmt ist von der deutschen Integrationsgeschichte vom Zivilisationsbruch zur Zivilmacht; wesentlich mehr als von ihrer primär systematisch auf Institutionen, Parteien und Verbänden beruhenden innerdeutschen oder neuerdings wieder europäischen und westlichen Geschichte. ${ }^{295}$ Bevor wir jedoch dieses größere Narrativ anhand der folgenden Kapitel entfalten, sei abschließend noch Folgendes zum Narrativ der Migration und Integration in den 1960er und 1970er Jahren erwähnt: Da körperliche Bedürfnisse, Kontakte und Verhaltensweisen den Kern ihrer Verhandlungen in den dokumentarischen, politischen und ästhetischen Beschreibungen ausmachen, ist die Integration in diese an erster Stelle eine Frage der Diskretion. Und dort, wo diese besondere Eigenschaft zivilen Verhaltens fehlt, muss Europa - wie es die Gastarbeiter in Yıldız' Text Türkler Almanyada auf ihrer Zugfahrt nach Deutschland auch festhalten - als Gesellschaft irgendwo anders sein. Literatur und Film zur Migration verzeichnen einen Komplexitätszuwachs in der bundesrepublikanischen Gesellschaft, die an sich Informationsgewinn und eine erweiternde Orientierung »in der Welt« bedeuten kann, wenn sie zusammengeführt wird. Wenn nicht, birgt sie die Gefahr, zu einer »spezifischen ১Schizophrenie der Kultur« « zu führen; zu einem Zerfall in »zahlreiche wechselseitig antagonistische >kulturelle Persönlichkeiten ««. ${ }^{296}$ Das hier von Lotman

295 Siehe hierzu erneut: WeHLER (2008); SCHMID (2009); WoLFRUM (2006).

296 Lotman, Juri (2004): »Der Platz der Filmkunst im Mechanismus der Kultur«. In: Juri Lotman. Das Gesicht im Film. Zeitschrift für Theorie und Geschichte audiovisueller Kommunikation 13, Marburg: Schüren, S. 92-106, hier S. 96. 
angedeutete Problem gesellschaftlicher und persönlicher Spaltung wird uns in den literarischen und filmischen Reflexionen zur Migration und Integration in der Bundesrepublik in den 1980ern besonders beschäftigen. In diesem Zusammenhang zeigt sich der türkische Film Almanya, Aci VATAN (Bittere Heimat Deutschland) von 1979 als eine Schwellenerzählung, die vom bedürfnisorientierten Leitsatz »Wir wollten alle Amerikaner werden« der 1960 und 1970er Jahre zum kulturellen Leitsatz »Wie lebt es sich als Türke in Deutschland?« überleitet. Der erste Leitsatz der vorliegenden Kulturgeschichte läuft in diesem Film im wahrsten Sinne des Wortes gegen die Wand.

»Die Situation der Kinder hier ist viel schlimmer als die der Älteren«, sagt der Gastarbeiter Talat (Suavi Eren) in der zweiten Hälfte von Şerif Görens Film Almanaya, Aci Vatan. Mit »hier« meint Talat Deutschland und die Kinder, um die es geht, sind die der türkischen Gastarbeiter. „Die meisten von ihnen haben ihre Augen hier geöffnet. Sie eifern den deutschen Jugendlichen nach. Sie sind eine Generation halb Deutsch, halb Türkisch. Sehr schlimm, sehr ...«. ${ }^{297}$ Kurz zuvor haben er und Mahmut, ein weiterer türkischer Gastarbeiter, ihren Kollegen Şehmuz davon abgebracht, seine Tochter zu schlagen. Sie hat zum wiederholten Male ohne seine Erlaubnis die Wohnung verlassen, dabei schließt Şehmuz die Tür am Wochenende immer ab, dass sie nicht entwischen kann. Als Talat seinen Kommentar zu dieser Gewaltszene abgibt, stehen Mahmut, er und Güldane (Hülya Kocyiǧit), die Protagonisten des Films, im Wohnungstrakt von Şehmuz und seiner Tochter.

Dass Görens Film Ende der 1970er Jahre auf solch einen kulturellen Diskurs und topografisch auf die Dominanz von Wohnungseinstellungen zusteuern würde, ist in der ersten Hälfte des Films überhaupt nicht abzusehen. Diese ist ebenfalls, wie die zuvor behandelten und analysierten Erzählungen, von Waren, Geld, Arbeit, Disziplin, öffentlichen und Übergangsräumen, von Männer- und Frauengruppen und von Sexualität bestimmt. Der Bruch mitten im Film geht auch mit einem Wechsel von einem komisch zu einem tragisch geprägten Film über.

Am Anfang von Almanya, Aci Vatan geht es noch um Dinge und um Frauen aus dem Westen. Wir sehen gleich in der ersten Einstellung einen Mercedes vor einem türkischen Dorfcafé. In diesem zeigt ein Gastarbeiter, dem das Auto gehört, den männlichen Dorfbewohnern auf humorvolle Art deutsche Sexhefte und regt damit ihre Fantasien an, was alles in Deutschland möglich ist. Auf ihre Fragen, wer denn die Frauen in diesen Heften seien, antwortet der Deutschländer, dass sie alle ihre Tanten seien (»Yengen«). Man könnte dieses Gebaren des »Deutschländers« als äußerst unfair betrachten, da in der Erzählzeit des Films die Bundes-

297 GöREn, Şerif (1979): Almanya, Acı Vatan, Türkei, Gülşah Film. 
republik schon keine Gastarbeiter mehr aufnimmt. Mahmut kommt von draußen in das Café und möchte mit dem Gastarbeiter aus ihrem Dorf reden, weil er wissen will, wie er nach Deutschland kommen kann. Deutschland nimmt niemanden mehr auf, antwortet er ihm, aber es sei toll dort, die Autos, die Frauen. Er macht Mahmut den Vorschlag, dass er Güldane aus dem Dorf fragen soll, ob sie mit ihm eine Scheinehe eingeht, sie ist eine Gastarbeiterin und über eine Ehe mit ihr könnte er nach Deutschland kommen. Güldane, die in der nächsten Sequenz des Filmes Waren aus Deutschland gewinnbringend an die anderen Dorfbewohner verkauft, lacht vergnügt und reagiert amüsiert auf Mahmuts Angebot einer Scheinehe. Sie sei doch nicht verrückt. Die Ehe sei nichts für sie. Als er ihr aber viel Geld und sein Grundstück verspricht, geht sie schließlich doch darauf ein. Sie lässt ihn einen selbstverfassten Vertrag unterschreiben und auf den Koran schwören, dass er und sie nach einer standesamtlichen Heirat in der Türkei und sobald sie in Deutschland sind, wieder getrennte Wege gehen. Tatsächlich lässt Güldane Mahmut einfach so am Berliner Bahnhof zurück. Er wird die erste Nacht draußen verbringen, die Polizei wird ihn auflesen und zu seiner Frau nach Berlin-Kreuzberg bringen. Güldane wohnt in einer türkischen Frauen-WG. Über ihnen wohnen drei türkische Männer zusammen und ganz oben Şehmuz mit seiner Tochter. Mahmut zieht in die Männer-WG ein und findet bald Arbeit. Ab diesem Zeitpunkt ist der Film wie die anderen von Arbeit, Geld und Sexualität geprägt. Die Akteurinnen und Akteure sind dabei sehr unterschiedlich angelegt. Güldane hat zwar wegen des Geldes geheiratet, möchte aber weder einen Mann noch eine Familie haben. Eine ihrer WG-Freundinnen trifft sich hingegen oft in Bars mit Männern und versteht Güldanes Wunsch nach Unabhängigkeit nicht. In der Männer-WG treffen ebenfalls sehr unterschiedliche Personen zusammen - von Kavalieren bis zu verantwortungsbewussten Vätern. Palla beispielsweise hat acht Kinder in der Türkei, die er mit seiner Arbeit bei der Müllabfuhr mittels Geldüberweisungen in die Türkei versorgt. Ein anderer Kollege von Mahmut trifft sich hingegen oft mit deutschen Frauen in Bars. Wieder ein anderer führt ihn, als sie am Wochenende nicht wissen, was sie machen sollen, mit der Aussage, sie könnten einen Ausflug machen, in einen Sexshop, in dem sie übergroße Dildos bestaunen.

Der Film zeigt Frauen und Männer aber auch als sehr fleißige und disziplinierte Menschen, die sehr auf das Geldverdienen konzentriert sind. Ihr Leitspruch ist: »Herşey hesap, herşey para ve bir mark otuz lira « (»alles ist Rechnung, alles ist Geld und eine Mark sind dreißig Lira«). Wir sehen ähnlich wie in den anderen Produktionen Frauen oft bei der Arbeit. Doch es gibt auch entscheidende Unterschiede. In Almanya, AcI VATAN gibt es weder einen Großgrundbesitzer in Güldanes und Mahmuts Dorf noch einen Schichtführer in der Fabrik. Dort kontrolliert die Arbeitsabläufe und teilt die Arbeitsaufträge eine »sprechende«, computergesteuerte Maschine ein. Ein weiterer bemerkenswerter Unterschied zu den 
zuvor behandelten Filmen ist, dass wir Güldane oft mit sich selbst aus dem Off kommend sprechen hören. Sie sagt sich immer wieder, wenn sie noch eine Zeitlang soviel weiterarbeitet, dann kann sie in der Türkei ein weiteres Stockwerk auf ihr Haus bauen lassen und danach wieder eines. Eine weitere Besonderheit ist, dass in der Mitte des Films die Darstellung von Gruppen aufhört. Im Falle Güldanes geht sie damit einher, weil ein anderer türkischer Mann sie im öffentlichen Raum sexuell oft bedrängt, so dass sie sukzessive beginnt, aus Schutzgründen ihren Mann als ihren wirklichen Ehemann anzuerkennen. Allerdings ist dies, wie oben schon angedeutet, nicht die einzige Wendung mitten im Film. Neben den Sorgen um die zweite Generation spielt und singt Mahmut in der Mitte des Films mit Langhalslaute ein türkisches Lied, währenddessen alle Protagonisten in ruhenden Positionen und nicht mehr in Bewegung oder bei der Arbeit einzeln eingefangen werden. Mahmut und Güldane verlassen ihre WGs und ziehen in eine eigene Wohnung im Haus ein. Nach ein paar schönen Verabredungen der beiden als Paar draußen hat man das Gefühl, dass dieser Film, in dem es die ganze Zeit ums Geldverdienen ging, nun zu einem Liebesfilm wird, zumal Güldane schwanger ist. Doch sind in ihrer neuen eigenen Zwei-Zimmer-Wohnung keine persönlichen Gegenstände oder Dinge für das Kind zu sehen. Vielmehr fällt in ihrem Schlafzimmer, das wir am häufigsten im zweiten Teil dieses Filmes zu sehen bekommen, ein riesengroßes Plakat der bekannten Marlboro-Werbung auf, das die gesamte Wand neben der Matratze des Paares einnimmt. Wir sehen auf ihm den bekannten Marlboro-Mann auf den Betrachter zureiten.

Wenn in Aras Örens Poem Was will Niyazi in der Naunynstraße über eine ganze Seite plastisch wie ein Film beschrieben wird, warum man Amerikaner werden will und dieses Leben in der Bundesrepublik, in den USA wie auch in der Türkei gelebt werden kann, wird der Westen in Şerif Görens Film zu einer bewegungslosen Wand in einer Kreuzberger Wohnung. Er steht bewegungslos im Schlafzimmer von Mahmut und Güldane. Dieser topografisch und ästhetisch-deskriptive Wandel führt zu einer neuen Konstellation von Innen und Außen, die die Personen und den Film spaltet. Auch Mahmut verändert sich. Kaum wohnen sie zusammen, verbietet er Güldane zu rauchen. In dem von Gören fotografierten Raum mit dem Marlboro-Plakat wirkt dies wie eine Distanzierung vom Westen. Und als Güldane Mahmut ebenfalls im Schlafzimmer davon erzählt, das sie schwanger ist, war dieser Momente vorher ins Zimmer gekommen und hatte wütend und klagend mit Geld um sich geworfen, dass sie alles nur dafür gemacht hätten. Als er von ihrer Schwangerschaft erfährt, freut er sich zunächst, wendet dann aber doch schnell ein, dass sie abtreiben solle, weil sie sich ein Kind nicht leisten können. Kurz zuvor hatten sie miterlebt, wie Şehmuz seine Tochter schlägt, weil dieser nicht will, dass sie wie die Deutschen wird. Auch ihre türkischen Kolleginnen bei der Arbeit raten zu einer Abtreibung; ob aus finanziellen Gründen oder weil die Kinder nicht in 
Deutschland aufwachsen sollen, bleibt wie bei Mahmut ungeklärt und ambivalent nebeneinander bestehen. Güldane sagt aber von nun an $\mathrm{zu}$ allem nein und entscheidet sich für das Kind, kündigt ihre Arbeit und flieht in die Türkei, um es zu schützen. Ob sie es damit vor Deutschland oder vor den Türken, die in Deutschland leben, schützen will, lässt sich nicht entscheiden. In der Schlusssequenz des Films, es ist die am schlechtesten ausgeleuchtete Szene, sehen wir sie mit einem vollbepackten Gepäckwagen am Flughafen in Bewegung. Doch sie stolpert und zwei Babypuppen fallen vom Wagen herunter. Güldane ist im gesamten Film sehr viel im öffentlichen Raum unterwegs. Mag es zu Anfang im türkischen Dorf sein oder später auf dem Weg von der Wohnung über die Straßen in Kreuzberg zur Arbeit. Sie bewegt sich dabei sehr souverän und man erwartet kein einziges Mal, dass sie stolpern könnte. Wie die Marlboro-Wand im Schlafzimmer von Güldane und Mahmut verweist ihr Stolpern am Ende des Films auf eine Form der Immobilität, die für einen Wandel in der Konstellation des Deutsch-Türkischen für eine des Privaten und Öffentlichen steht. Denn Güldane bleibt auf dem Boden sitzen, betrachtet die Puppen und beginnt zu weinen. Sie erinnert sich dabei an Szenen in der Bundesrepublik, wie ihr der zudringliche Türke auflauert und ihr Mann mit ihr schimpft, als sie ihn beim Fremdgehen erwischt. Auf diese Erinnerungen folgt, dass Güldane aus dem Off sich immer wieder denselben Satz sagt: »Ev, Metro, Fabrika, bidaha ... Ev, Metro, Fabrika, bidaha ... Ev, Metro, Fabrika, bidaha« (»Haus, Metro, Fabrik, und noch einmal«). An die Stelle der Tränen um die Kinder, der Wut auf die türkischen Männer tritt ein lautes Lachen über die Eindimensionalität ihres Lebens und das der anderen Türken in Deutschland. Es wird zum Hohn darüber, was sie und die anderen Türken alles gemacht haben - und hebt ihr erstes Lachen im Dorf wieder auf, als Mahmut sie danach fragte, ob sie ihn nicht einfach so heiraten könne. Parallel zu diesem unerwarteten Schluss führt Gören ab der Mitte des Filmes Sendungen aus dem türkischen und deutschen Fernsehen und Radio aus dem Off in den Film ein, in denen es um die Probleme der Integration geht; besonders um die Probleme, mit denen es die zweite Generation zu tun haben wird, die »halb deutsch und halb türkisch« (»yarı Alman, yarı Türk«) ist. Dass diese Probleme nicht allein für die zweite Generation gelten, zeigen Figuren, besonders Güldane, in Görens Film eindrücklich. Tatsächlich kommt es Ende der 1970er Jahre in der Bundesrepublik zu den ersten Integrationsdebatten, die den Begriff der Kultur ins Zentrum der Auseinandersetzung rücken.

Als Bekir Ylldız Mitte der 1960er Jahre und mitten in seinem autobiografischen Roman seine Frau und ihr Kind in die Bundesrepublik nachkommen ließ, hat die Familienzusammenführung seine Erzählung nicht verändert. Sie war weiterhin auf Konsum, Dinge, Gegenstände und Verhaltensweisen fokussiert und bestimmt von der Frage, was und wo Zivilisation sei. Auch blieben sowohl die türkische als auch die deutsche Community heterogen. Denn am Ende seines 
Textes hat er sich über diese Themen am besten mit Henning, einem Deutschen, der ihn in Istanbul besuchte, darüber unterhalten können. Auch in Örens Poem Was will Niyazi in der Naunynstraße ist es ein Deutscher, mit dem sich Niyazi am Ende am besten über die türkischen Dörfler unterhalten kann. Mit Frau Kutzer hätte er sich wahrscheinlich auch gut verstanden, wenn sie miteinander gesprochen hätten. Und das Weitersprechen zwischen Emmi und Ali hat in Fassbinders ANGST ESSEN SEELE AUf dazu geführt, dass sie die Diskriminierung von außen, die sich nach innen verlagerte, wieder nach draußen führen konnten. In der zweiten Hälfte des Films Almanya, AcI VATAN wird diese Dialogizität gekappt. Denn die Kritik am Konsum und an der Nachahmung des Westens führt im Unterschied zu den anderen Produktionen hier nicht zu einem Weitersprechen mit zwei Seiten, sondern zu einem Selbstgespräch, das Güldane allein führt. Auch wenn Almanya, Aci VATAn ebenso wie Türkler Almanyada, Dönüş, Was will Niyazi in der Naunynstraße und SHIRINS HochzEIT mit dem Fokus auf die komplexe Bindung von Bedürfnissen, heterogenen Gruppen und auf Verhaltensweisen setzt, denunziert Güldane all diese am Ende des Films. Wenn ihr erstes Lachen zu Beginn des Films ein souveränes war, weil sie viel Geld in Deutschland verdient hat, ist ihr zweites Lachen auf dem Boden am Flughafen eines des Opfers. Das Leben in Deutschland hat in eine Sackgasse, gegen eine Wand geführt und die »ungerichteten Bewegungsimpulse« verschieben sich nun von außen, öffentliche Räume nach innen in die Wohnungen und in die Personen. Doch betrifft diese Verschiebung und Transformation keineswegs allein die zweite Generation, wie es der Gastarbeiter Talat in ALMANYA, AcI VATAN festhält. Sie gilt, wie wir im nächsten Kapitel sehen werden, bereits für die erste Generation. Dieser Wandel steht für eine neue Störung der Kommunikation, die in den 1980er Jahren mitbestimmt, was passiert, wenn nun nicht mehr Arbeiter, sondern Türken und Deutsche sich begegnen. 